\title{
Untersuchungen zur Sinapinsäureestersuppression und zur Expression von Resveratrol in transgener Rapssaat (Brassica napus L.)
}

\author{
Dissertation \\ zur Erlangung des Doktorgrades \\ der Fakultät für Agrarwissenschaften \\ der Georg-August-Universität Göttingen
}

vorgelegt von

Alexandra Hüsken

geboren in Stadtlohn

Göttingen, April 2004 
D7

1. Referent: Prof. Dr. Heiko C. Becker

2. Referentin: Prof. Dr. Elke Pawelzik

Tag der mündlichen Prüfung: 27. Mai 2004 
Glücklich sind die Menschen, die nicht wissen

wie Gesetze und Würste zustande kommen.

Chinesisches Sprichwort 


\section{Inhaltsverzeichnis}

1 Einleitung 1

1.1 Sinapinsäureester 2

1.1.1 Metabolismus der Sinapinsäureester in der Pflanze 2

1.2 Resveratrol 3

1.2.1 Metabolismus des Resveratrols in der Pflanze 4

1.3 Zielsetzung der Arbeit 6

2 Material und Methoden 7

$\begin{array}{lll}2.1 & \text { Material } & 7\end{array}$

2.1.1 Bakterienstämme und Plasmide $\quad 7$

2.1.2 Bakteriennährmedien und-anzucht 7

2.1.3 Bestimmung von Wachstumsparametern 8

2.1.4 Antibiotika und Herbizide 8

$\begin{array}{lll}\text { 2.1.5 Oligonukleotide } & 9\end{array}$

2.1.6 Pflanzenmaterial 9

2.1.7 Chemikalien und Enzyme 9

$\begin{array}{lll}2.2 & \text { Molekularbiologische Methoden } & 10\end{array}$

2.2.1 Behandlung von Geräten und Lösungen 10

$\begin{array}{ll}\text { 2.2.2 Isolierung von Plasmid-DNA } & 10\end{array}$

2.2.2.1 Isolierung von Plasmid-DNA aus E. coli 10

2.2.2.2 Minipräparation von Plasmid-DNA 11

2.2.2.3 Maxipräparation von Plasmid-DNA 11

$\begin{array}{lll}2.2 .3 & \text { Isolierung von Raps-Gesamt-DNA } & 11\end{array}$

2.2.4 Bestimmung von Nukleinsäurekonzentrationen 12

2.2.5 Reinigung und Konzentrierung von DNA 13

2.2.6 Restriktionsanalyse der genomischen DNA 13

2.2.7 Agarose-Gelelektrophorese von Nukleinsäuren 13

$\begin{array}{lll}2.2 .8 & \text { DNA-Größenstandards } & 14\end{array}$

2.2.9 Amplifizierung von DNA-Fragmenten aus Raps-Gesamt-DNA mittels Polymerasekettenreaktion 14

2.2.10 Southern Blot Analyse 15

2.2.10.1 Herstellung nicht-radioaktiv markierter Sonden 16

2.2.10.2 Hybridisierung der Membranen 16 
2.2.10.3 Detektion genomischer DNA-Fragmente 16

2.2.11 Transformation von E. coli und A. tumefaciens 17

2.2.11.1 Herstellung kompetenter Zellen 17

$\begin{array}{lll}2.2 .11 .2 & \text { Elektroporation } & 17\end{array}$

$\begin{array}{ll}2.3 & \text { Biochemische Methoden }\end{array}$

$\begin{array}{lll}2.3 .1 & 19\end{array}$

$\begin{array}{lll}2.3 .2 & 19\end{array}$

$\begin{array}{lll}\text { 2.3.3 Fettsäureanalysen } & 19\end{array}$

2.3.4 Analyse des Sinapinsäureestergehaltes 20

2.3.5 Analyse des Resveratrolgehaltes 21

2.3.6 Bestimmung des Öl-, Protein- und Glycosinolatgehaltes 21

2.4 Gewebekulturtechniken 22

2.4.1 Pflanzenanzucht 22

2.4.2 Agrobacterium tumefaciens vermittelte Transformation 22

$2.5 \quad$ Gewächshausversuche 25

2.5.1 Pflanzenanzucht 25

2.5.2 Merkmalserhebung 25

2.5.3 Segregation der transgenen Pflanzen 26

2.6 Statistische Auswertung 26

$\begin{array}{lll}3 & \text { Ergebnisse und Diskussion } & 27\end{array}$

$\begin{array}{lll}3.1 & \text { Sinapinsäureestersuppression } & 27\end{array}$

3.2 Resveratrolexpression und Sinapinsäureestersuppression 31

4 Zusammenfassung 35

$5 \quad$ Literaturverzeichnis $\quad 38$ 
Die folgenden Manuskripte im Anhang I und II sind Teil dieser Dissertation:

I. Reduction of the sinapic acid ester content in transgenic oilseed rape (Brassica napus L.)

II. Resveratrol production in seeds of transgenic oilseed rape (Brassica napus L.) 


\section{Abkürzungsverzeichnis}

A

Abb.

as

ATP

A. tumefaciens

BAP

bidest.

bp

BSA

bzw.

C

ca.

CaMV

cDNA

CIM

CTP

2,4-D

demin.

d. h.

DNA

dNTP

dsDNA

ds-RNAi

E. coli

EDTA

ELISA

et al.

evt.

FAD

FM

G

$\mathrm{GA}_{3}$

ges.

GTP

GUS

HP

HPLC

Hrsg.

IAA

IBS
Adenin

Abbildung

antisense

Adenosintriphosphat

Agrobacterium tumefaciens

6-Benzylaminopurin

bidestilliert

Basenpaar

Bovine Serum Albumin

beziehungsweise

Cytosin

circa

Cauliflower mosaic virus

copy DNA

Callus inducing medium

Cytosintriphosphat

2,4-Dichlorophenoxyessigsäure

demineralisiert

das heißt

Desoxyribonukleinsäure

Desoxynukleotidtriphosphat

doppelsträngige DNA

doppelstrang- Ribonukleinsäuren-interferenz

Escherichia coli

Ethylendiamintetraessigsäure

Enzyme linked immunosorbent assay

et alteri

eventuell

Flavinadenindinukleotid

Frischmasse

Guanin

Gibberillinsäure

gesamt

Guanintriphosphat

$\beta$-Glucuronidase

Homogenisationspuffer

High performance liquid chromatography

Herausgeber

Indolessigsäure

Indolbuttersäure 


\begin{tabular}{|c|c|}
\hline IgG & Immunglobulin $\mathrm{G}$ \\
\hline Kan & Kanamycin \\
\hline $\mathrm{kb}$ & Kilobasen \\
\hline $\mathrm{kDa}$ & Kilodalton \\
\hline LB-Medium & Luria-Bertrani-Medium \\
\hline mod. & modifiziert \\
\hline MS-Medium & Murashige-Skoog-Medium \\
\hline $\mathrm{n}$ & Stichprobenumfang \\
\hline $\mathrm{N}$ & Stickstoff \\
\hline NIRS & Nah-Infrarot-Reflexions-Spektroskopie \\
\hline nos & Nopalinsynthase-Gen \\
\hline NptII & Neomycintranferase II \\
\hline OD & Optische Dichte \\
\hline
\end{tabular}

$\begin{array}{ll}\text { PAT } & \text { Phosphinothricin-Acelyltransferase } \\ \text { PCR } & \text { Polymerasekettenreaktion } \\ \text { PMS } & \text { Phenazinmethosulfat } \\ \text { PMSF } & \text { Phenylmethansulfonylfluorid } \\ \text { PPT } & \text { Phosphinothricin } \\ \text { PVPP } & \text { Polyvinylpolypyrrolidon } \\ & \\ \text { rel. } & \text { relativ } \\ \text { RNA } & \text { Ribonukleinsäure } \\ \text { RNaseA } & \text { Ribonuklease A } \\ \text { rpm } & \text { Umdrehungen pro Minute } \\ \text { RT } & \text { Raumtemperatur } \\ \text { R } & \text { Resveratrol } \\ \text { RGlc } & \text { Resveratrolglucosid } \\ & \\ \text { s } & \text { sense } \\ \text { s. } & \text { siehe } \\ \text { SAE } & \text { Sinapinsäureester } \\ \text { SGT } & \text { Sinapinsäure Glucosyltransferase } \\ \text { STS } & \text { Stilbensynthase } \\ \text { SDS } & \text { Natriumdodecylsulfat } \\ \text { SGlc } & \text { Sinapoylglucose } \\ \text { Sinrest } & \text { bislang nicht identifizierte Sinapinsäureester } \\ \text { s. o } & \text { siehe oben } \\ \text { T } & \text { Thymin } \\ \text { Tab. } & \text { Tabelle } \\ \text { TCA } & \text { Trichloressigsäure } \\ \text { T-DNA } & \text { Transfer-DNA } \\ \text { TM } & \text { Trockenmasse } \\ \text { Tris } & \text { Tris(hydroxymethylaminomethan) } \\ & \\ & \\ & \end{array}$


TTP

$\mathrm{U}$

veg.

$\mathrm{v} / \mathrm{v}$

$\mathrm{w} / \mathrm{v}$

z. B.
Thymintriphosphat

Unit

vegetativ

Volumen zu Volumen

Gewicht zu Volumen

zum Beispiel

Einheitensymbole für physikalische Größen sowie die weiteren im Text verwendeten Abkürzungen richten sich nach den DIN-Normen. 


\section{$1 \quad$ Einleitung}

Raps (Brassica napus L.) stellt im europäischen Raum die wichtigste und weltweit die zweitwichtigste Ölsaat dar (FAO, 2002). Die rapide Entwicklung des Rapsanbaus innerhalb der letzten 25 Jahre stützt sich auf die enormen Erfolge der klassischen Pflanzenzüchtung, der es zunächst gelang, die für bedenklich erklärte Erucasäure (C 22:1) aus dem Öl zu eliminieren. Ein weiteres Hauptproblem stellten die Samenglucosinolate dar, die ebenfalls durch klassische Züchtung weitestgehend eliminiert werden konnten. Der so entstandene Doppel-Null (00) Raps wurde im Jahr 1987 in der BRD als Standardqualität eingeführt (RÖBBELEN, 1999). Dies führte zu einem enormen Anstieg der Anbaufläche, in den letzten Jahren hat sich der Rapsanbau in Deutschland auf einem vergleichsweise hohem Niveau von mehr als 1,2 Mio ha stabilisiert (FAO, 2003).

Das Rapsöl steht heute - zusammen mit dem Olivenöl - an der Spitze der gesunden und ernährungsphysiologisch empfohlenen Speiseöle (OHLSON, 1978; TRAUTWEIN und ERBERSDOPLER, 1998). In gleicher Weise trägt eine Nutzung des bei der Ölgewinnung zurückbleibenden Schrots in der Tierernährung zum Erfolg der Rapssaat bei (UFOP, 2003). Eine verstärkte Nachfrage und Wertschätzung von Seiten der Ernährungsindustrie hat in den letzten Jahren zu einem steigenden Bedarf an Rapssaat in der Humanernährung geführt (UFOP, 2004). Die züchterische Entwicklung von neuen Rapsformen mit spezifischen Qualitäten eröffnet somit weitere Absatzmöglichkeiten. Die Wettbewerbsfähigkeit von Raps wird aber nicht zuletzt von der Qualität des Rapsmehls als Kopplungsprodukt der Ölgewinnung bestimmt. Um die Verwendungsmöglichkeiten der wertvollen Rapssaat zu verbessern, gilt es die Samenqualität zu optimieren und den Gehalt an wertmindernden Schrotinhaltsstoffen zu reduzieren. Im Rahmen dieser Arbeit, welche eingebettet ist in den BMBF-Forschungsverbund „Napus 2000 - gesunde Lebensmittel aus transgener Rapssaat", kommen gentechnische Ansätze zur Verbesserung der Rapssamenqualität zur Anwendung. Napus 2000 zielt auf eine umfassende Nutzung des Rapskorns im Rahmen einer gesunden menschlichen Ernährung ab. Neue Rapssamenqualitäten sollen erzeugt werden und eine erhöhte Wertschöpfung und eine Gesundheitsförderung bezwecken. Vor allem die Proteinfraktion soll als Quelle für ein hochwertiges Eiweiß als Lebensmittel nutzbar gemacht werden (LECKBAND, 2002). 


\subsection{Sinapinsäureester}

Theoretisch könnte eine mit der Ausweitung des Rapsanbaues verbundene Mehrerzeugung von Proteinen einen weitgehend unbegrenzten Einsatz in der Human- und Tierernährung finden. Tatsächlich wird jedoch die Verwendung von Rapsprodukten durch einige Pflanzeninhaltsstoffe wie den Sinapinsäureestern erheblich limitiert, da sie infolge ihrer antinutritiven Eigenschaften die Qualität von Lebens- und Futtermitteln beeinträchtigen (KOZLOW-SKA et al., 1990; NACZK et al, 1998; SHAHIDI und NACZK, 1992). In Hinblick auf ihren bitteren Geschmack sowie die durch sie hervorgerufene Schwarzfärbung von Protein-produkten gehören sie zu den unerwünschten Inhaltsstoffen in der Ernährung (BELL, 1984; GRIFFITH, 1989; SINGLETON, 1981; SOZULSKI, 1979). Sinapinsäureester, welche zum größten Teil aus dem Bitterstoff Sinapin, dem Sinapoyl-Cholin, bestehen liegen im Rapsmehl durchschnittlich zwischen 1 und 2\% vor (BELL, 1993; ZUKALOVA und VASAK, 1999). Sinapin ist die im Rapssamen am häufigsten vorkommende Phenolsäureesterverbindung, deren Anteil etwa $80 \%$ beträgt (DABROWSKI und SOSULSKI 1984; POKORNY und REBLOVA, 1995).

\subsubsection{Metabolismus der Sinapinsäureester in der Pflanze}

Die Sinapinsäure ist die im Raps vorherrschende phenolische Säure (BOUCHEREAU et al., 1991), die sich aus der Zimtsäure ableitet. Die Zimtsäuresynthese nimmt ihren Ausgang über den Shikimat-Weg. Ausgangssubstanzen sind hier die Aminosäuren Tyrosin und Phenylalanin; durch oxidative Decarboxylierung werden diese in Zimtsäure bzw. pCumarsäure umgewandelt. Beschleunigt wird diese Reaktion durch Ammonium-Lyasen. Ausgehend von der Zimtsäure verläuft die weitere Biosynthese über Kaffeesäure, Ferulasäure und 5-Hydroxi-Ferulasäure hin zur Sinapinsäure. Diese Reaktionen werden durch Hydroxilasen und o-Methyl-Tranferasen katalysiert. Raps enthält neben dem Sinapin, das im Samen vorherrscht, weitere Sinapinsäureester, die nach STRACK et al. (1983) während der Entwicklung der Pflanze verschiedenen Umwandlungsprozessen unterliegen.

Nach STRACK et al. (1983) lautet die Gesamtgleichung der Sinapinsäureestersynthese:
a. Sinapinsäure + UDP-Glucose $\longrightarrow$ 1-Sinapoylglucose + UDP
b. 1-Sinapoylglucose + Cholin $\longrightarrow$ Sinapoylcholin + Glucose
c. 1-Sinapoylglucose + L-Malat $\longrightarrow$ Sinapoylmalat + Glucose 
Das Enzym Sinapinsäure-Glucolsyltransferase (SGT) katalysiert im Samen die Bildung von Sinapoylglucose aus Sinapinsäure und UDP-Glucose (a). Die Sinapoylglucose ist nur ein Zwischenprodukt; sie dient als Sinapinsäure-Donator für die Bildung von Sinapin (b) bzw. Sinapoylmalat (c). Das Sinapin wird aus 1-0-Sinapoyl-ß-D-Glucose und Cholin gebildet (b). Diese Reaktion wird durch das Enzym Sinapoyl-Cholintransferase (SCT) beschleunigt. Die Sinapoylmalat-Bildung wird durch das spezifische Enzym Sinapoyl-LMalattranferase (SMT) katalysiert (STRACK et al., 1983; CHAPPLE et al., 1992). Sinapoylglucose und Sinapin werden, neben fünf anderen, bislang nicht identifizierten Sinapinsäureestern (BOUCHERAU et al., 1992), spezifisch im Samen synthetisiert, während in den vegetativen Pflanzenteilen hauptsächlich Sinapoylmalat gebildet wird (STRACK et al., 1983; LORENZEN et al., 1996).

\subsection{Resveratrol}

Ein weiteres sehr interessantes Biomolekül für eine gentechnische Veränderung der Rapssaatqualität ist Resveratrol. Resveratrol (3,5,4-trihydroxy-trans-Stilben) gehört zu den Flavoniden und wird der Klasse der Phytoalexine zugeordnet. Resveratrol wurde erstmals aus Knöterichpflanzen isoliert und identifiziert. Diese Substanz kommt aber auch in Weintrauben (LANGCAKE und PRYCE, 1976), Kiefern (KINDL, 1985) Lein- und Sesamsaat (HETTWER, 1997) und Erdnüssen (SCHOEPPNER und KINDL, 1984) vor. Phytoalexine sind eine Klasse von antibiotischen Polyphenolverbindungen, die das Abwehrsystem der Pflanzen stärken. Resveratrol wird in den Pflanzen bei erhöhter Belastung als Stressmetabolit gebildet, beispielsweise durch hohe Ozon- und UVBelastung sowie bei Insekten- und Pilzbefall (HAIN et al., 1993; HIPSKIND und PAIVA, 2000; LECKBAND und LÖRZ, 1998). Resveratrol entfaltet seine abwehrstärkenden Fähigkeiten nicht allein in der Pflanze, sondern auch im menschlichen Körper. Das beruht vorwiegend auf seinen antioxidativen Wirkungen. Resveratrol ist vor allem ein Fänger von Peroxyl-Radikalen, es senkt außerdem die Lipidperoxidation von Lipoproteinen (LDL) und Zellen, und es schützt vor den schädlichen Folgen von oxidiertem LDL (FRANKEL et al., 1993; MANNA et al., 2000). Resveratrol kann Herzkrankheiten vorbeugen (BERTELLI et al., 1995; SUBBARAMAIAH et al., 1998; MANNA et al., 2000). Zudem ist es als Hemmstoff der Arachidonsäure bekannt ((KIMURA et al. 1985; PACE-ASCIAK et al. 1995) Resveratrol kann außerdem auf Prozesse einwirken, welche die Bildung von Krebszellen sowie deren weitere Entwicklung hemmen können (JANG et al., 1997). Allerdings kommt Resveratrol natürlicherweise im Raps nicht vor. Bis heute wurden 
Stilbensynthasegene in Tabak (HAIN et al., 1993), Reis (STARK-LORENZEN et al., 1997), Luzerne (HIPSKIND und PAIVA, 2000), Gerste und Weizen (LECKBAND und LÖRZ, 1998), Weinrebe (COUTOS-THEVENOT et al., 2000) und Apfel (SZANKOWSKI et al., 2003) transformiert um eine erhöhte Pilzresistenz zu erreichen, lediglich in Kiwi wurde die Transformation auch in Hinblick auf eine Verwendung als Lebensmittel durchgeführt (KOBAYASHI et al., 2000).

\subsubsection{Metabolismus des Resveratrols in der Pflanze}

Die Resveratrolbiosynthese nimmt ihren Ausgang über den Shikimat-Weg. Ausgangssubstanz ist hier die Aminosäure Phenylalanin (Abb.1), welche durch oxidative Decarboxylierung in p-Cumarsäure umgewandelt wird. Beschleunigt wird diese Reaktion durch Ammonium-Lyasen. Die Produktion von Resveratrol wird durch das Enzym Stilbensynthase (STS) reguliert, welches ausgehend von der p-Cumarsäure ein Molekül pCoumaroyl-CoA und drei Moleküle Malonyl-CoA in 3,5,4-Trihydroxistilben verwandelt. p-Coumaroyl-CoA und Malonyl-CoA entstammen dem Malonatweg, welcher in allen Pflanzen vorkommt und mit Hilfe der Chalconsynthase zur Bildung von Chalcon führt. 


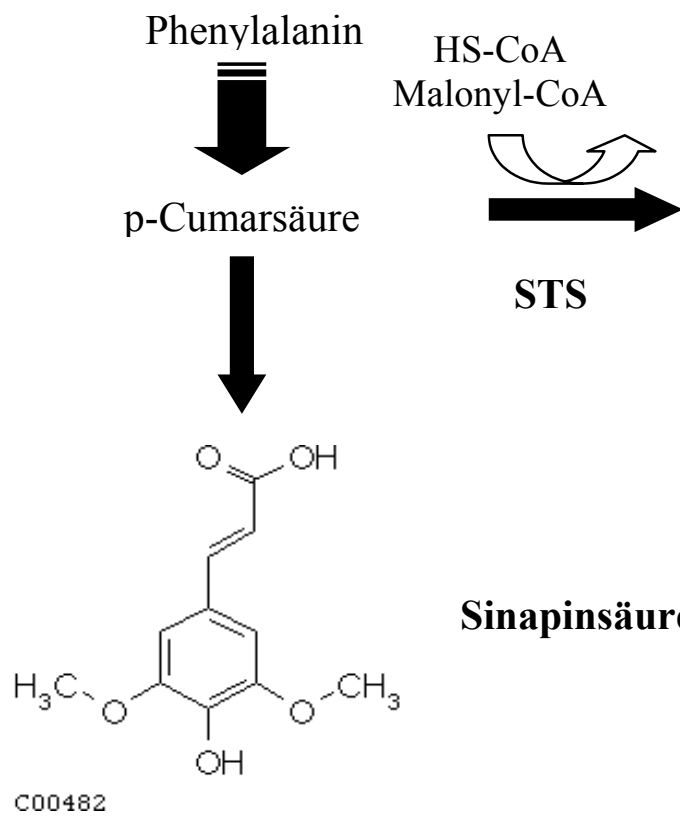<smiles>Oc1ccc(/C=C/c2cc(O)cc(O)c2)cc1</smiles>

Resveratrol<smiles>COc1cc(/C=C/C(=O)O)cc(OC)c1O[C@@H]1O[C@H](CO)[C@@H](O)[C@H](O)[C@H]1O</smiles>

\section{Sinapoylglucose}

Malate Glucose

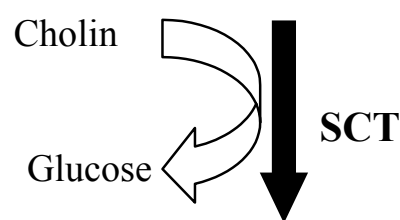

$\mathrm{H}_{3} \mathrm{C}^{\mathrm{CH}_{3}} \mathrm{CH}^{-\mathrm{N}}$<smiles>C=Cc1cc(OC)c(O)c(OC)c1</smiles>

$\operatorname{co0933}$

\section{Sinapoylcholin}

Abb. 1: Biosynthese der Sinapinsäureester und des Resveratrols (nach STRACK et al., 1983 und MELCHIOR und KINDL, 1991) 


\subsection{Zielsetzung der Arbeit}

Ziel der Arbeit war es, einen Beitrag zur Verbesserung der Rapssamenqualität zu leisten. Hierzu sollte mit Hilfe eines transgenen Ansatzes die Aktivität der Sinapinsäure Glucosyltransferase (SGT) reduziert werden, um eine Verringerung des Sinapinsäureestergehaltes im Samen zu erreichen. Ferner sollte die Stilbensynthase (STS) aus Vitis vinifera in Raps exprimiert werden, um in Verbindung mit einer SGT-Supprimierung eine möglichst effiziente Biosynthese von Resveratrol zu ermöglichen. Mit Hilfe der Agrobakterium vermittelten Transformation und Co-Transformation sollten transgene Pflanzen hergestellt werden. Diese sollten molekulargenetisch und biochemisch charakterisiert und im Rahmen eines Gewächshausversuches sollten die Auswirkungen der veränderten Enzymaktivitäten auf den Phänotyp untersucht werden.

\section{Reduzierung der Sinapinsäure Glucosyltransferase Aktivität}

Ihre Schlüsselstellung im Sinapinsäureestermetabolismus macht die Sinapinsäure Glucosyltransferase (SGT) zu einem attraktiven Ziel für eine genetische Manipulation von Brassica napus. Die Volllängen-cDNA des SGT-Gens wurde aus Brassica napus isoliert (MILKOWSKI et al., 2000) und als 200 bp-Fragment in ein Doppelstrang-RNAInterferenz-Konstrukt (SGT-ds-RNAi) integriert. Im Rahmen der vorliegenden Arbeit sollten mittels der Agrobakterium vermittelten Transformation transgene SGT-ds-RNAi Linien erstellt und charakterisiert werden.

\section{Expression der Stilbensynthase}

Zur Expression von Resveratrol wurde das Stilbensynthasegen VST1 (MELCHIOR und KINDL, 1991) aus Vitis vinifera für Transformationsversuche verwendet. Da durch eine Suppression der Sinapinsäureester vermehrt p-Cumarsäure als Substrat für die Resveratrolsynthese zur Verfügung stehen könnte (Abb.1), wurde ein Co-Transformationsversuch mit dem o.g. SGT-RNAi-Konstrukt durchgeführt. Transgene VST1+SGT-ds-RNAi Linien sollten mittels der Agrobakterium vermittelten Co-Transformation erstellt und charakterisiert werden. 


\section{$2 \quad$ Material und Methoden}

\subsection{Material}

\subsubsection{Bakterienstämme und Plasmide}

Der in dieser Arbeit verwendete Escherichia coli-Stamm XL1-Blue (BULLOCK et al., 1987) wurde für die Amplifizierung von Plasmid-DNA verwendet. Die Transformationen von Brassica napus L. wurden mit den Agrobakterium tumefaciens-Stämmen AGL 1 (HELLENS et al., 2000) und ATHV C58C1 (HELLENS et al., 2000) durchgeführt. Die in dieser Arbeit verwendeten Plasmide sind in Tab. 1 aufgeführt (Plasmidkarten s. III/1; Abb.1, III/2; Abb.2).

Tab. 1: Die in dieser Arbeit verwendeten Plasmide

\begin{tabular}{lll}
\hline Plasmid & Beschreibung & Referenz \\
\hline pLH-Bn SGT-GUS & $\begin{array}{l}\text { cDNA der UDP-Glucose:Sinapinsäure-Glucosyl- } \\
\text { transferase aus Brassica napus in pLH-7000 }\end{array}$ \\
pPSty5 & $\begin{array}{l}\text { cDNA der Stilbensynthase aus Vitis vinifera in } \\
\text { pPZP111 }\end{array}$ & (1) \\
\hline
\end{tabular}

(1) Milkowski et al., 2000, (2) P. Jorasch, Uni Hamburg

\subsubsection{Bakteriennährmedien und -anzucht}

E. coli wurde ausschließlich in LB-Medium, A. tumefaciens in YEB-Medium angezogen.

LB-Medium: $\quad 1 \mathrm{~g} / 1$ Hefeextrakt

$5 \mathrm{~g} / 1$ Pepton (Kasein)

$10 \mathrm{~g} / 1 \mathrm{NaCl}$

YEB-Medium: $\quad 1 \mathrm{~g} / \mathrm{l}$ Hefeextrakt

$5 \mathrm{~g} / 1 \quad$ Fleischextrakt

$5 \mathrm{~g} / 1$ Pepton (Kasein)

$0,5 \mathrm{~g} / 1 \mathrm{MgSO}_{4} \cdot 7 \mathrm{H}_{2} \mathrm{O}$

$5 \mathrm{~g} / \mathrm{l}$ Saccharose 
Zur Herstellung von Agarplatten wurde beiden Medien 1,5\% (w/v) Agar hinzugefügt. Die Anzucht erfolgte in $250 \mathrm{ml}$-Erlenmeyerkolben auf einem Rundschüttler (200 rpm) bei $37^{\circ} \mathrm{C}$ (E. coli) bzw. $27^{\circ} \mathrm{C}$ (A. tumefaciens).

Für die Herstellung der E. coli- und A. tumefaciens-Stammkulturen wurden die Zellen im entsprechenden Medium bis zur exponentiellen Wachstumsphase angezogen, $500 \mu 1$ der Zellsuspension mit $500 \mu 187 \%$ igem Glycerin (v/v) versetzt und bei $-70{ }^{\circ} \mathrm{C}$ gelagert. Kulturen auf festem Medium wurden bei $4{ }^{\circ} \mathrm{C}$ aufbewahrt und alle 4 Wochen auf frisches Medium überimpft.

\subsubsection{Bestimmung von Wachstumsparametern}

Die Messung der optischen Dichte wurde in einem Photometer (Lambda 5, Perkin Elmer, Offenbach) gegen unbeimpfte Nährlösung in einem Extinktionsbereich von 0 bis 0,3 bei einer Wellenlänge von $660 \mathrm{~nm}$ durchgeführt. Die Probe wurde in einer Küvette mit einer Schichtdicke von $1 \mathrm{~cm}$ gemessen. Bei einer Zelldichte von OD > 0,2 wurde die Probe mit Nährlösung verdünnt. Der pH-Wert (pH-Meter, Wiss.-Techn.-Werkstätten, Weilheim) der Proben und auch aller anderen Lösungen und Medien wurde gemessen. Vor der Messung wurde das pH-Meter mit Hilfe von Standardlösungen definierten $\mathrm{pH}-$ Wertes geeicht.

\subsubsection{Antibiotika und Herbizide}

Die für die Selektion verwendeten sterilfiltrierten Antibiotika und Phosphinothricin wurden in den in Tab. 2 aufgeführten Stammlösungen bei $-20{ }^{\circ} \mathrm{C}$ gelagert und in den entsprechenden Endkonzentrationen eingesetzt.

Tab. 2: Für die Selektion verwendete Antibiotika und Herbizide.

\begin{tabular}{lll}
\hline Antibiotikum/ Herbizd & Stammlösung & Endkonzentration \\
\hline Kanamycin & $50 \mathrm{mg} / \mathrm{ml}$ & 50 oder $25 \mathrm{mg} / 1$ \\
Carbenicillin & $500 \mathrm{mg} / \mathrm{ml}$ & $500 \mathrm{oder} 250 \mathrm{mg} / \mathrm{l}$ \\
Streptomycin & $100 \mathrm{mg} / \mathrm{ml}$ & $300 \mathrm{mg} / 1$ \\
Spectinomycin & $100 \mathrm{mg} / \mathrm{ml}$ & $100 \mathrm{mg} / 1$ \\
Phosphinothricin & $10 \mathrm{mg} / 1$ & 5 oder $10 \mathrm{mg} / 1$ \\
\hline
\end{tabular}




\subsubsection{Oligonukleotide}

Die in dieser Arbeit für Amplifizierungen verwendeten Oligonukleotide sind in Tab. 3 aufgeführt.

Tab. 3: Verwendete Oligonukleotide

\begin{tabular}{lll}
\hline Name & Sequenz & Fragmentlänge \\
\hline PAT-fw & 5 `-ATG GGC CCA GAA CGA CGC CC-3` & \multirow{2}{*}{$498 \mathrm{bp}$} \\
PAT-rev & 5`-GCG TGA TCT CAG ATC TCG GT-3` & \\
& & \\
NPT-II-fw & 5'-ATC GGG AGC GGC GAT ACC GTA-3` & 700 bp \\
NPT-II-rev & 5 `-GAG GCT ATT CGG CTA TGA CTG-3` & \\
\hline
\end{tabular}

\subsubsection{Pflanzenmaterial}

Die Agrobakterium tumefaciens vermittelte Transformation wurde mit der Sommerrapssorte Drakkar durchgeführt. Diese Sorte der Firma Serasem wurde 1986 in Frankreich zugelassen und stammt von Prota und Is 8716 L. 1 ab. Es handelt sich um eine Ölrapssorte der Doppelnullqualität. Das Saatgut wurde freundlicherweise von der Firma W. von Borries-Eckendorf, Leopoldshöhe, zur Verfügung gestellt.

\subsubsection{Chemikalien und Enzyme}

Die verwendeten Chemikalien wurden, soweit nicht anders vermerkt, von den Firmen Merck (Darmstadt), Sigma (St. Louis, USA) oder Fluka (Neu-Ulm) bezogen. Sie hatten den Reinheitsgrad ,pro analysis”. 


\subsection{Molekularbiologische Methoden}

\subsubsection{Behandlung von Geräten und Lösungen}

Alle hitzestabilen Geräte und Lösungen wurden zur Nukleaseinaktivierung für 20 min bei $121^{\circ} \mathrm{C}$ sterilisiert. Kleingeräte aus Metall wurden mit 96\%igem (v/v) Ethanol gespült und abgeflammt. Hitzelabile Lösungen wurden sterilfiltriert (Porengröße 0,2 $\mu \mathrm{m}$, Schleicher und Schüll, Dassel).

\subsubsection{Isolierung von Plasmid-DNA}

\subsubsection{Isolierung von Plasmid-DNA aus E. coli}

Die Überprüfung transformierter E. coli-Kolonien erfolgte nach BIRNBOIM und DOLY (1979, modifiziert). Die Zellen einer Einzelkolonie wurden in 1,5 ml LB-Medium mit entsprechendem Antibiotikum angeimpft und über Nacht inkubiert (s. 2.1.4). Die Zellen wurden abzentrifugiert (13000 rpm, 1 min, RT, Hettich-Tischzentrifuge, Tuttlingen). Das Bakterienpellet wurde in $150 \mu \mathrm{l}$ P1-Puffer resuspendiert. Anschließend wurden $150 \mu 1$ Lysis-Puffer P2 zugegeben und das Reaktionsgefäß mehrfach vorsichtig geschwenkt. Die Suspension wurde durch Zugabe von $150 \mu 1$ P3-Puffer und erneutem vorsichtigem Schwenken neutralisiert. Zelltrümmer, chromosomale DNA und ausgefallene Proteine wurden abzentrifugiert (13000 rpm, $10 \mathrm{~min}, 4{ }^{\circ} \mathrm{C}$, Biofuge, Heraeus, Hanau). Der Überstand wurde mit 0,7 Volumen Isopropanol versetzt und zentrifugiert (s. o.). Das Pellet wurde mit 70\%igem Ethanol (v/v) gewaschen, luftgetrocknet und in $15 \mu 1$ TE-Puffer aufgenommen.

$\begin{array}{lll}\text { P1-Puffer: } & 50 \mathrm{mM} & \text { Tris-HCl }(\mathrm{pH} 8,0) \\ & 10 \mathrm{mM} & \text { EDTA } \\ & 100 \mu \mathrm{g} / \mathrm{ml} & \text { RNase A }\end{array}$

$\begin{array}{lll}\text { P2-Puffer: } & 200 \mathrm{mM} & \mathrm{NaOH} \\ & 1 \%(\mathrm{w} / \mathrm{v}) & \mathrm{SDS} \\ & & \\ \text { P3-Puffer: } & 3 \mathrm{M} & \text { Kaliumacetat }(\mathrm{pH} \mathrm{5,5)} \\ & & \\ \text { TE-Puffer: } & 10 \mathrm{mM} & \text { Tris- } \mathrm{HCl}(\mathrm{pH} 8,0) \\ & 1 \mathrm{mM} & \text { EDTA }\end{array}$




\subsubsection{Minipräparation von Plasmid-DNA}

Diese Methode wurde für die Isolierung von Plasmid-DNA aus A. tumefaciens eingesetzt. Die Zellen einer Einzelkolonie wurden in $8 \mathrm{ml}$ YEB-Medium mit entsprechendem Antibiotikum $16 \mathrm{~h}$ angezogen (s. 2.1.2 und 2.1.4). Die Zellsuspension wurde auf vier $2 \mathrm{ml}$ Reaktionsgefäße verteilt und abzentrifugiert (13000 rpm, $1 \mathrm{~min}$, RT, HettichTischzentrifuge, Tuttlingen). Für die Minipräparation wurde der „QIAspin-prep-Kit” der Firma Qiagen, Hilden, verwendet. Die Pellets wurden nach Herstellerangaben weiterverarbeitet, wobei auch die optionalen Arbeitsschritte durchgeführt wurden. Die so erhaltene Plasmid-DNA wurde zur Aufkonzentrierung einer Ethanolfällung unterzogen. Das Pellet wurde in $15 \mu 1$ TE-Puffer aufgenommen.

\subsubsection{Maxipräparation von Plasmid-DNA}

Diese Methode wurde herangezogen, wenn große Mengen Plasmid-DNA benötigt wurden. Das eingesetzte Kulturvolumen hing von dem aufzureinigenden Plasmid ab: bei „high copy”-Plasmiden wurden $150 \mathrm{ml}$, bei „low copy”-Plasmiden $500 \mathrm{ml}$ LB- bzw. YEBMedium verwendet. Die Bakterienzellen wurden 12 (E. coli) bzw. 16 h (A.tumefaciens) angezogen (s. 2.1.2 und 2.1.4) und abzentrifugiert (6300 rpm, $10 \mathrm{~min}, 4{ }^{\circ} \mathrm{C}$, Suprafuge, Rotor HFA 14290, Heraeus, Hanau). Für die Maxipräparation wurde der „Qiagen Maxi Kit” der Firma Qiagen, Hilden, verwendet. Die Verarbeitung des Bakterienpellets erfolgte nach Herstellerangaben. Das am Ende erhaltene DNA-Pellet wurde in $500 \mu$ l (bei „high copy”-Plasmiden) bzw. $150 \mu \mathrm{l}$ (bei „low copy”-Plasmiden) TE-Puffer aufgenommen.

\subsubsection{Isolierung von Raps-Gesamt-DNA}

Gesamt-DNA von in vitro- oder Gewächshaus-Pflanzen wurde mit Hilfe des „Nucleon Phytopure-Kit” der Firma Amersham Life Science (Buckinghamshire, England) gewonnen. 1 bis 1,5 g Blattmaterial wurden im vorgekühlten Mörser unter Verwendung von flüssigem Stickstoff zu Pulver gemahlen und nach Herstellerangaben verarbeitet. Der optionale Einsatz von 2-Mercaptoethanol und RNaseA wurde dabei berücksichtigt. Das so erhaltene DNA-Pellet wurde in 300 bis $500 \mu$ TE-Puffer aufgenommen und für $1 \mathrm{~h}$ bei $65^{\circ} \mathrm{C}$ inkubiert. Die vollständige Lösung des Pellets erfolgte über mehrere Tage bei $4{ }^{\circ} \mathrm{C}$. 


\section{DNA-Extraktion mit dem Qiagen DNeasy Plant Mini Kit}

Das Pflanzenmaterial (100 mg) wurde in flüssigem Stickstoff zermörsert und in 1,5 ml Eppendorf Reaktionsgefäße gefüllt. $400 \mu 1$ des von dem Hersteller mitgelieferten Puffers und $4 \mu 1$ der RNAseA A Stammlösung $(100 \mathrm{mg} / \mathrm{ml})$ wurden zugefügt und die Mischung stark gemischt. Während einer Inkubationszeit von 10 min bei $65{ }^{\circ} \mathrm{C}$ wurde die Lösung 23x gemischt. $130 \mu 1$ des Puffers AP2 wurden zu dem Lysatmix gegeben und 5 min auf Eis inkubiert. Anschließend wurde die Lösung auf eine QIAshredder spin Säule gegeben, die sich auf einem $2 \mathrm{ml}$ Sammelgefäß befand. Nach einem Zentrifugationsschritt von 2 min bei $6000 \mathrm{xg}$, wurde die Durchflußfraktion in ein neues E-cup gegeben und 1,5 Volumenteile des Puffers AP3/E zugefügt. $650 \mu 1$ der Lösung wurden in eine DNeasy Mini Spin Säule pipettiert, die sich auf einem $2 \mathrm{ml}$ Sammelgefäß befand und bei $6000 \mathrm{xg}$ für $1 \mathrm{~min}$ zentrifugiert. Der Durchfluß wurde verworfen. Die restliche Lösung wurde auf die Säule aufgetragen und ebenso zentrifugiert. Zum Waschen der Säulenmembran wurden $500 \mu 1$ des Puffers AW einpipettiert und wiederum zentrifugiert. Auf die Säule wurde daraufhin $100 \mu \mathrm{l}$ des $65{ }^{\circ} \mathrm{C}$ heißen Puffers AE aufgebracht und die Säule in ein frisches 1,5 ml Reaktionsgefäß gesetzt. Die Säule wurde bei 6000 xg für 5 min zentrifugiert.

\subsubsection{Bestimmung von Nukleinsäurekonzentrationen}

Die Konzentrationsbestimmung doppelsträngiger DNA wurde in entsprechenden Verdünnungen photometrisch bei einer Wellenlänge von 260 nm (Gene Quant, Pharmacia Biotech, Freiburg) gegen TE-Puffer in Quarzglasküvetten durchgeführt. Bei einer Schichtdicke von $1 \mathrm{~cm}$ gilt für eine $\mathrm{OD}_{260} \mathrm{~nm}$ von 1 eine Referenzkonzentration von $50 \mu \mathrm{g} / \mathrm{ml}$ dsDNA (DAVIS et al., 1980). Zudem wurde die Reinheit der DNA durch die Bestimmung des Verhältnisses von $\mathrm{OD}_{260 \mathrm{~nm}} \mathrm{zu} \mathrm{OD}_{280 \mathrm{~nm}}$ überprüft. Bei reinen DNALösungen sollte das Verhältnis mindestens 1,8 betragen (SAMBROOK et al., 1989). Eine zweite Möglichkeit der Konzentratbestimmung von DNA-Lösungen war die Messung mit einem Fluorometer der Firma Pharmacia (Freiburg). Hierbei wurde nach Herstellerangaben vorgegangen. Der Farbstoff bis-Benzimidazol (Hoechst 33258), ein Fluorochrom, bindet hochspezifisch an DNA und die Flureszenz dieses DNA-Farbstoff-Komplexes kann mit Hilfe des Fluorometers gemessen werden. Die Konzentration der Probe konnte nach Vergleich mit einer Referenz-DNA-Lösung bekannter Konzentration bestimmt werden. Eventuell vorhandene RNA in den Proben hatte hierbei keine Auswirkungen auf die DNAKonzentrationsbestimmung, da der Farbstoff fast ausschließlich an DNA bindet. 


\subsubsection{Reinigung und Konzentrierung von DNA}

Zur Konzentrierung und Reinigung von Nukleinsäuren wurde eine Ethanolfällung durchgeführt. Eine Erhöhung der Konzentration an monovalenten Kationen erfolgte durch Zugabe $3 \mathrm{M}$ Natriumacetat-Lösung ( $\mathrm{pH}$ 5,5). Zur Fällung wurden 2 Volumen eiskalten 96\%igen Ethanols (v/v) zugegeben und für mindestens $20 \mathrm{~min}$ bei $-70{ }^{\circ} \mathrm{C}$ oder $2 \mathrm{~h}$ bei $-20{ }^{\circ} \mathrm{C}$ inkubiert. Die DNA wurde zentrifugiert (13000 rpm, $30 \mathrm{~min}, 4{ }^{\circ} \mathrm{C}$, Biofuge $13 \mathrm{R}$, Heraeus, Hanau) und das Pellet zweimal mit eiskaltem 70\%igem Ethanol (v/v) gewaschen. Die DNA wurde anschließend an der Luft getrocknet und im gewünschten Volumen TEPuffer oder $\mathrm{H}_{2} \mathrm{O}_{\text {bidest. gelöst. }}$

\subsubsection{Restriktionsanalyse der genomischen DNA}

Die genomische DNA aus transgenem Blattmaterial bzw. aus Kontrollpflanzen und die Plasmid-DNA von Agrobacterium tumefaciens wurden einem EcoR1-Verdau unterworfen, wobei 5-10U des Enzyms pro $\mu \mathrm{g}$ DNA eingesetzt wurden. Ein spezifischer Puffer der für optimale Reaktionsbedingungen sorgt, wurde im Verhältnis von 1:10 hinzugegeben. Es wurden 5-10 $\mu \mathrm{g}$ der genomischen DNA bzw. $200 \mathrm{ng}$ des Ti-Plasmids pro Restriktion eingesetzt. Die Restriktion erfolgte über Nacht bei $37^{\circ} \mathrm{C}$ unter Schütteln. Die fragmentierte DNA wurde gefällt auf einem 0,8\%igem Agarosegel aufgetrennt (30V, 16h).

\subsubsection{Agarose-Gelelektrophorese von Nukleinsäuren}

Zur analytischen und präparativen Auftrennung von DNA wurden Agarosegelelektrophoresen in horizontalen Gelkammern (Easy-Cast Electrophoresis System, AGS, Heidelberg, und DNA Sub Cell, Bio-Rad, München) durchgeführt. Die Gelvolumina betrugen 10 bis $20 \mathrm{ml}$ für analytische und 100 bis $150 \mathrm{ml}$ für präparative Gele. Es wurden je nach Fragmentgröße Agarosekonzentrationen von 0,8\% bis 1,5\% (w/v) in 1x TAE-Puffer verwendet. Vor dem Auftragen wurden die Proben mit 0,2 bis 0,5\% Volumen Loading Dye (MBI Fermentas, St. Leon-Rot) beschwert. Die Elektrophorese wurde bei einer Spannung von 30 bis $100 \mathrm{~V}$ in 1x TAE-Puffer durchgeführt.

50x TAE-Puffer: $\quad 800$ mM Tris- $\mathrm{HCl}(\mathrm{pH} \mathrm{8,0)}$

$400 \mathrm{mM}$ Eisessig

$40 \mathrm{mM}$ EDTA 
Durch Variation der Agarosekonzentration und damit der Porengröße, wurde der Trennbereich eines Gels der zu erwartenden Fragmentgröße angepaßt. Die genauen Verhältnisse sind Tabelle 6 zu entnehmen.

Tab. 4: Fragmentauftrennung in Agarosegelen

\begin{tabular}{l|l}
\hline Agarosekonzentration (\%) & Optimale Auftrennung von Fragmenten der Größen \\
\hline 0,3 & $5-90 \mathrm{~kb}$ \\
0,6 & $1-20 \mathrm{~kb}$ \\
0,7 & $0,8-10 \mathrm{~kb}$ \\
0,9 & $0,5-7 \mathrm{~kb}$ \\
1,2 & $0,4-6 \mathrm{~kb}$ \\
1,5 & $0,2-3 \mathrm{~kb}$ \\
2,0 & $0,1-2 \mathrm{~kb}$ \\
\hline
\end{tabular}

\subsubsection{DNA-Größenstandards}

Der für die DNA-Größenbestimmung herangezogene Standard ist nachfolgend mit den Fragmentgrößen aufgeführt:

1 KB DNA Ladder (peqlab, Göttingen): 10000 bp, 8000 bp, 6000 bp, 5000 bp, 4000 bp, 3500 bp, 3000 bp, 2500 bp, 2000 bp, 1500 bp, 1000 bp, 750 bp, 500 bp, 250 bp

\subsubsection{Amplifizierung von DNA-Fragmenten aus Raps-Gesamt-DNA mittels Polymerasekettenreaktion}

Gesamt-DNA von potentiell transgenen Pflanzen wurde mit Hilfe der Polymerasekettenreaktion (PCR) einem ersten Screening unterzogen, indem das Transgen oder ein Teil davon mit spezifischen Primern amplifiziert wurde. Die PCR wurde im „DNA Thermal Cycler 480“ (Perkin Elmer, Norwalk, USA) durchgeführt. Der PCRAnsatz betrug $25 \mu 1$ und erfolgte in einem $200 \mu 1$-Reaktionsgefäß. Es wurde unabhängig von der Konzentration immer $1 \mu 1$ der isolierten Gesamt-DNA (s. 2.2.3) als TemplateDNA eingesetzt: 


$\begin{array}{lll}\text { Template-DNA } & & 1 \mu \mathrm{l} \\ \text { 10x PCR-Puffer } & & 2,5 \mu \mathrm{l} \\ \mathrm{MgCl}_{2} & 25 \mathrm{mM} & 1,25 \mu \mathrm{l} \\ \text { Forward-Primer } & 10 \mu \mathrm{M} & 2,5 \mu \mathrm{l} \\ \text { Reverse-Primer } & 10 \mu \mathrm{M} & 2,5 \mu \mathrm{l} \\ \text { dNTPs } & 1,25 \mathrm{mM} & 4 \mu \mathrm{l} \\ \text { Taq-Polymerase } & 5 \mathrm{U} / \mu \mathrm{l} & 0,75 \mu \mathrm{l} \\ \mathrm{H}_{2} \mathrm{O}_{\text {bidest. }} & \text { ad } & 25 \mu \mathrm{l}\end{array}$

Folgende PCR-Bedingungen (PAT und NPTII) wurden gewählt:

$\begin{array}{llll}1 \mathrm{x} & \text { Denaturierung } & 3 \mathrm{~min} & 95^{\circ} \mathrm{C} \\ & & & \\ 30 \mathrm{x} & \text { Denaturierung } & 1 \mathrm{~min} & 95^{\circ} \mathrm{C} \\ & \text { Anlagerung der Primer } & 1 \mathrm{~min} & 54^{\circ} \mathrm{C} \\ & \text { Synthese } & 2 \mathrm{~min} & 72^{\circ} \mathrm{C}\end{array}$

\subsubsection{Southern Blot Analyse}

Für den Transfer auf eine Nylonmembran wurden jeweils 5-10 $\mu$ g der restringierten genomischen DNA mit 1/5 Volumen Farbmarker versetzt und in einem 0,8\%igem Agarosegel für $16 \mathrm{~h}$ bei $35 \mathrm{~V}$ elektrophoretisch aufgetrennt. Das Agarosegel wurde vor dem eigentlichen Blotten vorbehandelt:

- 15 min Depurinierung

- 5 min Waschen mit Aqua dest

- 30 min Denaturierung

- 30 min Neutralisierung

- 15 min Äquilibrierung

Der vertikale DNA-Transfer aus dem Gel auf eine positiv geladene Membran N+ (Amersham, Braunschweig) erfolgte über einen Southern Blot (Southern, 1975) mit Hilfe einer 0,4 M NaOH-Lösung (kovalente Bindung) über Nacht. In Whatman-3MMFilterpapier und Alufolie eingewickelt konnte der Blot für längere Zeit bei $4^{\circ} \mathrm{C}$ bis zur Hybridisierung aufbewahrt werden. 


\subsubsection{Herstellung nicht-radioaktiv markierter Sonden}

Bei der nicht-radioaktiven Markierung wird über enzymatischen Einbau von Digoxigenin11-dUTP-Nukleotiden die DNA-Sonde markiert. Die Markierung der Sonden erfolgte nach den Angaben der Dig-High-Prime-Markierungsvorschrift von Boehringer Mannheim. Dabei wurden mittels PCR die einzelnen Nukleotide dATP, dCTP, dGTP, dTTP sowie das dUTP komplementär zur Matrizen-DNA eingebaut.

\subsubsection{Hybridisierung der Membranen}

Mittels der Hybridisierungen sollten auf DNA-Ebene die beim Verdau entstandenen Fragmente, die die transgene DNA enthalten, aufgespürt werden. Vor der eigentlichen Hybridisierung wurde die Membran durch eine im Kit gelieferte DIG-Easy-Hyb-Lösung (Roche) prähybridisiert. Die Prähybridisierung erfolgte bei $42^{\circ} \mathrm{C}$ im Hybridisierungsofen für mindestens zwei Stunden. Für die Hybridisierung wurde die Sonde vor der Zugabe zur DIG-Easy-Hyb-Lösung bei $95^{\circ} \mathrm{C}$ zehn Minuten denaturiert. Es wurden 25ng SondenDNA/ml Hybridisierungslösung hinzugefügt. Die Membran wurde bei $42^{\circ} \mathrm{C}$ für $16 \mathrm{~h}$ im Hybridisierungsofen hybridisiert. Nach der Hybridisierung mußte die unspezifisch gebundene Sonden-DNA von der Membran entfernt werden. Dies geschah durch Waschschritte unterschiedlicher Stringenz. Die Membran wurde zweimal 5 min mit $2 \mathrm{xSSC} / 0,1 \%$ SDS bei Raumtemperatur und $2 \times 15$ min mit $0,1 \times S S C / 0,1 \%$ SDS bei $68^{\circ} \mathrm{C}$ gewaschen.

\subsubsection{Detektion genomischer DNA-Fragmente}

Nach den Waschschritten mußte die Membran in Waschpuffer äquilibriert werden. Schließlich wurden freie Membranbereiche an denen die Sonde nicht gebunden hatte, mit einem Blocking-Reagenz (Roche) bedeckt. Daran anschließend wurde die Membran in Anti-Digoxigenin-AP-Konjugat (Roche), 1:10000 verdünnt in 1\% Blocking Lösung, inkubiert. In zwei Waschschritten wurde der nicht gebundene Antikörper entfernt. Nachdem die Membran mit dem Detektionspuffer auf die Chemilumineszenz vorbereitet war, wurde sie in eine Folie geschweißt und mit $2 \mathrm{ml}$ CSPD-ready to use (Boeringer Mannheim) beträufelt. Nach zehn Minuten wurde die überschüssige CSPD-Lösung entfernt und die Membran luftblasenfrei in eine neue Folie eingeschweißt. Die Folie wurde in einer Filmkassette befestigt und für eine Stunde bei $37^{\circ} \mathrm{C}$ inkubiert. In der 
Dunkelkammer wurde ein Chemilumineszenzfilm (Kodak, Berlin) aufgelegt. Zur Detektion der DNA-Fragmente, die das Transgen enthielten wurden zwei Stunden benötigt.

\subsubsection{Transformation von E. coli und A. tumefaciens}

\subsubsection{Herstellung kompetenter Zellen}

Mit einer 4 ml-Vorkultur wurde eine 400 ml-Hauptkultur angeimpft und bei $37{ }^{\circ} \mathrm{C}$ (E. coli) bzw. $27^{\circ} \mathrm{C}$ (A. tumefaciens) bis zu einer $\mathrm{OD}_{600 \mathrm{~nm}}$ von 0,5 bis 0,6 angezogen. Die Zellsuspension wurde für 15 bis $30 \mathrm{~min}$ auf Eis gestellt und anschließend abzentrifugiert (3000 rpm, $4{ }^{\circ} \mathrm{C}, 15 \mathrm{~min}$, Suprafuge, Rotor HFA 14.290, Heraeus, Hanau). Das so erhaltene Bakterienpellet wurde auf Eis mit $400 \mathrm{ml}$ eiskaltem, sterilem $\mathrm{H}_{2} \mathrm{O}_{\text {bidest. }}$ gewaschen. Nach erneuter Zentrifugation (s. o.) wurde das Pellet mit $200 \mathrm{ml}$ eiskaltem, sterilem $\mathrm{H}_{2} \mathrm{O}_{\text {bidest. }}$ gewaschen, erneut zentrifugiert (s. o.) und anschließend einmal mit $8 \mathrm{ml}$ eiskaltem 10\%igem Glycerin (v/v) gewaschen. Die Zellen wurden erneut zentrifugiert. Das erhaltene Bakterienpellet wurde in $1 \mathrm{ml}$ eiskaltem 10\%igem Glycerin (v/v) aufgenommen und als $40 \mu$ l-Aliquots in flüssigem Stickstoff schockgefroren und bei $-70{ }^{\circ} \mathrm{C}$ gelagert.

\subsubsection{Elektroporation}

Die kompetenten Zellen und die Plasmid-DNA wurden auf Eis aufgetaut und die Elektroporationsküvetten auf Eis vorgekühlt. Die Plasmid-DNA wurde in einer Konzentration von 10 bis $100 \mathrm{ng} / \mu 1 \mathrm{zu}$ den kompetenten Zellen gegeben, gut durchmischt und $1 \mathrm{~min}$ auf Eis inkubiert. Die Lösung wurde in die Küvette pipettiert und in den Probenschlitten eingesetzt. Der elektrische Puls wurde appliziert $(2,5 \mathrm{kV}, 25 \mu \mathrm{F}, 200 \Omega$, BioRad, USA), der ca. $5 \mathrm{~ms}$ dauerte. Die Zellen wurden sofort in $450 \mathrm{ml} \mathrm{SOC-Medium}$ aufgenommen und $1 \mathrm{~h}$ bei $37^{\circ} \mathrm{C}$ (E. coli) bzw. $3 \mathrm{~h}$ bei $27^{\circ} \mathrm{C}$ (A. tumefaciens) inkubiert. Jeweils $200 \mu \mathrm{l}$ der Zellen wurden auf Selektivagarplatten ausplattiert und bei entsprechender Temperatur bis zum Auftreten von Kolonien inkubiert.

$\begin{array}{lll}\text { SOC-Medium: } & 20 \mathrm{~g} / 1 & \text { Trypton } \\ 5 \mathrm{~g} / 1 & \text { Hefeextrakt } \\ 0,5 \mathrm{~g} / 1 & \mathrm{NaCl} \\ 0,2 \mathrm{~g} / 1 & \mathrm{KCl}\end{array}$


nach dem Autoklavieren des SOC-Mediums wurden folgende Lösungen zugefügt:

$10 \mathrm{mM} \mathrm{MgCl}_{2} \cdot 6 \mathrm{H}_{2} \mathrm{O}$

$10 \mathrm{mM} \mathrm{MgSO}_{4} \cdot 7 \mathrm{H}_{2} \mathrm{O}$

$20 \mathrm{mM}$ Glucose 


\subsection{Biochemische Methoden}

\subsubsection{NPTII-ELISA-Test}

Für den NPTII-ELISA-Test wurden von in vitro-Pflanzen ca. 50 mg Blattmasse mit $400 \mu 1$ Extraktionspuffer $(0,25 \mathrm{M}$ Tris-HCl, $\mathrm{pH} 7,8$, mit $1 \mathrm{mM}$ PMSF) und einer Spatelspitze Seesand versetzt und mit Hilfe eines Laborrührers (Heidolph, Retheim) mit einem konischen Mikrohomogenisatorstempel (Neolab, Heidelberg) als Pistill auf Eis homogenisiert. Es schlossen sich zwei Zentrifugationsschritte (je $10 \mathrm{~min}, 4{ }^{\circ} \mathrm{C}, 13000 \mathrm{rpm}$; Biofuge 13R, Heraeus, Hanau) zur Abtrennung unlöslicher Zellbestandteile an.

Der NPTII-ELISA-Test (Agdia, USA) diente dem schnellen Nachweis der Expression des NeomycinphosphotransferaseII (NptII)-Proteins in Blattrohextrakten transgener Pflanzen. Jeweils 40 bis $80 \mu \mathrm{g}$ Protein wurden für den Test eingesetzt. Es wurde nach Herstellerangaben verfahren, wobei die Inkubationszeit der Blocklösung über Nacht ausgedehnt wurde. Das gebildete p-Nitrophenol wurde bei $450 \mathrm{~nm}$ nach 15 min Inkubation quantitativ bestimmt (Titertek Multiskan MC, Flow Laboratories).

\subsubsection{PAT-ELISA-Test}

Für den PAT-ELISA-Test wurden von in vitro-Pflanzen ca. $100 \mathrm{mg}$ Blattmasse mit $100 \mu 1$ Extraktionspuffer (Steffens, Ebringen) und einer Spatelspitze Seesand versetzt und mit Hilfe eines Laborrührers (Heidolph, Retheim) mit einem konischen Mikrohomogenisatorstempel (Neolab, Heidelberg) als Pistill auf Eis homogenisiert. Es schlossen sich zwei Zentrifugationsschritte (je $10 \mathrm{~min}, 4{ }^{\circ} \mathrm{C}, 13000 \mathrm{rpm}$; Biofuge 13R, Heraeus, Hanau) zur Abtrennung unlöslicher Zellbestandteile an. Es wurde nach Herstellerangaben verfahren, das gebildete Protein wurde bei $625 \mathrm{~nm}$ nach $15 \mathrm{~min}$ Inkubation quantitativ bestimmt (Titertek Multiskan MC, Flow Laboratories).

\subsubsection{Fettsäureanalysen}

Die Fettsäurezusammensetzung wurde mittels gaschromatographischer Auftrennung bestimmt. Verwendet wurde ein Gaschromatograph (Perkin Elmer, Modell 8600) mit einer 25 m langen Trennsäule (Macherey \& Nagel). Als Trägergas wurde Wasserstoff eingesetzt. Die Trennung erfolgte über drei Minuten bei $213{ }^{\circ} \mathrm{C}, 130 \mathrm{k}$ Pa Druck sowie einer Injektor- und Detektortemperatur von $230{ }^{\circ} \mathrm{C}$. Zur Bestimmung der Fettsäurezusammensetzung der Samen wurden ca. 1,5 g in einer Kaffeemühle 15 sec. 
gemahlen. Hiervon wurden ca. $50 \mathrm{mg}$ in ein Reagenzglas $(3 \mathrm{ml})$ gefüllt und mit den folgenden Reagenzien versetzt:

+ $500 \mu 1 \quad 0,5$ mol Na-Methylat/ 1 Methanol, zur Extraktion und Transmethylierung der Fettsäuren bei $20^{\circ} \mathrm{C}$ für $20 \mathrm{~min}$.

$+100 \mu 1 \quad$ Iso-Oktan

$+300 \mu \mathrm{l} \quad 5 \%$-ige $\mathrm{NaHSO}_{4}$-Lösung in Wasser, gut gemischt und zentrifugiert

Nach dem Zentrifugieren wurden vom Überstand ca. $200 \mu 1$ abpipettiert und in ein Probenfläschchen mit Septum gefüllt. Die Lagerung erfolgte im Kühlschrank bei $4{ }^{\circ} \mathrm{C}$.

\subsubsection{Analyse des Sinapinsäureestergehaltes}

Zur Analyse der Sinapinsäureester wurde ein lineares Gradienten-HPLC-Verfahren angewandt, welches am Institut für Pflanzenbiochemie der Universität Halle durch die Arbeitsgruppe von Herrn Dr. A. Baumert durchgeführt wurde:

\section{HPLC-Bedingungen:}

Detektor: PDA

Wellenlänge: $\quad 330 \mathrm{~nm}$

Säule: $\quad 250 \times 4 \mathrm{~mm}$ I.D.

Phasenmaterial: $\quad$ Nucleosil $\mathrm{C}_{18}(5 \mu \mathrm{m}$, Macherey \& Nagel)

Eluent: $\quad$ Lösungsmittel A: $1.5 \%$ Phosphorsäure

Lösungsmittel B: Acetonitril

Flow-rate: $\quad 1 \mathrm{ml} / \mathrm{min}$

Die verwendeten Chemikalien wurden von den Firmen Fluka (Neu-Ulm), Merck (Darmstadt) oder Scharlau (Barcelona, Spanien) bezogen. Sie hatten den Reinheitsgrad ,proanalysis“. 


\subsubsection{Analyse des Resveratrolgehaltes}

Zur Analyse des Resveratrolglucosidgehaltes wurde ein lineares Gradienten-HPLCVerfahren angewandt, welches am Institut für Pflanzenbiochemie der Universität Halle durch die Arbeitsgruppe von Herrn Dr. A. Baumert durchgeführt wurde:

\section{HPLC-Bedingungen:}

Detektor: $\quad$ PDA

Wellenlänge: $\quad 300 \mathrm{~nm}$

Säule: $\quad 250 \times 4 \mathrm{~mm}$ I.D.

Phasenmaterial: $\quad$ Nucleosil $\mathrm{C}_{18}(5 \mu \mathrm{m}$, Macherey \& Nagel $\left.)\right)$

Eluent: $\quad$ Lösungsmittel A: $1.5 \%$ Phosphorsäure

Lösungsmittel B: Acetonitril

Flow-rate: $\quad 1 \mathrm{ml} / \mathrm{min}$

Die verwendeten Chemikalien wurden von den Firmen Fluka (Neu-Ulm), Merck (Darmstadt) oder Scharlau (Barcelona, Spanien) bezogen. Sie hatten den Reinheitsgrad „proanalysis“.

\subsubsection{Bestimmung des Öl-, Protein- und Glycosinolatgehaltes}

Die Bestimmung der Öl-, Protein- und Glucosinolatgehalte im Rapssamen jeder geselbsteten Einzelpflanze in \% der TM (GSL: $\mu \mathrm{mol} / \mathrm{g}$ ) erfolgte per NIRS (Near-InfraredReflectance-Spectroscopy). Die Messung wurde mit einer Standardküvette, unter Verwendung von 3 g Samengewicht durchgeführt. Der Feuchtegehalt der Samen lag bei 7 \%. Die Bestimmung der Protein-, Glucosinolat- und Ölgehalte erfolgte nach REINHARDT (1992) mit der Kalibrierung Raps2001.eqa. Bei dem verwendeten Gerät handelt es sich um den „NIRSystems Autocup Sampler“ (NIRS-Systems 6500, Foss, Hamburg). 


\subsection{Gewebekulturtechniken}

\subsubsection{Pflanzenanzucht}

Die Anzucht der Pflanzen in Gewebekultur erfolgte bei $24{ }^{\circ} \mathrm{C}$ und einem Licht/DunkelWechsel von 16/8 h. Die Erhaltung und Vermehrung der in vitro-Pflanzen erfolgte auf MSMedium (MURASHIGE und SKOOG, 1962). Die Pflanzen wurden alle 4 bis 5 Wochen auf frisches Medium umgesetzt. Die Wurzelbildung konnte durch den Zusatz von NAA (bis zu $0,5 \mathrm{mg} / \mathrm{l}$ ) induziert werden.

MS-Medium: 4,4 g/l MS mit Nitsch-Vitaminen (Duchefa, Leiden, Niederlande) $20 \mathrm{~g} / \mathrm{l}$ Saccharose $\mathrm{pH} 5,7$

Zur Herstellung von Agarplatten wurde 10 g/l Agar zugesetzt.

\subsubsection{Agrobakterium tumefaciens vermittelte Transformation}

Die Agrobakterium tumefaciens vermittelte Transformation erfolgte nach DE BLOCK et al. (1989, modifiziert).

\section{Auslegen steriler Rapssamen}

Die Rapssamen wurden 30 min in 5\%iger $\mathrm{Ca}(\mathrm{OCl})_{2}$-Lösung sterilisiert und 3x mit sterilem $\mathrm{H}_{2} \mathrm{O}$ gewaschen. Jeweils 15 bis 20 Samen wurden auf $1 / 2$ MS-Schrägagarplatten ausgelegt und auf den Rand gestellt 5 Tage im Licht/Dunkelwechsel (16/8 h) bzw. im Dauerlicht inkubiert.

\section{Anzucht von Agrobakterium tumefaciens}

Mit einer Agrobakterium tumefaciens Einzelkolonie wurden $40 \mathrm{ml}$ YEB-Medium mit 300 mg/l Streptomycin und $100 \mathrm{mg} / \mathrm{l}$ Spectomycin (Stamm AGL1) bzw. 50 mg/l Kanamycin (Stamm C58C1) beimpft und über Nacht inkubiert. 


\section{Infektion der Hypokotyle}

Fünf Tage nach Auslegen der Rapssamen hatten die Keimlinge den gegenüberliegenden Rand der Petrischalen erreicht. Die Kotyledonen und die Wurzeln wurden entfernt, die Hypokotyle wurden in ca. $5 \mathrm{~mm}$ lange Stücke geschnitten und in $15 \mathrm{ml}$ flüssiges CIMMedium gegeben.

$\begin{array}{lll}\text { CIM-Medium: } & 5,3 \mathrm{~g} / \mathrm{l} & \text { MS (Duchefa, Leiden, Niederlande) } \\ & 0,1 \mathrm{~g} / \mathrm{l} & \text { Myo-Inositol } \\ & 2 \mathrm{ml} / 1 & \text { BAP }(1 \mathrm{mg} / \mathrm{ml}) \\ & 0,001 \mathrm{mg} / 1 & \text { Picloram } \\ & 5 \mathrm{mg} / 1 & \text { AgNO3 } \\ & 20 \mathrm{~g} / 1 & \text { Saccharose } \\ & \text { pH } 5,7 & \end{array}$

Festmedium: $\quad 5,4 \mathrm{~g} / 1 \quad$ Agarose

Die für die Infektion benötigte Agrobakterien-Zellzahl betrug $10^{8}$ Zellen/ml. Die OD einer 1:5-Verdünnung der Agrobakterien-Übernachtkultur wurde photometrisch (Lambda 5 UV/VIS Spektrophotometer, Perkin Elmer, Offenbach) bei $660 \mathrm{~nm}$ bestimmt. Eine $\mathrm{OD}_{660 \mathrm{~nm}}$ von eins entspricht dabei einer Konzentration von $3 \times 10^{9}$ Zellen/ml. Die errechnete Menge an Bakterienkultur wurde $\mathrm{zu}$ den Hypokotylsegmenten gegeben. Bakterien und Hypokotyle wurden 40 min bei $80 \mathrm{rpm}$ und $23{ }^{\circ} \mathrm{C}$ zusammen inokuliert. Anschließend wurde die Bakteriensuspension abgesaugt und die Hypokotylsegmente 3x mit sterilem $\mathrm{H}_{2} \mathrm{O}$ gewaschen und auf Filterpapier kurz getrocknet.

\section{Pflanzenregeneration}

Die Hypokotylsegmente wurden auf Cim-Festmedium mit $500 \mathrm{mg} / \mathrm{l}$ Carbenicillin und 25 mg/l Kanamycin bzw. 5 mg PPT als Selektionsmedium gelegt. Die Hypokotylsegmente wurden bei $22{ }^{\circ} \mathrm{C}$ und Dauerlicht für 4 Wochen inkubiert, danach wurden Hypokotylsegmente mit grünem Kallus alle 14 Tage auf frisches DKW-Medium (incl. Selektionsantibiotika) überführt. Sich regenerierende Pflanzen wurden vom Kallus abgetrennt und auf MS-Medium mit $500 \mathrm{mg} / \mathrm{l}$ Carbenicillin und $50 \mathrm{mg} / \mathrm{l} \mathrm{Kanamycin} \mathrm{bzw.} \mathrm{10mg/l} \mathrm{PPT)}$ gesetzt. 
DKW-Medium: $\quad 5,3 \mathrm{~g} / 1 \quad$ DKW (Duchefa, Leiden, Niederlande)

$20 \mathrm{~g} / 1 \quad$ Saccharose

$1 \mathrm{mg} / \mathrm{l} \quad$ BAP

$0,01 \mathrm{mg} / 1$ IBA

$5,4 \mathrm{~g} / 1 \quad$ Agarose

pH 5,7

nach dem Sterilisieren wurden folgende Lösungen zugefügt:

$$
\begin{array}{ll}
0,01 \mathrm{mg} / 1 & \mathrm{GA}_{3} \\
3 \mathrm{ml} / \mathrm{l} & \mathrm{AgNO}_{3}(12 \mathrm{mM}) \\
3 \mathrm{ml} / \mathrm{l} & \mathrm{Na}_{2} \mathrm{~S}_{2} \mathrm{O}_{3}(96 \mathrm{mM})
\end{array}
$$




\subsection{Gewächshausversuche}

\subsubsection{Pflanzenanzucht}

Pflanzen, die von der Gewebekultur ins Gewächshaus überführt werden sollten, wurden sorgfältig vom Medium befreit und in mit Fruhstorfer Erde Typ T (50\% Hochmoortorf, 35\% Vulkanton, 15\% Rindenhumus; Industrie-Erdenwerk Archut, Lauterbach) gefüllte Multitopfplatten (Durchmesser $55 \mathrm{~mm}$ ) überführt. Für die Untersuchung der $\mathrm{T}_{2}$-Generation transgener Pflanzen wurde Saatgut von den Kontrollpflanzen und den transgenen Pflanzen in mit Fruhstorfer Erde Typ T gefüllte Multitopfplatten angekeimt. Die Multitopfplatten wurden in den ersten 5 Tagen zur Erhöhung der Luftfeuchtigkeit mit einer Plastikhaube abgedeckt. Die Pflanzen wurden nach 10 bis 14 Tagen in $13 \times 13 \mathrm{~cm}$-Kunststofftöpfe $\left(\mathrm{T}_{2}\right.$ Versuche und Saatgutgewinnung) umgetopft. Der Pflanzenschutz wurde durch den Einsatz von biologischen Mitteln gewährleistet. Für die Saatgutgewinnung wurde der Haupttrieb zwecks Selbstung eingetütet (Crispaec-Beutel, Supermikro-Lochung, BaumannSaatzuchtbedarf, Waldenburg) und Nebentriebe entfernt. Das Gewächshaus wurde mit Hilfe einer Zusatzbeleuchtung (Phillips-400 W-Lampen, SONT AGRO, $48000 \mathrm{~lm}$ ) auf einen Tag/Nacht-Rhythmus von 16/8 h eingestellt. Die Pflanzen wurden vollständig randomisiert über die Tische verteilt, um Einwirkungen unterschiedlicher Beleuchtung oder Randlage auszugleichen.

\subsubsection{Merkmalserhebung}

Die im Gewächshaus erhobenen Merkmale sind in Tab. 4 aufgeführt.

Tab. 4: Beschreibung der im Gewächshaus erfaßten Merkmale.

\begin{tabular}{ll}
\hline Merkmal & Erfassung \\
\hline Blühbeginn [d nach Auspflanzen] & erste Blüte offen \\
Wuchshöhe Blühbeginn [cm] & $\begin{array}{l}\text { Messung von Austrittstelle der Stengel aus } \\
\text { dem Boden bis zur Spitze des Haupttriebes }\end{array}$ \\
Blühende [d nach Auspflanzen] & alle Blüten des Haupttriebes abgeblüht \\
Wuchshöhe Blühende [cm] & $\begin{array}{l}\text { Messung von Austrittstelle der Stengel aus } \\
\text { dem Boden bis zur Spitze des Haupttriebes }\end{array}$ \\
\hline
\end{tabular}




\subsubsection{Segregation der transgenen Pflanzen}

Jeweils 20 T2-Keimlinge (pLH-SGT-GUS) von ausgewählten T1 Pflanzen wurden auf ihr Segregationverhalten hin überprüft. Die T2 Samen sind auf einem PPT-haltigem MSMedium (10 mg/1 PPT) in vitro ausgelegt worden. Sensitive Basta-Symptome wurden nach einer Woche bonitiert.

Jeweils 55 T2-Keimlinge (pPSty5+pLH-SGT-GUS) von ausgewählten T1 Pflanzen wurden auf ihr Segregationverhalten hin überprüft. Die T2 Samen sind auf einem Kanamycin-haltigem MS-Medium (70 mg/l Kan) in vitro ausgelegt worden. Sensitive Basta-Symptome wurden nach einer Woche bonitiert. Alle T2-Keimlinge wurden anschließend auf PPT-haltiges MS-Medium (10 mg/l PPT) umgesetzt. Sensitive BastaSymptome wurden nach einer Woche bonitiert.

\subsection{Statistische Auswertung}

Zur Erfassung von Unterschieden zwischen den transgenen Pflanzen und den Kontrollpflanzen wurden multiple Mittelwertsvergleiche nach dem Tukey-Kramer-Test durchgeführt. Die Berechnungen erfolgten mit dem Statistik-Programm „Statgraphics” (Version 1.1 für Windows). Die ermittelten Signifikanzen wurden mit folgenden Symbolen dargestellt:

* signifikant unterschiedlich im Vergleich $\mathrm{zu}$ den Kontrollpflanzen bei einer Irrtumswahrscheinlichkeit von $5 \%(\mathrm{p}<0,05)$

** signifikant unterschiedlich im Vergleich $\mathrm{zu}$ den Kontrollpflanzen bei einer Irrtumswahrscheinlichkeit von $1 \%(\mathrm{p}<0,01)$. 


\section{$3 \quad$ Ergebnisse und Diskussion}

\subsection{Sinapinsäureestersuppression (ausführliche Darstellung siehe Manus- kript im Anhang I)}

In den Transformationsversuchen zur samenspezifischen Sinapinsäureestersuppression unter Verwendung des pLH-SGT-GUS Konstruktes konnten 30 PPT-resistente Pflanzen regeneriert werden, die darüber hinaus auch im PAT-ELISA-Test und in der PAT-PCR positive Ergebnisse zeigten. In Abhängigkeit vom Experiment variierte die Transformationsrate von 2,8 bis 4,3\%. Im Mittel lag sie bei 3,6\%. (s. I/8; Tab.1, Fig.3). Diese T1Pflanzen wurden ins Gewächshaus überführt, geselbstet und die T2-Samen wurden mittels HPLC auf den Sinapinsäureestergehalt untersucht. Die Variabilität des Gesamt-Sinapinsäureestergehaltes (Gesamt-SAE) in den T1-Pflanzen lag zwischen 2,84 mg/g und 10,61 $\mathrm{mg} / \mathrm{g}$ Samen. In den Kontrollen $(\mathrm{n}=30)$ wurden dagegen Gehalte zwischen 7,28 und 10,33 mg/g Samen ermittelt (s. I/9; Fig.4). Zwischen den einzelnen SAE-Komponenten waren hohe signifikante Korrelationen zu verzeichnen. Der Gehalt an Sinapoylglucose war hoch signifikant korreliert mit dem Sinapingehalt $\left(\mathrm{r}_{\mathrm{s}}=0,76^{* *}\right)$ sowie mit den bislang nicht identifizierten Sinapinsäureestern $\left(\mathrm{r}_{\mathrm{s}}=0,92 * *\right)$ und dem Gesamt-SAE-Gehalt $\left(\mathrm{r}_{\mathrm{s}}=0,91 * *\right)$ (s. I/9; Tab.2, I/10; Fig.5). Zwischen den T1-Pflanzen und den Kontrollen lagen hinsichtlich wichtiger agronomischer Merkmale, wie Öl-, Protein- und Glucosinolatgehalt sowie Fettsäurezusammensetzung keine signifikanten Unterschiede vor (s. III/3; Tab.1 und 2).

Es wurden drei transgene Linien mit den niedrigsten Gesamt-SAE-Gehalten $(2,84 \mathrm{mg} / \mathrm{g}-$ $3,83 \mathrm{mg} / \mathrm{g}$ ) für die weitere Charakterisierung ausgewählt (s. I/10; Tab.3). Durch Untersuchung der Aufspaltung der PPT-Resistenz in den T2-Keimlingen sowie mit Hilfe der 'Southern Blot'-Analyse (T1-Planzen) wurde die Anzahl integrierter Kopien des Transgens bestimmt. Die Segregationsanalyse zeigte, das die drei ausgewählten T1-Pflanzen jeweils nur eine Kopie des Transgens enthielten. Diese Ergebnisse konnten im 'Southern Blot' bestätigt werden (s. I/11; Tab.4, Fig.6). Von den drei ausgewählten transgenen T1-Pflanzen mit jeweils einer integrierten Kopie des Transgens wurden jeweils 20 T2-Samen im Gewächshaus zur Gewinnung von T3-Samen ausgesät und zusammen mit 22 untransformierten Kontrollpflanzen (cv. Drakkar) geprüft. In den T2-Pflanzen $(n=60)$ variierte der Gesamt-SAE-Gehalt zwischen 1,82 und 9,00 mg/g Samen, während der Gehalt bei den Kontrollpflanzen $(\mathrm{n}=22)$ zwischen 7,48 und 10,55 mg/g Samen lag. In einer homozygoten 
T2-Pflanze der Linie 1501.24 war der Gesamt-SAE-Gehalt auf 1,82 mg/g Samen reduziert, was verglichen mit der Kontrollpflanze mit dem niedrigsten Gesamt-SAE-Gehalt (7,48 $\mathrm{mg} / \mathrm{g}$ ) einer Reduktion von 76\% entspricht. In dieser homozygoten T2-Pflanze war der Sinapingehalt um $72 \%$ auf $2,66 \mathrm{mg} / \mathrm{g}$ Samen und die bislang nicht identifizierten Sinapinsäureester sowie der Sinapoylglucosegehalt um $100 \%$ auf $0,00 \mathrm{mg} / \mathrm{g}$ Samen reduziert (s. I/12; Tab.5). Von den transgenen T2-Pflanzen (20 pro T1-Pflanze) wurden jeweils 20 T3-Samen zur Untersuchung der Aufspaltung der PPT-Resistenz angekeimt. Homozygot transgene Pflanzen mit einer Kopie enthielten die niedrigsten Sinapin- und Gesamt-SAE-Gehalte im Samen, während hemizygote mittlere und homzygot nicht transgene die höchsten Sinapin- und Gesamt-SAE-Gehalte akkumulierten (s. I/12; Fig.7). Diese Zuordnung entsprach der erwarteten 1:2:1 Spaltung.

Es konnte gezeigt werden, das homozygot transgene Pflanzen mit einer integrierten Kopie des ds-RNAi-Konstruktes pLH-SGT-GUS sehr niedrige Sinapin- und Gesamt-SAE Gehalte aufwiesen. Auch LIU et al. (2002) berichteten, das in Transformationsexperimenten mit Baumwolle in den Pflanzen eine maximale Supprimierung der Genaktivität gefunden werden konnte, die eine Kopie eines ds-RNAi-Konstruktes in ihr Genom integriert hatten. Desweiteren zeigten Studien in Arabidoposis, daß in homozygot transgenen Pflanzen mit einer integrierten Kopie generell eine stärkere Supprimierung erreicht werden konnte als in hemizygot transgenen Pflanzen (SINGH et al., 2000; STOUTJESDIJK et al., 2002).

Die Ergebnisse dieser Arbeit belegen, daß mit Hilfe eines transgenen Ansatzes unter Verwendung des ds-RNA-interferenz Konstruktes pLH-SGT-GUS eine signifikante Abnahme des Sinapinsäureestergehaltes im Samen erreicht werden konnte. Mit dieser als „post-transcriptional gene silencing (PTGS)“ bezeichneten Suppression einer Genaktivität kann eine maximale Unterdrückung von 100\% erreicht werden. SINGH et al. (2000) zeigten, das mit Hilfe eines FAD2-ds-RNAi-Konstruktes in Arabidopsis eine 100\% PTGS induziert werden konnte. Bei Verwendung eines FAD2-antisense Konstruktes wurde lediglich eine 15\% Supprimierung der Genaktivität erreicht. Im Rahmen dieser Arbeit konnte in einer homozygoten T2-Pflanze mit einer integrierten Kopie der Gesamt-Sinapinsäureestergehalt (Gesamt-SAE) im Vergleich zu der Kontrollpflanze mit den niedrigsten Gesamt-SAE-Gehalten um 76\% reduziert werden. Eine Hypothese, die die nicht 100\%ige Suppression des Gesamt-SAE-Gehaltes erklären könnte ist, daß weitere mit der SGT verwandte Enzyme an dem Sinapinsäureester Biosyntheseweg beteiligt sein könnten (LIM 
et al., 2001). MILKOWSKI et al. (2004) zeigten in Southern-Blot-Analysen, daß Brassica napus als amphidiploider Organismus zwei SGT-Gene enthält. Neben diesen zwei Hauptbanden konnten sie noch einige dem SGT-Gen verwandte Banden detektieren. Dies würde auch die in diesem Versuch geringere Korrelation $\left(r_{s}=0,76^{* *}\right)$ zwischen Sinapin und Sinapoylglucose erklären, im Gegensatz zur hohen Korrelation zwischen Sinapoylglucose und den bislang nicht identifizierten Sinapinsäureestern $\left(\mathrm{r}_{\mathrm{s}}=0,92 * *\right)$. Letztere wurden in den T3-Samen von homozygoten T2-Pflanzen um 100\% reduziert. Ausgeschlossen werden kann, das die SGT ihre höchste Aktivität zu einem späteren Zeitpunkt als der im Konstrukt verwendete Napinpromoter entwickelt. MILKOWSKI et al. (2004) zeigten bei Brassica napus, das das SGT-Transkriptionsniveau vom frühen bis zum mittleren Samenentwicklungsstadium zunimmt und dann bis zum Ende der Samenentwicklung konstant bleibt. Der verwendete Napinpromoter ist in dem frühen bis zum mittleren Samenentwicklungsstadium aktiv (EZCURRA, 1998). VOGT et al. (1993) fanden heraus, das die SAEAnreicherung im Rapssamen im mittleren Samenentwicklungsstadium stattfindet, während MILKOWSKI et al. (2004) zeigen konnten, daß eine Sinapoylglucose- und Sinapinanreicherung im mittleren Samenentwicklungsstadium beginnt und ihr höchstes Niveau gegen Ende der Samenentwicklung erreicht. In dieser Phase ist der verwendete Napinpromoter nicht mehr aktiv (EZCURRA, 1998), so daß es im transgenen Samen zu einer späten Sinapoylglucoseanreicherung kommen kann, welche dann nahezu vollständig in Sinapin umgewandelt wird. NAIR et al. (2000) konnten berichten, daß durch eine Transformation mit einem Ferulasäure-5-Hydroxylase (F5H) -antisense Konstrukt unter Kontrolle eines konstitutiven 35S-Promoters der Sinapingehalt im Rapssamen um 40\% reduziert wurde. Wurde jedoch ein samenspezifischer Napin Promoter in diesem Konstrukt eingesetzt lag die Sinapinreduktion lediglich bei 20\%. Die Möglichkeit, daß SAE in den maternalen Teilen der Pflanze gebildet und dann in die Samen transportiert werden, kann nicht ausgeschlossen werden.

Von besonderem züchterischem Interesse ist die Beziehung zwischen Öl, Protein, Glucosinolaten, Fettsäuren und Sinapinsäureestern. Es konnten in diesem Versuch keine signifikanten Unterschiede zwischen den Transformanden und Kontrollen im Öl-, Protein-, und Glucosinolatgehalt, sowie in der Fettsäurezusammensetzung festgestellt werden (s. III/3; Tab.1, Tab.2). ZUM FELDE (2004) untersuchte die Beziehung zwischen Sinapinsäureestern und den wichtigen agronomischen Merkmalen in segregierenden doppelhaploiden Winterrapspopulationen. Es fanden sich keine signifikanten Korrela- 
tionen zwischen Sinapinsäureestern und Öl-, Protein-, Fettsäuren- und Glucosinolatgehalt. Insgesamt kann man davon ausgehen, daß eine erhebliche Reduzierung des Sinapinsäureestergehaltes in Brassica napus keine negativen Effekte auf andere Samenqualitätsmerkmale haben wird.

Bislang wurde nur ein Gen, das Ferulasäure-5-Hydroxylase-Gen (F5H), welches in den Sinapinsäure-Biosyntheseweg integriert ist, aus Brassica napus kloniert. NAIR et al. (2000) zeigten, das durch eine Transformation von Brassica napus mit einem F5H-antisense Konstrukt unter Kontrolle eines konstitutiven 35S-Promoters der Sinapingehalt im Rapssamen von 9,00 mg/g (Mittel der Kontrollen) auf 5,3 mg/g reduziert werden konnte. Wurde ein samenspezifischer Napin-Promoter in diesem Konstrukt eingesetzt konnte der Sinapingehalt lediglich auf $6,9 \mathrm{mg} / \mathrm{g}$ gesenkt werden. Es wäre denkbar, das eine Kreuzung zwischen SGT-ds-RNAi-Transformanden (Napin Promoter) und den F5H-as-Transformanden (35S-Promoter) bzw. eine Transformation von Brassica napus mit dem SGT-ds-RNAi Konstrukt unter der Kontrolle des 35S-Promoters zu weiteren Reduzierungen führen könnte.

Ein wichtiger Aspekt bei der Beurteilung der Notwendigkeit einer gentechnischen Veränderung des Sinapinsäureestergehaltes sind Untersuchungen zum Sinapinsäureestergehalt im klassischen Züchtungsmaterial. VELASCO und MÖLLERS (1998) konnten unter mehr als 1300 Brassica napus Samenproben Genotypen mit SAE-Gehalten von 5,0 bis $17,7 \mathrm{mg} / \mathrm{g}$ Samen (NIRS) identifizieren. ZUM FELDE et al. (2003) fanden in 549 Samenproben von voneinander abweichenden Winter-raps Genotypen eine Variation von 3,5 bis 13,0 mg/g Samen (HPLC). Mit Hilfe des im Rahmen dieser Arbeit verwendeten gentechnischen Ansatzes konnte im Vergleich zum klassischem Zuchtmaterial eine deutliche Reduzierung des SAE-Gehaltes erreicht werden. Eine Kreuzung zwischen niedrigem klassischem und niedrigem transgenem Material könnte $\mathrm{zu}$ einer weiteren erheblichen Reduzierung des SAE-Gehaltes im Samen führen. 


\subsection{Resveratrolexpression und Sinapinsäureestersuppression (ausführliche Darstellung siehe Manuskript im Anhang II)}

In den Co-Transformationsversuchen zur samenspezifischen Resveratrolexpression und Sinapinsäureestersuppression konnten insgesamt 28 im NPT-II- und im PAT-ELISA-Test sowie in der NPT-II- und PAT-PCR positive, transgene Pflanzen regeneriert werden. In Abhängigkeit vom Experiment variierte die Transformationsrate von 1,2 bis 2,3\%. Im Mittel lag sie bei 1,8\% (s. II/8; Tab.1, Fig.3). Die im ELISA-Test und in der PCR positiven T1-Pflanzen wurden ins Gewächshaus überführt, geselbstet und die Ernteproben mit Hilfe der HPLC auf den Resveratrolgehalt untersucht. Die transgenen Pflanzen akkumulierten Resveratrol im Samen in seiner glycosidischen Form. In den T1-Pflanzen variierte der Resveratrolglucosidgehalt zwischen 0 und $361 \mu \mathrm{g} / \mathrm{g}$ Samen. In den Samen der Kontrollpflanzen $(\mathrm{n}=30)$ konnte dagegen in keinem Fall Resveratrolglucosid nachgewiesen werden (s. II/9; Tab.2). Die Variabilität des Gesamt-Sinapinsäureestergehaltes (Gesamt-SAE) in den T1-Pflanzen lag zwischen 2,54 mg/g und 10,46 mg/g Samen. In den Kontrollen ( $\mathrm{n}=30)$ wurden dagegen Gehalte zwischen 7,28 und 10,33 mg/g Samen ermittelt (s. II/9; Tab.3). Für den Zusammenhang zwischen Resveratrolgucosid und den einzelnen SAEKomponenten wurde in den untersuchten T1-Pflanzen ein Spearman rank Korrelationskoeffizient $\left(r_{s}\right)$ zwischen $r_{s}=-0,34$ und $r_{s}=-0,36$ ermittelt. Zwischen den einzelnen SAEKomponenten waren hohe signifikante Korrelationen $\mathrm{zu}$ verzeichnen. Der Gehalt an Sinapoylglucose war hoch signifikant korreliert mit dem Sinapingehalt $\left(\mathrm{r}_{\mathrm{s}}=0,93 * *\right)$ sowie mit den bislang nicht identifizierten Sinapinsäureestern $\left(\mathrm{r}_{\mathrm{s}}=0,92^{* *}\right)$ und dem Gesamt-SAEGehalt $\left(\mathrm{r}_{\mathrm{s}}=0,97 * *\right)(\mathrm{s} . \mathrm{II} / 10$; Tab.4). Zwischen den Transformanden und den Kontrollen lagen hinsichtlich wichtiger agronomischer Merkmale, wie Öl-, Protein- und Glucosinolatgehalt sowie Fettsäurezusammensetzung keine signifikanten Unterschiede vor (s.III/3; Tab.3, Tab.4).

Drei transgene Linien mit den höchsten Resveratrolglucosidgehalten $(308-361 \mu \mathrm{g} / \mathrm{g})$ wurden für die weitere Charakterisierung ausgewählt (s. II/10; Tab.5). Auch hier wurde durch Untersuchung der Aufspaltung der Kanamycin- und PPT-Resistenz in T2-Keimlingen $(\mathrm{n}=55)$ sowie mit Hilfe der 'Southern Blot'-Analyse die Anzahl integrierter Kopien der Transgene bestimmt. Die Segregations- und Integrationsanalyse zeigte, das die ausgewählten T1-Pflanzen jeweils nur eine Kopie der Transgene enthielten (s. II/11; Tab.6, Fig.4). Pro ausgewählter T1-Pflanze wurden 20 T2-Samen im Gewächshaus ausgesät. Die 
Pflanzen wurden geselbstet, beerntet und auf ihren Resveratrolglucosid- und Sinapinsäureestergehalt im Samen untersucht. Für den Resveratrolglucosidgehalt konnte eine Variation zwischen $0 \mathrm{mg} / \mathrm{g}$ und $424 \mu \mathrm{g} / \mathrm{g}$ Samen ermittelt werden. Der Gesamt-SAEGehalt variierte in diesen Pflanzen zwischen 1,27 mg/g Samen und 9,37 mg/g Samen, die Kontrollpflanzen $(\mathrm{n}=22)$ enthielten zwischen 7,50 mg/g und 10,55 mg/g Samen. In einer T2-Pflanze der Linie 1502.15 war der Resveratrolglucosidgehalt mit $424 \mu \mathrm{g} / \mathrm{g}$ am höchsten. Der Gesamt-SAE-Gehalt war in dieser Pflanze auf $1,30 \mathrm{mg} / \mathrm{g}$ reduziert, was verglichen mit der niedrigsten Kontrollpflanze $(7,48 \mathrm{mg} / \mathrm{g})$ einer Gesamt- Sinapinsäureesterreduktion von 83 \% entspricht (s. II/12; Tab.7). Für den Zusammenhang zwischen Resveratrolglucosid und Gesamtsinapinsäureester wurde in den untersuchten T3-Samen $(n=60)$ ein Spearman rank Korrelationskoefficient $\left(r_{s}\right)$ von $r_{s}=-0,69 * *$ ermittelt (s. II/12; Fig.5). Von den transgenen T2-Pflanzen (20 pro T1-Pflanze) wurden jeweils 20 T3-Samen zur Untersuchung der Aufspaltung der PPT- und Kanamycin-Resistenz angekeimt. Es konnte gezeigt werden, daß homozygot und hemizygot transgene Pflanzen mit jeweils einer integrierten Kopie des pPSty5 und SGT-ds-RNAi-Konstruktes die höchsten Resveratrolglucosid- und die niedrigsten SAE-Gehalte aufwiesen. Desweiteren wurde deutlich, das die 20 Nachkommen einer transgenen Linie in der erwarteten 9:3:3:1 Aufspaltung segregierten (s. II/13; Fig.6).

Die im Rahmen dieser Arbeit untersuchten transgenen Pflanzen akkumulierten Resveratrol in seiner glycosidischen Form. SOTHEESWARAN and PASUPATHY (1993) zeigten, das Resveratrolglucosid und andere Resveratrolderivate im Resveratrolbiosyntheseweg einiger Pflanzen entstehen können. JEANDET et al. (1997) untersuchten Phytoalexine des Weins und stellten in ihren HPLC Analysen fest, das Resveratrolglucosid eine kürzere Retentionszeit hat als Resveratrol. Eine Resveratrol- (R) bzw. Resveratrolglucosid- (RGlc) Anreicherung in den Pflanzen wurde beschrieben für Wein (50-100 $\mu \mathrm{g}$ R/g Frischmasse (FM) Trauben, LANGCAKE and PRYCE, 1976), transgenem Weizen (2 $\mu \mathrm{g}$ RGlc/g FM Blatt, FETTIG and HESS, 1998), transgener Kiwi (182 $\mu \mathrm{g}$ RGlc/g FM Blatt, KOBAYASHI et al., 2000), transgener Luzerne (20 $\mu \mathrm{g}$ RGlc/g FM Blatt, HIPSKIND und PAIVA, 2000) und transgenem Raps (159 $\mu \mathrm{g}$ RGlc/g Samen, ORSINI et al., 2003). Diese Resveratrolglucosidgehalte sind erheblich geringer als der in dieser Arbeit in einer homozygoten T2-Pflanze ermittelte Resveratrolglucosidgehalt in der Höhe von $424 \mu \mathrm{g} / \mathrm{g}$ Samen. 
KOMARI et al. (1996) fanden in Co-Transformationsversuchen mit zwei separaten TDNAs (integriert in einen bzw. zwei Bakterienstämme (Oktopin-Typ)) heraus, daß nach erfolgreicher Transformation und Co-Transformation von Tabak und Reispflanzen die zwei T-DNAs in beiden Versuchen unabhängig voneinander im Genom integriert wurden. DE BLOCK und DEBROUWER (1991) beobachteten hingegen, daß gekoppelte Integrationsorte in Brassica napus Co-Transformationsversuchen (mit zwei separaten TDNAs, integriert in zwei Bakterienstämme (Nopalin-Typ)) bevorzugt wurden. Sie schlossen daraus, daß der Nopalin-Typ in Transformationsversuchen, im Gegensatz zum Oktopin-Typ, gekoppelte Integrationsorte favorisiert. Die Verwendung eines Nopalin-Typs (C58C1) und eines Succinamopin-Typs (AGL1) führte im Rahmen dieser Arbeit zu nicht gekoppelten Integrationsorten, die Nachkommen der T1-Pflanzen mit einer integrierten Einfachkopie der beiden Transgene, segregierten unabhängig voneinander für beide Transgene. Im Rahmen dieses Versuches war die mittlere Co-Transformationsrate mit $1,8 \%$ um die Hälfte niedriger als in den in Kapitel 3.1 beschriebenen Transformationsversuchen. KOMARI et al. (1996) konnten zeigen, das die Co-Transformationsrate unter Verwendung von zwei Bakterienstämmen deutlich geringer war als bei Verwendung von einem Bakterienstamm.

Der Zusammenhang zwischen integrierter Kopienanzahl und Expressionstärke des Gens ist in einigen Untersuchungen negativ korreliert (CERVERA et al., 2000; HOBBS et al., 1993; MANNERLÖF et al., 1997), nicht korreliert (BAUER et al., 1998; HOBBS et al., 1993; MCCABE et al., 1999) und in anderen positiv korreliert (GENDLOFF et al., 1990; HOBBS et al., 1993; MCCABE et al., 1999; VOELKER et al. 1996). In den meisten Berichten basierten diese Ergebnisse auf untersuchten T1-Pflanzen (CERVERA et al., 2000; GENDLOFF et al., 1990; HOBBS et al., 1990; MANNERLÖF et al., 1997). HIPSKIND und PAIVA (2000) fanden in Transformationsversuchen mit Luzerne heraus, das die T1-Pflanzen, die nur eine Kopie des Stilbensynthasegens enthielten, die höchsten Resveratrolglucosidgehalte akkumulierten, während die geringer akkumulierenden Pflanzen meist zwei oder drei Kopien des Transgens enthielten. Dies bestätigt die in dieser Arbeit erzielten Ergebnisse, das die auf höchsten Resveratrolglucosidgehalt selektierten T1-Pflanzen ausschließlich eine Kopie des Transgens enthielten. Eine geringe Expressionsstärke des Gens gekoppelt mit Mehrfachkopien wird häufig durch ,posttranscriptional-gene-silencing“ (PICKFORD and COGONI, 2003) oder „transcriptionalgene-silencing“ (JAKOWITSCH et al., 1998) erklärt. 
Eine Hypothese in diesem Versuch war, daß durch eine Suppression der Sinapoyl-GlucoseTransferase der Resveratrolgehalt im Samen durch vermehrt vorliegende p-Cumarsäure erhöht werden könnte. Orsini et al. (2003) berichteten, das Brassica napus cv. Drakkar Pflanzen, transformiert mit dem pPSty5 Konstrukt (welches auch in der vorliegenden Arbeit verwendet wurde), einen maximalen Resveratrolglucosidgehalt von $159 \mu \mathrm{g} / \mathrm{g}$ aufwiesen. Im Rahmen dieser Arbeit konnte durch eine Reduzierung des Sinapinsäureestergehaltes von 7,48 mg/g (Kontrollpflanze mit den niedrigsten GesamtSAE-Gehalten) auf 1,30 mg/g Samen ein Resveratrolglucosidgehalt von $424 \mu \mathrm{g} / \mathrm{g}$ Samen realisiert werden. Für den Zusammenhang zwischen Resveratrolglucosidzunahme und Sinapinsäureesterabnahme wurde ein Korrelationskoefficient von $r_{s}=-0,69 * *$ ermittelt.

Es wurde gezeigt, daß es möglich ist hohe Resveratrolglucosidgehalte ( $424 \mu \mathrm{g} / \mathrm{g})$ und eine drastische Reduzierung des Gesamt-SAE-Gehaltes $(1,30 \mathrm{mg} / \mathrm{g}) \mathrm{im}$ Samen $\mathrm{zu}$ realisieren. Es konnten in diesem Versuch keine signifikanten Unterschiede zwischen den CoTransformanden und Kontrollen im Öl-, Protein-, und Glucosinolatgehalt sowie in der Fettsäurezusammensetzung festgestellt werden (s.III/3; Tab.3, Tab.4). In Tabak und Petunien führte die Überexprimierung des Stilbensynthasegens unter der Kontrolle eines 35S-Promoters zu männlicher Sterilität (FISCHER et al., 1997). In diesem Versuch war kein Hinweis auf männliche Sterilität zu finden, was durch die Verwendung eines samenspezifischen Napin-promoters erklärt werden kann. ZUM FELDE (2004) untersuchte die Beziehung zwischen Sinapinsäureestern und wichtigen agronomischen Merkmalen in segregierenden doppel haploiden Winterrapspopulationen. Es fanden sich keine signifikanten Korrelationen zwischen Sinapinsäureestern und Ö1-, Protein-, Fettsäuren- und Glucosinolatgehalt. Insgesamt kann man davon ausgehen, daß eine hohe Akkumulierung von Resveratrol-glucosid und eine drastische Reduzierung des SAEGehaltes in Brassica napus keine weiteren negativen Effekte auf andere Samenqualitätsmerkmale haben wird. 


\section{$4 \quad$ Zusammenfassung}

Die Verwendung von Rapsprotein in der Human- und Tierernährung wird durch phenolische Verbindungen wie Sinapinsäureester erheblich limitiert, da sie infolge ihrer antinutritiven Eigenschaften die Qualität von Lebens- und Futtermitteln beeinträchtigen. Die SinapinsäureGlucosyltransferase (SGT) stellt das zentrale Enzym der Sinapinsäureester-Biosynthese im Samen dar. Mit Hilfe der Agrobakterium vermittelten Transformation sollte unter Verwendung des SGT-Doppelstrang-RNA-Interferenz (SGT-ds-RNAi) Konstruktes pLH-SGT-GUS die Aktivität der Sinapinsäure-Glucosyltransferase im Samen supprimiert werden.

Ein weiteres interessantes Biomolekül für eine gentechnische Veränderung der Samenqualität ist das Phytoalexin Resveratrol, welches natürlicherweise nicht im Raps vorkommt. Durch seine antioxidative und anticancerogene Wirkung kann es gesundheitsfördernd wirken. Im zweiten Teil der Arbeit sollte das Gen der Stilbensynthase (VST1) aus Vitis vinifera unter Kontrolle eines samenspezifischen Promoters (pPSty5 Konstrukt) in Verbindung mit dem o.g. pLH-SGT-GUS Konstrukt in Agrobakterium vermittelten Co-Transformationsversuchen im Raps zur Expression gebracht werden.

In den Transformationsversuchen zur samenspezifischen Sinapinsäureestersuppression unter Verwendung des ds-RNAi Konstruktes pLH-SGT-GUS konnten 30 transgene Pflanzen regeneriert werden; die Transformationsrate lag im Mittel bei 3,6\%. Die Variabilität des Gesamt-Sinapinsäureestergehaltes (Gesamt-SAE) in den im Gewächshaus angezogenen T1Pflanzen lag zwischen 2,84 mg/g und 10,61 mg/g . In den Kontrollen ( $\mathrm{n}=30)$ wurden dagegen Gehalte zwischen 7,28 und 10,33 mg/g Samen ermittelt. Der Gehalt an Sinapoylglucose war hoch signifikant korreliert mit dem Sinapingehalt $\left(\mathrm{r}_{\mathrm{s}}=0,76^{* *}\right)$ sowie mit den bislang nicht identifizierten Sinapinsäureestern $\left(\mathrm{r}_{\mathrm{s}}=0,92 * *\right)$ und dem Gesamt-SAE-Gehalt $\left(\mathrm{r}_{\mathrm{s}}=0,91 * *\right)$. Zwischen den Transformanden und den Kontrollen lagen hinsichtlich wichtiger agronomischer Merkmale, wie Öl-, Protein- und Glucosinolatgehalt sowie Fettsäurezusammensetzung keine signifikanten Unterschiede vor. Es wurden drei transgene T1Pflanzen mit den niedrigsten Gesamt-SAE-Gehalten $(2,84 \mathrm{mg} / \mathrm{g}-3,83 \mathrm{mg} / \mathrm{g})$ für die weitere Charakterisierung ausgewählt. Durch Untersuchung der Aufspaltung der Phosphinothricin (PPT)-Resistenz in den T2-Keimlingen sowie mit Hilfe der 'Southern Blot' - Analyse wurde gezeigt, daß die drei ausgewählten T1-Pflanzen jeweils nur eine Kopie des Transgens enthielten. Von diesen T1-Pflanzen wurden jeweils 20 T2-Samen im Gewächshaus zur 
Gewinnung von T3-Samen ausgesät und zusammen mit 22 untransformierten Kontrollpflanzen (cv. Drakkar) geprüft. In einer homozygoten T2-Pflanze konnte der Sinapinsäureestergehalt, im Vergleich zu der Kontrollpflanze mit den niedrigsten Gesamt-SAE-Gehalten $(7,48 \mathrm{mg} / \mathrm{g})$, um $76 \%$ auf $1,83 \mathrm{mg} / \mathrm{g}$ reduziert werden. In dieser T2-Pflanze war der Sinapingehalt um $72 \%$ auf $2,66 \mathrm{mg} / \mathrm{g}$ Samen und die bislang nicht identifizierten Sinapinsäureester sowie der Sinpoylglucosegehalt um 100\% auf 0 mg/g Samen reduziert.

In den Transformationsversuchen zur samenspezifischen Resveratrolexpression und Sinapinsäureestersuppression unter Verwendung des pPSty5- und des pLH-SGT-GUS-Konstruktes konnten nach Agrobakterium vermittelter Co-Transformation 28 transgene Pflanzen regeneriert werden; die Co-Transformationsrate lag im Mittel bei 1,8\%. Die im Gewächshaus angezogenen T1-Pflanzen akkumulierten Resveratrol im Samen in seiner glycosidischen Form. Drei T1-Pflanzen mit den höchsten Resveratrolglucosidgehalten $(308-361 \mu \mathrm{g} / \mathrm{g})$ wurden für die weitere Charakterisierung ausgewählt. Zwischen den Transformanden und den Kontrollen $(n=30)$ lagen hinsichtlich wichtiger agronomischer Merkmale, wie Ö1-, Proteinund Glucosinolatgehalt sowie Fettsäurezusammensetzung keine signifikanten Unterschiede vor. Die Integrations- (Southern Blot-Analyse) und Segregationsanalyse (Aufspaltung der Kanamycin- und PPT-Resistenz) zeigte, daß die ausgewählten T1-Pflanzen jeweils nur eine Kopie der Transgene enthielten. Pro selektierter transgener Linie wurden 20 T2-Samen im Gewächshaus ausgesät. Für den Zusammenhang zwischen Resveratrolglucosid und Gesamtsinapinsäureester in den untersuchten T3-Samen $(n=60)$ wurde ein Korrelationskoeffizient von $r_{s}=-0,69$ ermittelt. In einer homozygoten T2-Pflanze war der Resveratrolglucosidgehalt mit $424 \mu \mathrm{g} / \mathrm{g}$ am höchsten. Der Gesamt-SAE-Gehalt war in dieser Pflanze auf $1,30 \mathrm{mg} / \mathrm{g}$ reduziert, was verglichen mit der niedrigsten Kontrollpflanze (7,48 mg/g) einer relativen Gesamt-Sinapinsäureesterreduktion von $83 \%$ entspricht.

Die hier dargestellten Ergebnisse zeigen, daß mit Hilfe eines transgenen Ansatzes unter Verwendung des ds-RNA-Interferenz Konstruktes pLH-SGT-GUS eine signifikante Abnahme des Sinapinsäureestergehaltes im Samen um 76\% erreicht werden konnte. Insgesamt kann man davon ausgehen, das ein niedriger Sinapinsäureestergehalt im Samen von Brassica napus mit allen agronomisch wichtigen Leistungsdaten kombiniert werden kann. Desweiteren wurde gezeigt, daß es möglich ist, hohe Resveratrolglucosidgehalte $(424 \mu \mathrm{g} / \mathrm{g})$ und eine erhebliche Reduzierung des Gesamt-SAE-Gehaltes $(1,30 \mathrm{mg} / \mathrm{g}) \mathrm{im}$ Samen nach Agrobakterium vermittelter Co-Transformation unter Verwendung des pPSty5-Konstruktes und des 
pLH-SGT-GUS-Konstruktes zu realisieren. Auch hier kann man davon ausgehen, das eine hohe Akkumulierung von Resveratrolglucosid und eine drastische Reduzierung des SAEGehaltes in Brassica napus keine negativen Effekte auf andere agronomische Merkmale haben wird. Aus beiden Transformations- und Co-Transformationsversuchen stehen homozygote Linien für die weitere züchterische Bearbeitung zur Verfügung. 


\section{Literaturverzeichnis}

Bauer, M., Libantova, J., Moravcikova, J. and Bekesiova, I., 1998: Transgenic tobaccco plants constitutively expressing acidic chitinase from cucumber. Biologia $\underline{52}, 749-758$.

Bell, J.M., 1984: Nutrients and Toxicants in Rapeseed Meal: A review.J. Anim. Sci. 모, 9961010.

Bell, J.M., 1993: Factors affecting the nutritional value of Canola Meal: A review. Can. J. Anim. Sci. 73, 679-697.

Bertelli, A., Giovannini, L., Giannessi, D., Migliori, M., Bernini, W. and Fregoni, M., 1995: Antiplatelet activity of synthetic and natural resveratrol in red wine. Int. J. Tissue React. 17, 1-3.

Birnboim, H.C. and Doly, J., 1979: A rapid alkaline extraction procedure for screening plasmid DNA. Nucl. Acids Res. ㄱ, 1513-1523.

Bouchereau, A., Hamelin, J.,Lamour, I., Renard, M. and Larher, F., 1991: Distribution of sinapine and related compounds in seeds of Brassica and allied Genera. Phytochemistry $\underline{30}$, $1873-1881$.

Bouchereau, A., Hamelin, J., Renard, M. and Larher, F, 1992: Structural changes in sinapic acid conjugates during seedling development of rape. Plant Physiol. Biochem. 30, 467-475.

Bullock, W. O., Fernandez, J.M. and Short, J.M., 1987: XL1-Blue: a high efficiency plasmid transforming recA E. coli strain with $\beta$-galactosidase selection. BioTechniques $\underline{5}$, 376-378.

Cevera, M., Pina, J.A., Juarez, J., Navarro, L. and Pena, L., 2000: A broad exploration of a transgenic population of citrus: stability of gene expression and phenotype. Theor. Appl. Genet. 100, 670-677.

Chapple, C., Vogt, T., Ellis, B.E., Somerville, C.S., 1992: An Arabidopsis mutant defective in the general phenylproanoid pathway. The Plant Cell $\underline{4}, 1413-1424$. 
Coutos-Thevenot, P., Poinssot, B., Bonomelli, A., Yean, H., Breda, C., Buffard, D., Esnault, R., Hain, R., Boulay, M., 2000: In vitro tolerance to Botrytis cinera of grapevine 41B rootstock in transgenic plants expressing the stilbene synthase Vst1 gene under the control of

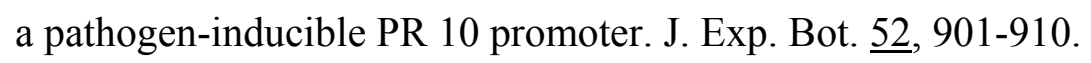

Dabrowski, K.J. and Sosulski, F.W., 1984: Composition of free and hydrolyzable phenolic acids in defatted flours of ten oilseeds. J. Agric. Food Chem. $\underline{32}$, 128-130.

De Block, M., De Brouwer, D. and Tenning, P., 1989: Transformation of Brassica napus and Brassica oleracea using Agrobacterium tumefaciens and the Expression of the bar and neo Genes in the Transgenic Plants. Plant Phyiol. 91, 694-701.

De Block, M. and De Brouwer, D., 1991: Two T- DNA`s cotransformed into Brassica napus by a double Agrobacterium tumefaciens infection are mainly integrated at the same locus. Theor. Appl. Genet. $\underline{82}$, 257-263.

Ezcurra, I., 1998: Studies on the regulation of the Napin napA Promoter by Abscisic Acid and the Transciptional Activator AB13. Doctoral thesis, Swedish University of Agricultural Sciences, Agraria 102.

FAO, 2002: http: www.fao.org

FAO, 2003: http: www.fao.org

Fettig, S., Hess, D., 1999: Expression of a chimeric stilbene synthase gene in transgenic wheat lines. Transgenic Research $\underline{8}, 179-189$.

Fischer, R., Budde, I. and Hain, R., 1997: Stilbene synthase gene expression causes changes in flower colour and male sterility in tobacco. Plant J. $\underline{11}, 489-498$.

Frankel, E.N., Waterhouse, A.L., Kinsella J.E., 1993: Inhibition of human LDL oxidation by resveratrol. Lancet 24, 1103-1104. 
Gendloff, E.H., Bowen, B. and Buchholz, W.G., 1990: Quantitation of chloramphenicol acetyl transferase in transgenic tobacco plants by ELISA and correlation with gene copy number. Plant Mol. Biol. 14, 575-583.

Griffith, D.W., 1989: Polyphenolics and their possible effects on nutritive value. Aspects of Applied Biology 19, 93-103.

Hain, R., Reif, H.J., Krause E., Langebartels, R., Kindl, H., Vornam, B., Wiese, W., Schmelzer, E., Schreier, P.H., Stöcker, R.H., Stenzel, K., 1993: Disease resistance results from foreign phytoalexin expression in a novel plant. Nature $\underline{361}, 153-156$.

Hellens, R.P., Mullineaux, P., Klee, H., 2000: A guide to Agrobacterium binary Ti vectors. Trends in Plant Sci. $\underline{5}$ (10), 446-451.

Hettwer, U., 1997: Kurzberichte aus der Wissenschaft: Brot und Wein gegen Krebs. Naturw. Rdsch. 50. Jahrgang (9), 358-359.

Hipskind, J.D., Paiva, N.L., 2000: Constitutive accumulation of a resveratrol-glucoside in transgenic alfalfa increases resistance to Phoma medicaginis. Mol. Plant Microbe Interact $\underline{13}$, $551-562$.

Hobbs, S. L.A., Kpodar, P. and DeLong, C.M.O., 1990: The effect of T-DNA copy number, position and methylation on reporter gene expression in tobacco transformants. Plant Mol. Biol. 15, 851-864.

Hobbs, S. L.A., Warkentin, T.D. and DeLong, C.M.O., 1993: Transgene copy number can be positively or negatively associated with transgene expression. Plant Mol. Biol. 21, 17-26.

Jang, M., Cai, L., Udeani, G.O., Slowing, K.V., Thomas, C.F., Beecher, C.W.W., Fong, H.H.S., Farnswoth, N.R., Kinghorn, A.D., Metha, R.G., Moon, R.C. and Pezzuto, J.M., 1997: Cancer chemopreventive activity of resveratrol, a natural product derived from grapes. Science 275, 218-220. 
Jeandet, P., Breuil, A.C., Adrian, M., Weston, L.A., Debord, S., Meunier, P., Maume, G. and Bessis, R., 1997: HPLC analysis of grapevine phytoalexins coupling photodiode array detection and fluorometry. Anal. Chem. $\underline{69}, 5172-5177$.

Jakowitsch, J., Papp, I., Moscone E.A., van der Winden, J., Matzke, M. and Matzke, A.J., 1999: Molecular and cytogenetic characterization of a transgene locus that induces silencing and methylation of homologous promoters in trans. The Plant Journal $17(\underline{2}), 131-140$.

Kimura, Y., Pkuda, H. and Arichi, S., 1985: Effects of stilbenes on arachidonate metabolism in leukocytes. Biochem. Biophys. Acta $\underline{834}, 275-278$.

Kindl, H., 1985: Biosythesis of stilbenes. In: Biosynthesis and biodegradation of wood components (T. Higuchi, Ed.), Academic Press, New York, 349-377.

Kobayashi, S., Ding, C.K., Nakamura, Y., Nakajima, I. and Matsumoto, R., 2000: Kiwifruit (Actinida deliciosa) transformed with a Vitis stilbene synthase gene produce piceid (resveratrol-glucoside). Plant Cell Rep. 19, 904-910.

Komari, T., Hiei, Y., Saito, Y., Murai, N. and Kumashiro, T., 1996: Vectors carrying two TDNA for cotransformation of higher plants mediated by Agrobacterium tumefaciens and segregation of transformants free from selection markers. The Plant Journal $\underline{10}$ (1), 165-174.

Kozlowska, H., Naczk, M., Shahidi and Zadernowski, R., 1990: Phenolic acids and tannins in rapeseed and canola, pp. 193-210. In: Shahidi, F. (Ed.), Canola and Rapeseed. Production, Chemistry, Nutrition and Processing Technology. Van Nostrand Reinhold, New York.

Langcake, P. and Pryce, R.J., 1976: The production of resveratrol by Vitis vinifera and other members of the Vitaceae as a response to infection or injury. Physol. Plant Pathol. $\underline{9}$, 77-86.

Leckband, G., 2002: NAPUS 2000-Gesunde Lebensmittel aus transgener Rapssaat. In: Vom Genom zur Sorte, Vorträge für Pflanzenzüchtung $\underline{54}$, 167-172. 
Leckband, G. and Lörz, H., 1998: Transformation and expression of a stilbene synthase gene of Vitis vinifera L. in barley and wheat for increased fungal resistance. Theor. Appl. Genet. $\underline{96}$ , 1001-1012.

Lim, E.K., Parr, A., Jackson, D., Ashford, D.A., and Bowles, D.J., 2001: Identification of glucosyltransferase genes involved in sinpate metabolism and lignin synthesis in Arabidopsis..J. Biol.Chem. 276, 4344-4349.

Liu, Q., Singh, P.S., and Green, A.G., 2002: High-Stearic and high- Oleic cottonseed oils produced by Hairpin RNA-mediated post- transcriptional gene-silencing. Plant Physiol. $\underline{129}$, $1732-1743$.

Lorenzen, M., Racicot, V., Strack, D. and Chapple, C., 1996: Sinapic acid ester metabolism in wild type and a sinapoylglucose-accumulating mutant of Arabidopsis. Plant Physiol. 112, 1625-1630.

Manna, S.K., Mukhopadhyay, A., Aggarwal, B.B., 2000: Resveratrol suppresses TNFinduced activation of nuclear transcription factors NF- $k \mathrm{~B}$, activator protein-1, and apoptosis: potential role of reactive oxygen intermediates and lipid peroxidation. J. Immunol. 164, 65096519.

Mannerlöf, M., Tuvesson, S., Stehen, P. and Tenning, P., 1997: Transgenic sugar beet tolerant to glyphosate. Euphytica 94, 83-91.

McCabe, M.S., Mohapatra, U.B., Debnath, S.C., Power, J.B and Davey, M.R., 1999: Integration, expression and inheritance of two linked T-DNA marker genes in transgenic lettuce. Mol. Breed. $\underline{5}$, 329-344.

Melchior, F. and Kindl, H., 1990: Grapevine stilbene synthase cDNA only slightly differing from chalcone synthase cDNA is expressed in Escherichia coli into catalytically active enzyme. FEBS Lett 268, 17-20. 
Melchior, F. and Kindl, H., 1991: Coordinate- and elicitor-dependent expression of stilbene synthase and phenylalanine ammonialyase genes in Vitis cv. Optima. Arch. Biochem. Biophys. 288, 552-557.

Milkowski, C., Baumert, A., and Strack, D., 2000: Cloning and heterologous expression of a rape cDNA encoding UDP-glucose: sinapate glucosyltransferase. Planta 211, 883-886.

Milkowski, C., Baumert, A., Schmidt, D., Nehlin, L. and Strack, D., 2004: Molecular regulation of sinapate ester metabolism in Brassica napus: expression of genes, properties of the encoded proteins and correlation of enzyme activities with metabolite accumulation. The Plant Journal $\underline{38}, 80-92$.

Murashige, T. and Skoog, F., 1962: A revised medium for rapid growth and bioassays with tobacco tissue cultures. Physiol. Plant $\underline{15}$, 473-497.

Naczk, M., Aramowicz, A., Sullivan, A., and Shahidi, F., 1998: Current research developments on polyphenolics of rapesees/canola: a review. Food Chemistry $\underline{62}, 489-502$.

Nair, R.B., Joy, R.W., Schnaider, J., Kurylo, E., Shi, X. Datla, R.S.S., Keller, W.A. and Selvaraj, G., 2000: Identification of a CYP84 family of cytochrome P450- dependent monooxygenase genes in Brassica napus and perturbation of their expression for engineering sinspine reduction in the seeds. Plant Physiol. 123, 1623-1634.

Ohlson, R., 1978: Functional properties of rapeseed oil and protein product. In: Proceedings $5^{\text {th }}$ International Rapeseed Congress, pp. 152-167. Malmö, Sweden.

Orsini, J., Baumert, A., Milkowski, C., Weyen, J. and Leckband, G., 2003: Agrobacteriummediated production of Brassica napus transgenic plants with a stilbene synthase gene. In: Proceedings $11^{\text {th }}$ International Rapeseed Congress, Denmark.

Pace-Asciak, C.R., Hahn, S., Diamanidis, E.P., Soleas, G. and Goldberg, D.M., 1995: The red wine phenolics trans-resveratrol and quercetin block human platelet aggregation and eicosanoid synthesis: implications for protection against coronary heart disease. Clin. Chim. Acta 235, 207-219. 
Pickford, A.S. and Cogoni, C., 2003: RNA-mediated gene silencing. Cell. Mol. Life Sci. $\underline{60}$ (5), 871-82.

Pokorny, J. and Reblova, Z., 1995: Sinapines and other phenolics of Brassicaceae seeds. Potrav. Vedy $\underline{13}, 155-168$.

Reinhardt, T.C., 1992: Entwicklung und Anwendung von Nah-Infrarot-spektroskopischen Methoden für die Bestimmung von Öl-, Protein-, Glucosinolat-, Feuchte- und Fettsäuregehalte in intakter Rapssaat. Dissertation, Universität Göttingen.

Röbbelen, G., 1999: In: BioEngineering für Rapssorten nach Maß. Vorträge für Pflanzenzüchtung $\underline{45}, 9-27$.

Sambrook, J., Fritsch, I. and Maniatis, T., 1989: Molecular cloning, a laboratory manual. Cold Spring Harbor Laboratory Press, New York, USA.

Schoeppner, A. and Kindl, H., 1984: Purification and properties of a stilbene synthase from induced cell suspension cultures of peanut. J. Biol. Chem. 259, 6806-6811.

Shahidi, F. and Naczk, M., 1992: An overview of the phenolics of canola and rapeseed: Chemical, sensory and nutritional significance. J. Am. Oil Chem. Soc. 69, 917-924.

Singh, S., Green, A., Stoutjesdijk, P. and Liu, Q., 2000: Inverted-repeat DNA: a new genesilencing tool for seed lipid modification. $14^{\text {th }}$ International Symposium on Plant Lipids held at Cardiff University.

Singleton, V.L., 1981: Naturally Occuring Food Toxicants: Phenolic substances of plant origin common in foods. Adv. Food Res. 27, 149-242.

Sotheeswaran, S. and Pasuphaty, P., 1993: Distribution of resveratrol oligomers in plants. Phytochemistry $\underline{32}, 1083-1093$.

Sozulski, F., 1979: Organoleptic and nutritional effects of phenolic compounds on oilseed protein products: a review. JAOCS $\underline{56}, 711-715$. 
Stark-Lorenzen, P., Nelke, P., Hänßler, G., Mühlbach, H.P. and Thomzik, J.E., 1997: Tranfer of a grapevine stilbene synthase gene to rice (Oryza sativa L.). Plant Cell Rep. 16, 668-673.

Statistical Graphics Corp. 1997: Statgraphics Plus 3.0, Statistical graphic System by Statistical Grapic Corporation, Rockville.

Stoutjesdijk, P., Surinder, P.S., Liu, Q., Hurlstone, C.J., Waterhouse, P.A. and Green, A.G., 2002: hpRNA-mediated targeting of the Arabidopsis FAD2 gene gives highly efficient and stable silencing. Plant Physiol. 129, 1-9.

Strack, D., Knogge, W. and Dahlbender, B., 1983: Enzymatic synthesis of sinapine from 1-0sinapoylglucose and choline by a cell-free system from developing seeds of red radish (Raphanus sativus L.). Zeitschrift für Naturforschung 38c, 21-27.

Subbaramaiah, K., Chung, W.J., Michaluart, P., Telang, N., Tanabe, T., Inoue, H., Jang, M., Pezzuto, J.M. and Dannenberg, A., 1998: Resveratrol inhibits cyclooxygenase-2 transcription and activity in phorbol ester-treated human mammary epithelial cells. J. Biol. Chem. $\underline{273}$, 21875-21882.

Szankowski, I., Briviba, K., Fleschhut, J., Schönherr, J., Jacobsen, H.J. and Kiesecker, H., 2003: Transformation of apple (Malus domestica Borkh.) with the stilbene synthase gene from grapevine (Vitis vinifera L.) and a PGIP gene from kiwi (Actinida deliciosa). Plant Cell Rep. 22, 141-149.

Trautwein, E.A. und Ebersdopler, H.F., 1998: Rapsöl- ein wertvolles Speiseöl. UFOPSchriften, Heft 6. Union zur Förderung von Oel- und Proteinpflanzen e.V. Bonn.

UFOP, 2003: http: www. ufop.de

UFOP, 2004: http: www.ufop.de

Velasco, L. and Möllers, C., 1998: Nondestructive assement of sinapic acid esters in Brassica species: II. Evaluation of germplasm and identification of phenotypes with reduced levels. Crop Sci. 38, 1650-1654. 
Voelker, T.A., Hayes, T.R., Cranmer, A..M., Turner, J.C. and Davies, H.M., 1996: Genetic engineering of a quantitative trait: metabolic and genetic parameters influencing the accumulation of laurate in rapeseed. Plant J. $\underline{9}, 229-241$.

Vogt, T., Aebershold, R., and Ellis,B., 1993: Purification and characterization of sinapine synthase from seed of Brassica napus. Arch. Biochem. Biophys. $\underline{300}$ (2), 622-628.

Zukalova, H. and Vasak, J., 1999: Natural antioxidants in winter rape (Brassica napus L.). In: Rapskongreß (CD-Rom). Candorra. Australien.

Zum Felde, T., Baumert, A., Becker, H.C. and Möllers C., 2003: Genetic variation, inheritance and development of NIRS-calibrations for sinapic acid esters in oilseed rape (Brassica napus L.). In: Proceedings $11^{\text {th }}$ International Rapeseed Congress, Denmark.

Zum Felde, T., 2004: Genetische Variation und Vererbung von Sinpingehalt im Raps (Brassica napus L.) und Erstellung von definiertem Ausgangsmaterial. Dissertation, Universität Göttingen, in Vorbereitung. 


\title{
Reduction of the sinapic acid ester content in transgenic oilseed rape
}

(Brassica napus L.)

\begin{abstract}
In the Brassicaceae family, sinapic acid esters (SAE) are important anti-nutritional compounds. They contribute to the bitter taste and adstringency of rapeseed products. A substantial reduction of sinapic acid esters in oilseed rape could improve its use as a protein crop. Seeds accumulate primarily sinapoyl choline (sinapine) and smaller amounts of sinapoylglucose as well as some other not yet characterized sinapic acid containing compounds. This work focuses on the Agrobacterium tumefaciens mediated transformation of Brassica napus spring cultivar Drakkar with a ds-RNA-interference construct deduced from the sequence of the key enzyme sinapic acid glucosyltransferase (SGT). This resulted in a substantial decrease of sinapic acid esters from $7.28 \mathrm{mg} / \mathrm{g}$ in the lowest out of 30 control plants to $2.84 \mathrm{mg} / \mathrm{g}$ in the T2-seeds of one T1-plant. Among the transgenic T1-plants was a high and significant correlation between sinapoylglucose and all other sinapic acid esters, which ranged from $0.76^{* *}$ to $0.96^{* *}$. There was no significant difference in other important agronomic traits, like oil, protein, fatty acid and glucosinolate content in comparison to the control plants. In one homozygous T2-plant with a single copy integrated the total SAE content was reduced to $1.82 \mathrm{mg} / \mathrm{g}$, in comparison to $7.48 \mathrm{mg} / \mathrm{g}$ in the lowest out of 22 control plants. The sinapine content in this T2-plant was $2.66 \mathrm{mg} / \mathrm{g}$.
\end{abstract}

\section{Introduction}

The global production of rapeseed (Brassica napus L.) ranks second amongst oilseed crops (FAO, 2002). Rapeseed is grown principally for oil production, because rapeseed cultivars have a high oil content, about 40 to $50 \%$. The meal obtained after oil extraction contains about $40 \%$ protein (RÖBBELEN and THIES, 1986). The utilization of rapeseed is limited due to the presence of toxic and antinutritive compounds like erucic acid in the oil, glucosinolates, phytates, tannins and phenolics in the meal (SHAHIDI and NACZK, 1992). Breeding efforts led to the elimination of erucic acid and to the drastical reduction of glucosinolate content in rapeseed (DOWNEY, 1990). The quality of rapeseed protein as represented by its amino acid composition is well-balanced for human use (OHLSON, 1978). However, the use of rapeseed as a source of food protein is still thwarted by the presence of undesirable phenolic compounds; they remain as one of the principal antinutritive factors limiting the use of 
rapeseed as a protein source in food formulations (KOZLOWSKA et al., 1990; SOSULZKI, 1979; ISMAIL et al., 1981; SHAHIDI and NACZK, 1992).

Sinapic acid esters (SAE) are the predominant phenolic esters in rapeseed (SHAHIDI and NACZK, 1992; KOZLOWSKA et al., 1990). In Brassica napus, SAE constitutes 1-2\% of the seed dry matter (BELL, 1993; ZUKALOVA, 1999). SAE contributes to the bitter taste, adstringency and dark colour of rapeseed products (KOZLOWSKA et al., 1990; NACZK et al., 1998; SHAHIDI und NACZK, 1992). In addition, SAE may form complexes with proteins, thus lowering the nutritional value of the protein products (KOZLOWSKA et al., 1990; SHAHIDI und NACZK, 1992). Rape-seed accumulates three major sinapic acid esters, sinapoylglucose, sinapoylcholine (sinapine) and sinapoylmalate. Leaves contain only sinapoylmalate, whereas seeds accumulate primarily sinapine and smaller amounts of sinapoylglucose as well as some other not yet characterized sinapic acid containing compounds (STRACK et al., 1983; BOUCHEREAU et al., 1992; LORENZEN et al., 1996). The phenylpropanoid pathway produces from phenylalanine a number of hydroxy-cinnamate derivatives by a series of hydroxylations and methylations leading at one end to sinapic acid (Fig.1). Sinapic acid is converted to sinapoylglucose by sinapic acid:UDPG sinapoyltransferase (SGT). In developing seeds, sinapoylglucose is transesterified by sinapoylglucose:choline sinapoyl-transferase (SCT) to sinapine, which is presumed to serve as a choline reservoir in seeds (STRACK et al., 1983; CHAPPLE et al., 1992).

A substantial reduction of SAE in oilseed rape could improve its use as a protein crop. However, progress to develop Brassica napus cultivars with low SAE content have not yet been achieved. There are several studies on the genetic variability of SAE content in seeds of Brassica ssp. (KERBER and BUCHLOH, 1980; KOZLOWSKA et al., 1983; BOUCHEREAU et al., 1991; KRÄHLING et al., 1990; WANG et al., 1998; THIES, 1994; MATTHÄUS, 1997). VELASCO and MÖLLERS (1998) analysed 1361 samples of Brassica napus breeding lines for SAE content by using near infrared reflectance spectroscopy. The SAE content ranged from 5.0 to $17.7 \mathrm{mg} / \mathrm{g}$ seeds. ZUM FELDE et al. (2003) found a variation between 3.5 and $13.0 \mathrm{mg} / \mathrm{g}$ in 549 selected seed samples of genotypically divergent winter rapeseed material. These results offer a possibility of reducing SAE by conventional plant breeding. Molecular breeding approaches may complement these efforts. The gene encoding SGT is the first obvious transgenic target for suppressing sinapic acid ester synthesis (NAIR et al., 1999). MILKOWSKI et al. (2000) isolated a cDNA encoding SGT 
from a cDNA library obtained from immature seeds and young seedlings of Brassica napus. This offers the possibility of a manipulation in sinapic acid ester metabolism by genetic engineering.

The present work aimed at regenerating transgenic Brassica napus plants expressing the SGTds-RNAi construct, and to identify transgenic lines with reduced total SAE content. This paper describes the changes that occur in composition and concentration of sinapic acid esters in T1- and T2-plants. 


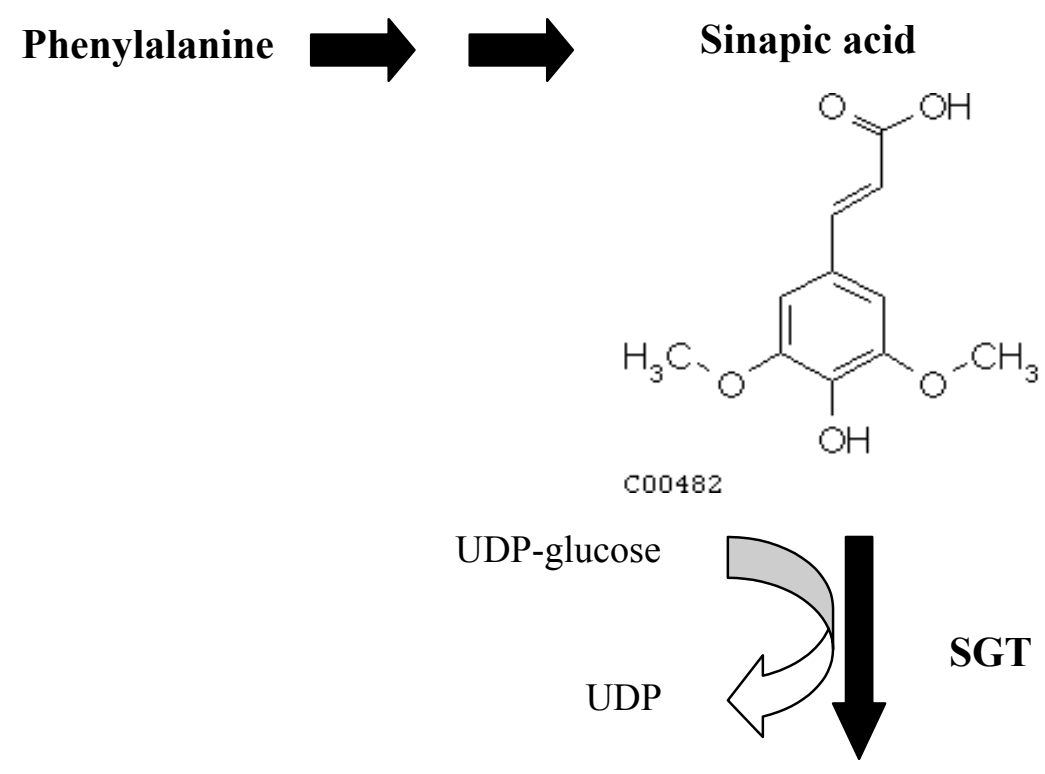

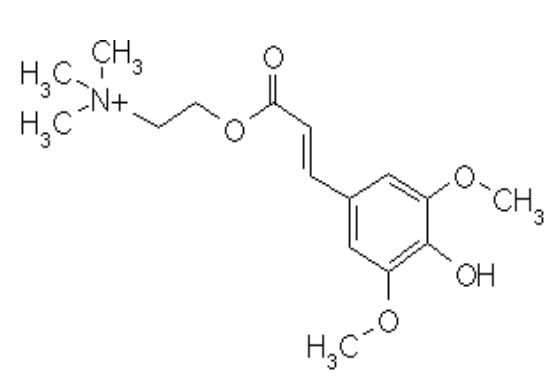

600933

\section{Sinapoyl-Choline SINAPINE}
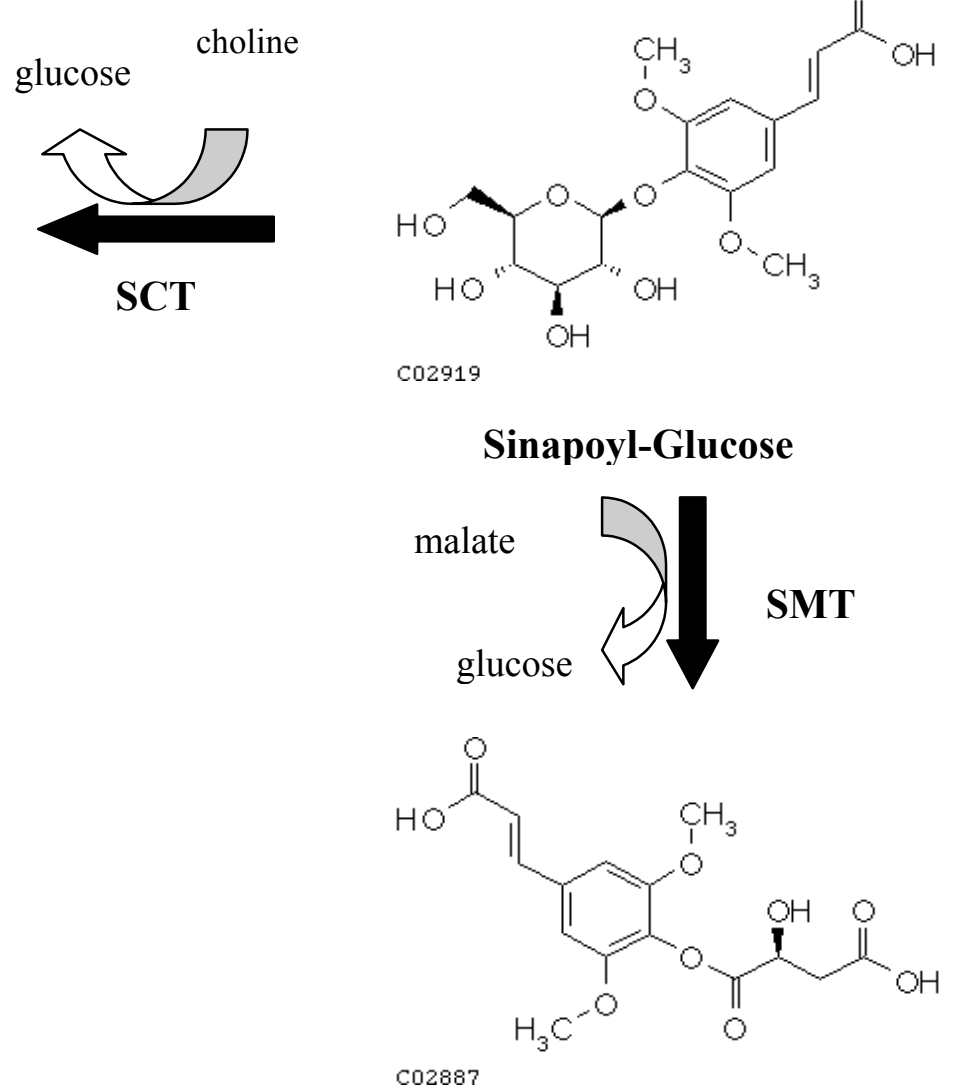

Sinapoyl-Malate

Fig. 1: Sinapic acid ester biosynthetic pathway of Brassicaceae (adapted from STRACK et al., 1983) 


\section{Materials and methods}

\section{Plasmid and bacterial strains}

The full-length cDNA of the SGT gene from Brassica napus has been isolated (Milkowski et al., 2000). A 200 bp-sequence was cloned as an inverted repeat with a GUS-spacer $(1 \mathrm{~kb})$ under control of a napin-promoter and a nos terminator. The plasmid was constructed (MILKOWSKI, unpublished) by cloning this SGT-ds-RNA-Interference fragment in the binary vector pLH7000 (HAUSMANN and TÖPFER, 1999) containing the PAT-gene under control of a CaMV35S-promoter (Fig. 2). Agrobacterium tumefaciens AGL1 (HELLENS et al., 2000) carrying the binary plasmid pLH-SGT-Gus was used for the production of transgenic Brassica napus lines.

LB

RB

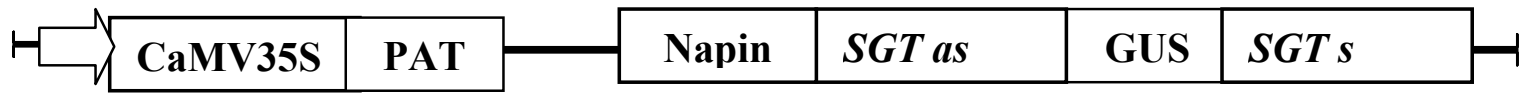

Fig.2: Schematic drawing of the T-DNA region of the binary plasmid pLH-SGT-GUS used for A. tumefaciens transformation of Brassica napus.

\section{Plant material}

Spring rapeseed (cv. Drakkar) with „00“-quality was used. Seeds were sterilized for $30 \mathrm{~min}$ in a 5\% sodium hypochlorite solution. Finally, the seeds were rinsed three times in sterile distilled water. They were germinated on $1 / 2$ MS-medium (MURASHIGE and SKOOG, 1962) in a growth chamber at $20^{\circ} \mathrm{C}$ with a daylength of $16 \mathrm{~h}$.

\section{Transformation, selection and regeneration}

Agrobacterium-mediated transformation methods and plant regeneration conditions were modified according to DE BLOCK et al. (1989). Hypocotyl segments were inoculated with Agrobacterium tumefaciens carrying the binary plasmid pLH-SGT-GUS. Transformed Drakkar hypocotyl segments were regenerated in two steps on selective medium with $5 \mathrm{mg} / 1$ and $10 \mathrm{mg} / \mathrm{l}$ phosphinothricin (PPT). Three to six weeks after selection, calli with small shoots were regenerated. Shoots were separated and transferred to MS-medium (MURASHIGE and SKOOG, 1962) for further regeneration and rooting. Surface sterilized seeds of cv. Drakkar were germinated in vitro and plants obtained were propagated. These plants were transferred to the greenhouse together with the transformants and used as controls. 
Plant cultivation in the greenhouse and analysis of morphological traits

Putative transgenic plants (T1-plants) propagated in vitro were transferred to the green-house and cultivated at $16 \mathrm{~h}$ light with a photon flux density of $200-900 \mu \mathrm{mol} \mathrm{m} \mathrm{m}^{-2} \mathrm{~s}^{-1}$ and $8 \mathrm{~h}$ dark conditions. The main shoot of each plant was selfed for seed production (T2-seeds). Selected T2-plants were selfed to obtain T3-seeds. The transgenic T1- and T2-plants were compared to non-transformed control plants in a randomized experiment.

\section{PAT-ELISA-test}

Leaf tissue (100mg) of putative transgenic plants were used. The PAT-ELISA-test was performed as described by the manufacturer (STEFFENS, Eberingen). The absorbance of the reaction mixture was measured at room temperature at $625 \mathrm{~nm}$. The standard curve was made following the manufacturer's instructions.

\section{DNA extraction, PCR and Southern blot analysis}

To detect the introduced transgene by PCR in the putative regenerated transgenic plants, DNA samples were extracted from leaf tissue using the DNAeasy-Mini-kit (Qiagen) fol-lowing the manufacturer`s instructions. A primer pair (Pat-fw 5`-ATG GGC CCA GAA CGA CGC CC3'; Pat-rev 5 -GCG TGA TCT CAG ATC TCG GT-3') for amplification of the 498 bp Patfragment (resistance marker) was designed and used for PCR. Southern blot analysis was performed to verify the integration of the transgenes and to determine the transgene copy number. For Southern blot analysis, DNA samples were extracted from leaf tissue of primary

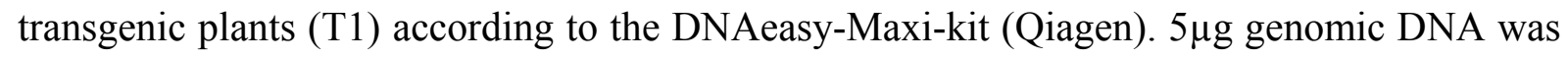
digested with EcoR1 and separated by $0.8 \%$ agarose gel electrophoresis. Separated DNA fragments were transferred onto a positively charged nylon membrane (Amersham Pharmacia). The probe (PAT-resistance marker) was labeled by PCR ( primer sequences see above) with digoxigenin using a DIG-HyPrime-kit (Roche), and a DIG Nucleic Acid Detection Kit (Roche) was used for filter hybridization and detection according to the manufacturer's instructions.

\section{Phosphinothricin resistance of T2-seedlings}

Primary transformants (T1-plants) were selfed to obtain T2-seeds. Seeds were sterilized for $30 \mathrm{~min}$ in a $5 \%$ sodium hypochlorite solution. Finally, the seeds were rinsed three times in sterile distilled water. 20 seeds per T1-plant were germinated on $1 / 2$ MS-medium including 10 $\mathrm{mg} / \mathrm{l} \mathrm{PPT}$ in a growth chamber at $20^{\circ} \mathrm{C}$ with a day length of $16 \mathrm{~h}$. The development of 
herbicide damage symptoms was scored until seven days post treatment. PPT-susceptible and PPT-tolerant seedlings could be easily distinguished. Susceptible ones didn't germi-nate.

\section{Sinapic acid ester analysis}

The sinapic acid ester analysis was performed by Dr. A. Baumert (Institut für Pflanzenbiochemie, Halle/Saale). Grinded seed material $(20 \mathrm{mg})$ was extracted with $1 \mathrm{ml}$ Methanol/ $\mathrm{H}_{2} \mathrm{O}(4: 1)$ in $2 \mathrm{ml}$-safe-lock tubes in the presence of zirconia beads $(1 \mathrm{~mm})$ using a bead beater (Bio Spec Products, Inc., Bartlesville, OK, USA). Reversed phase HPLC (Waters Separator 2795, Waters 2996 photodiode array detector and Waters 474 fluorescence detector) was carried out using a Nucleosil 5- $\mu \mathrm{m}_{18}$ column $(250 \mathrm{x} 4 \mathrm{~mm}$ i.d.; Machery\&Nagel). After centrifugation of the extracts $10 \mu 1$ samples were injected. Separation was achieved using a 20-min linear gradient at a flow rate of $1 \mathrm{ml} \mathrm{min}^{-1}$ from 10 to $50 \%$ solvent B (acetonitrile) in solvent A (1,5\% o-phosphoric acid in water). Sinapic acid esters were detected at $330 \mathrm{~nm}$ and quantified by external standardization with 1-O-sinapoylglucose, sinapine and sinapic acid, respectively. Sinapoylglucose (SINglc) was calculated as sinapoylglucose and sinapine as sinapine. Other not yet identified sinapic acid esters (SINrest) and the total sinapic acid ester content (total SAE) was calculated as sinapic acid.

\section{Statistical analysis}

All statistical parameters (mean, SD, $\chi^{2}$ ) were calculated using the StatGraphics Plus for Windows 3.0 (STATISTICAL GRAPHICS CORP. 1997). For correlation analysis Spearman rank correlation coefficients were used. 


\section{Results}

Regeneration and transformation efficiency

Altogether 51 PPT-resistant (10 mg/l, Tab.1) Drakkar lines were obtained from 850 explants. These results correspond to a mean regeneration efficiency of $6 \%$. PAT-ELISA-test and PAT-PCR analysis of leaves from putative transgenic plants confirmed the presence of the PAT-marker-gene. Thirty of the regenerants tested showed a PAT-ELISA signal (data not shown) and a PAT-specific band of the expected size (Fig. 3). The mean transformation efficiency was $3.6 \%$ and varied between the three experiments between 2.8 and $4.3 \%$ (Tab.1).

Tab.1: Regeneration and transformation efficiency of Brassica napus lines transformed with the pLH-SGT-GUS plasmid

\begin{tabular}{lcccccc}
\hline $\begin{array}{l}\text { Experi- } \\
\text { ment }\end{array}$ & explants & $\begin{array}{l}5 \mathrm{mg} / \mathrm{l} \\
\mathrm{PPT}\end{array}$ & $\begin{array}{l}10 \mathrm{mg} / \mathrm{l} \\
\mathrm{PPT}\end{array}$ & $\begin{array}{l}\text { Regeneration } \\
\text { efficiency }(\%)\end{array}$ & $\begin{array}{l}\text { ELISA }^{1} \text { and } \\
\text { PCR }^{1} \text { positive }\end{array}$ & $\begin{array}{l}\text { Transformation } \\
\text { efficiency (\%) }\end{array}$ \\
\hline 1 & 250 & 93 & 10 & 4.0 & 7 & 2.8 \\
2 & 300 & 106 & 21 & 8.0 & 13 & 4.3 \\
3 & 300 & 78 & 20 & 6.6 & 10 & 3.3 \\
Sum/mean & 850 & 277 & 51 & 6.0 & 30 & 3.6 \\
\hline
\end{tabular}

${ }^{1}$ PAT-ELISA-Test and PAT-PCR

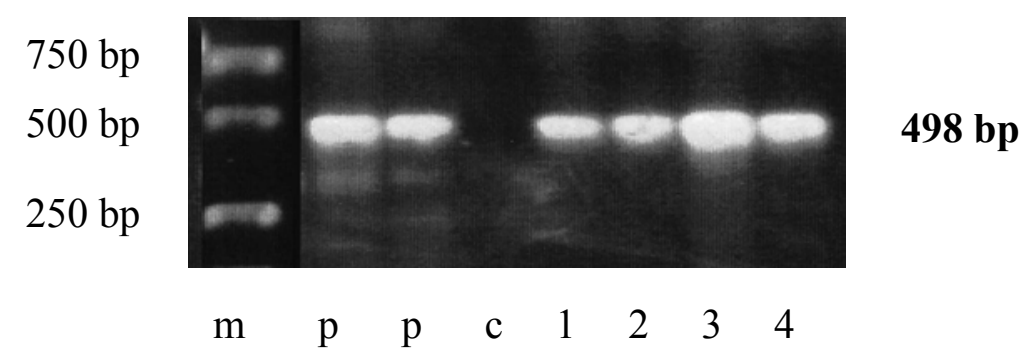

Fig. 3: PCR analysis of Brassica napus T1-plants transformed with the pLH-SGT-GUS plasmid. Gel electrophoresis of the amplified fragment with the expected length of $498 \mathrm{bp}$. Lanes: m: marker; p: plasmid; c: untransformed control; 1-4: T1-plants

\section{Sinapic acid ester content of T1-plants}

Thirty PAT-ELISA-test positive and PAT-PCR-positive T1-plants were transferred to the greenhouse. The transgenic plants were fully fertile and normal in growth and morphology in comparison to the controls (s. III/3; Tab. 1). There was no significant difference in other important agronomic traits, like oil, protein, fatty acid and glucosinolate content of the seeds 
(s. III/3; Tab.2). T2-seeds obtained from thirty T1-plants were analysed by HPLC for the accumulation of sinapic acid esters (SAE). They showed varying levels (Fig. 4) for the total SAE content. The average concentration of total SAE content in the control plants was $8.79 \pm$ $0,70 \mathrm{mg} / \mathrm{g}$. The lowest control plant contained $7.28 \mathrm{mg} / \mathrm{g}$ total SAE. The average concentration in the T1-plants was $7.30 \pm 2.44 \mathrm{mg} / \mathrm{g}$. The lowest T1-plant contained 2.84 $\mathrm{mg} / \mathrm{g}$ total SAE.

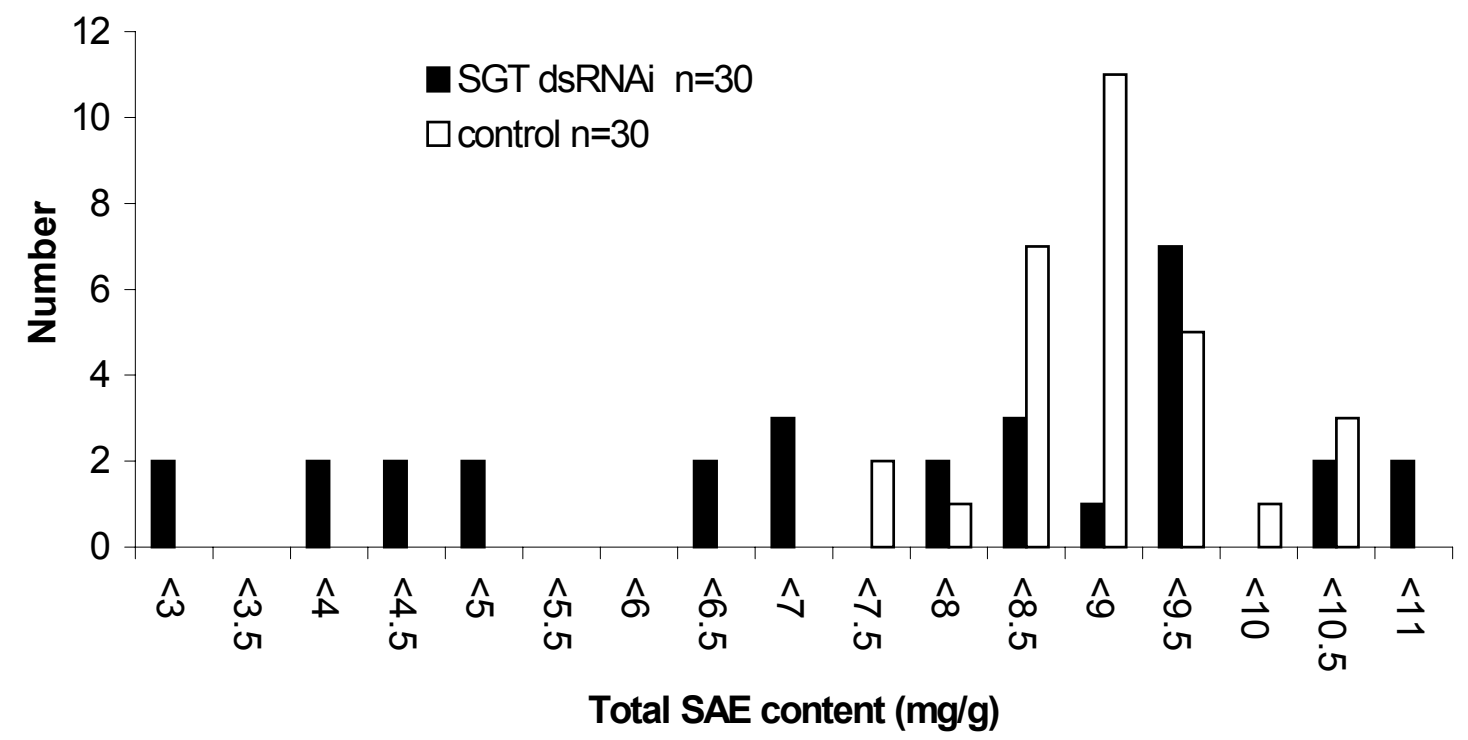

Fig 4: Frequency distribution for the total sinapic acid ester content (mg/g) in T1-plants (T2seeds) transformed with pLH-SGT-GUS plasmid and of control plants

Among the transgenic T1-plants was a high and significant correlation between sinapoylglucose and all other sinapic acid esters (Tab. 2), which ranged from $0.76^{* *}$ to $0.96^{* *}$. Furthermore, sinapine, the sum of not characterized SAE and the total SAE content were highly correlated to each other.

Tab.2: Spearman rank correlations $\left(\mathrm{r}_{\mathrm{s}}\right)$ between sinapic acid esters in T1 plants transformed with $\mathrm{pLH}-\mathrm{SGT}-\mathrm{GUS}$ plasmid $(\mathrm{n}=30)$

\begin{tabular}{lllc}
\hline & Sinapoylglucose & Sinapine & $\begin{array}{c}\text { Sum of not fully } \\
\text { characterized } \mathrm{SAE}^{1}\end{array}$ \\
\hline Sinapine & $0.76^{* *}$ & & \\
Sum of not fully characterized SAE & $0.92^{* *}$ & $0.76^{* *}$ & \\
Total SAE content $^{1}$ & $0.91^{* *}$ & $0.96^{* *}$ & $0.91^{* *}$ \\
\hline
\end{tabular}

${ }^{1}$ calculated as sinapic acid 
Figure 5 shows as an example the correlation $\left(\mathrm{r}_{\mathrm{s}}=0,91^{* *}\right)$ between sinapoylglucose and total SAE content in T1-plants transformed with the pLH-SGT-GUS plasmid.

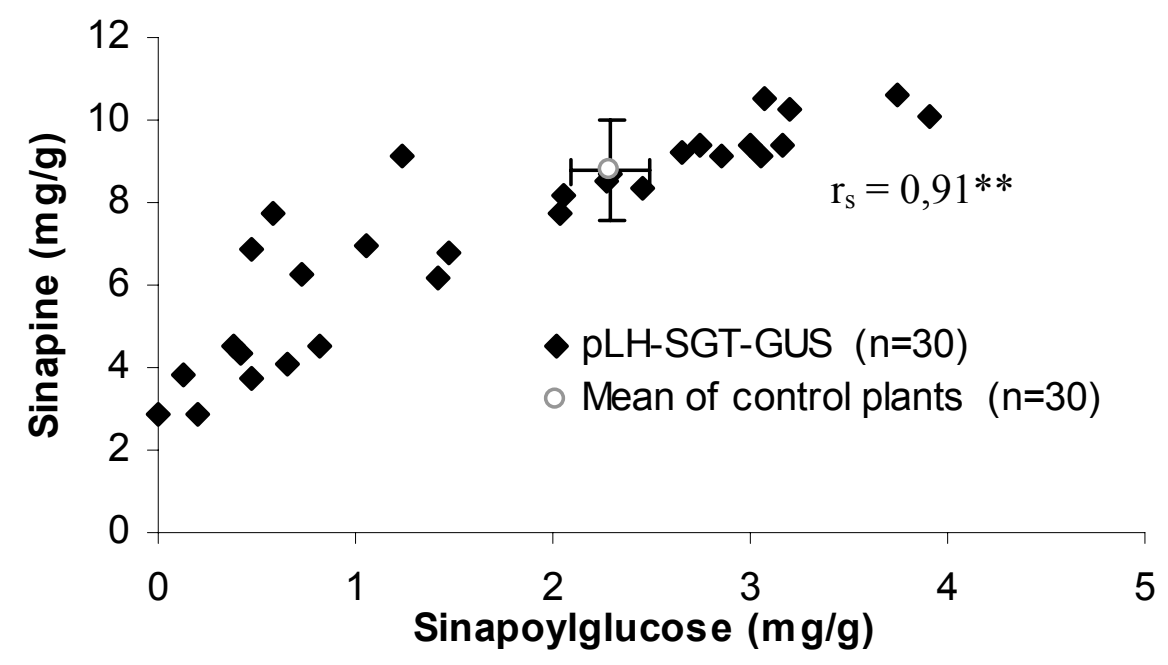

Fig.5: Correlation between sinapoylglucose $(\mathrm{mg} / \mathrm{g})$ and total sinapic acid ester content $(\mathrm{mg} / \mathrm{g})$ in T1-plants $(\mathrm{n}=30)$ transformed with the pLH-SGT-GUS plasmid. For comparison the mean of the untransformed controls $( \pm \mathrm{SD})$ is also shown.

Tab. 3 shows the sinapic acid ester composition of the three T1-plants with the lowest SAE content. One of the T1-plants (1501.24) showed a sinapoylglucose reduction to $0.00 \mathrm{mg} / \mathrm{g}$, whereas the minimum of the controls contained $1.21 \mathrm{mg} / \mathrm{g}$. The sinapine content in seeds of this line showed a reduction to $4.02 \mathrm{mg} / \mathrm{g}$, the total SAE content was reduced to $2.84 \mathrm{mg} / \mathrm{g}$.

Tab.3: Total amount (mg/g) of sinapic acid esters in the T2-seeds of selected B. napus T1plants transformed with the pLH-SGT-GUS plasmid and of a control plant

\begin{tabular}{lllll}
\hline Line & $\begin{array}{l}\text { Sinpoyl- } \\
\text { glucose }\end{array}$ & Sinapine & $\begin{array}{l}\text { Sum of not fully } \\
\text { characterized SAE }\end{array}$ & $\begin{array}{l}\text { Total SAE } \\
\text { content }^{1}\end{array}$ \\
\hline Control $^{2}$ & 1.21 & 7.44 & 0.72 & 7.28 \\
1501.6 & 0.12 & 5.3 & 0.00 & 3.83 \\
1501.24 & 0.00 & 4.02 & 0.00 & 2.84 \\
1501.26 & 0.20 & 3.71 & 0.07 & 2.86 \\
\hline
\end{tabular}

${ }^{1}$ calculated as Sinapic acid $(\mathrm{mg} / \mathrm{g})$

${ }^{2}$ control plant with the lowest total SAE content (from $n=30$ ) 
Transgene copy number as determined by PPT-resistance and Southern blot analysis

The three transgenic T1-plants with the lowest SAE content as determined in the T2-seeds were characterized for their PPT-resistance segregation in T2-seeds and analysed by Southern blot hybridisation for the integration of the transgene in T1-plants. The resistance to PPT of T2 -seeds $(n=20)$ was tested in this experiment. It was found, that 4 to 5 from 20 seedlings of each line were not resistant to PPT (Tab. 4), indicating a 3:1 inheritance, sug-gesting that each of the three transformants contain only one T-DNA locus. These results correspond to the integrated copy number as determined by Southern blot (Tab. 4, Fig. 6).

Tab.4: Phosphinothricin (PPT) resistance of T2-seedlings and copy number as determined by Southern blot

\begin{tabular}{llccc}
\hline Line & $\mathrm{r}^{1}$ & T2 seedlings & $\begin{array}{c}\text { Segregation } \\
\left(\chi^{2}\right)^{2}\end{array}$ & $\begin{array}{c}\text { Copy } \\
\text { Number }^{3}\end{array}$ \\
\hline 1501.6 & 16 & $4 .{ }^{1}$ & $3: 1(0.26)$ & 1 \\
1501.24 & 16 & 4 & $3: 1(0.26)$ & 1 \\
1501.26 & 15 & 5 & $3: 1(0.00)$ & 1 \\
\hline
\end{tabular}

${ }^{1}$ r. / n.r.: resistant / not resistant $(10 \mathrm{mg} / 1 \mathrm{PPT}){ }^{2}\left(\chi^{2}\right)=3,84(5 \%, 1 \mathrm{DF}){ }^{3}$ Southern blot

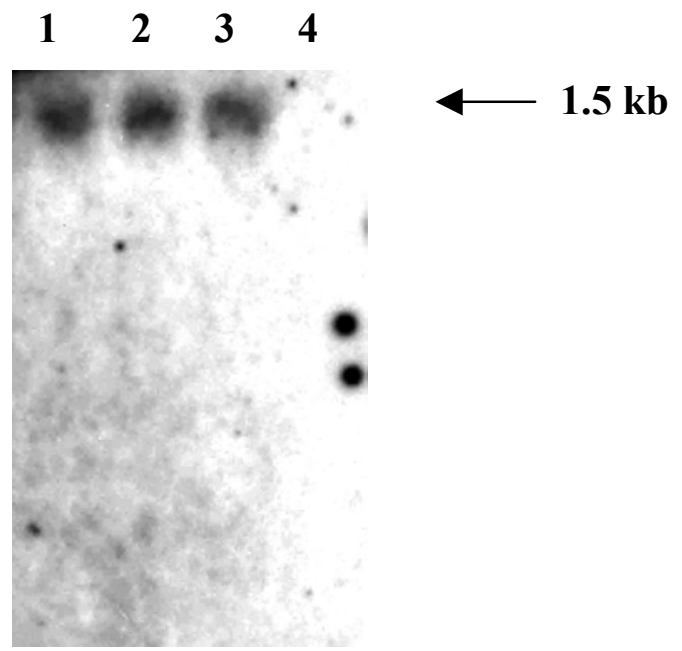

Fig. 6: Southern blot analysis (PAT-gene) of Brassica napus T1-plants transformed with the pLH-SGT-GUS plasmid. Lane 1 : 1501.6 ; Lane 2 : 1501.24 ; Lane 3 : 1501.26 ; Lane 4 : untransformed control

\section{Sinapic acid ester content of selected T2-plants}

From each of the three transgenic lines with the lowest SAE content and single copy integration twenty T2-seeds were sown together with cv. Drakkar control plants $(n=22)$ in the greenhouse. All T2-plants were normal during the vegetative and reproductive phase of their growth in the greenhouse (s. III/4; Tab.5,6). The SAE content of the mature seeds from the 
T2-plants (T3-seeds) was analysed. The average concentration of total SAE content in the control plants was $8.40 \pm 0.57 \mathrm{mg} / \mathrm{g}$. The average concentration in the T2-plants was $4.50 \pm$ $1.55 \mathrm{mg} / \mathrm{g}$ for line $1501.6,5.42 \pm 2.31 \mathrm{mg} / \mathrm{g}$ for line 1501.24 and $5.01 \pm 1.86 \mathrm{mg} / \mathrm{g}$ for line 1501.26. In one T2-plant of line 1501.24 the total SAE content was reduced to $1.82 \mathrm{mg} / \mathrm{g}$ (Tab.5). In comparison to the lowest control plant $(7.48 \mathrm{mg} / \mathrm{g})$ the reduction was $76 \%$. The sinapine content in this offspring of line 1501.24 was $2.66 \mathrm{mg} / \mathrm{g}$. This means a relative reduction of $72 \%$ (lowest control plant: $9.46 \mathrm{mg} / \mathrm{g}$ ).

Tab.5: Absolute (mg/g) and relative (\%) sinapine and total SAE content in T3- seeds of selected T2-plants with the lowest total SAE content, transformed with the pLH-SGT-GUS plasmid and of a control plant

\begin{tabular}{|c|c|c|c|c|}
\hline Line & Sinapine & $\%$ & Total $\mathrm{SAE}^{1}$ content & $\%$ \\
\hline Control $^{2}$ & 9.46 & 100 & 7.48 & 100 \\
\hline 1501.6 & 3.27 & 34.6 & 2.28 & 30.5 \\
\hline 1501.24 & 2.66 & 28 & 1.82 & 24 \\
\hline 1501.26 & 3.33 & 35 & 2.24 & 30 \\
\hline
\end{tabular}

${ }^{1}$ calculated as Sinapic acid

${ }^{2}$ control plant with the lowest total SAE content (from $n=22$ )

Twenty T2-plants derived from T1-plant 1501.6 were grouped according to their sinapine and total SAE content (T3-seeds). By analysing the PPT-resistance of the T3-seedlings of these T2-plants (data not shown) it could be shown that the homozygous resistant ones had the lowest sinapine and total SAE content, the hemizygous resistant ones had a medium and the homozygous not-resistant ones had the highest sinapine and total SAE content (Fig. 7). These groups (low, medium, high sinapine and total SAE content, respectively) are showing the expected 1:2:1 segregation.

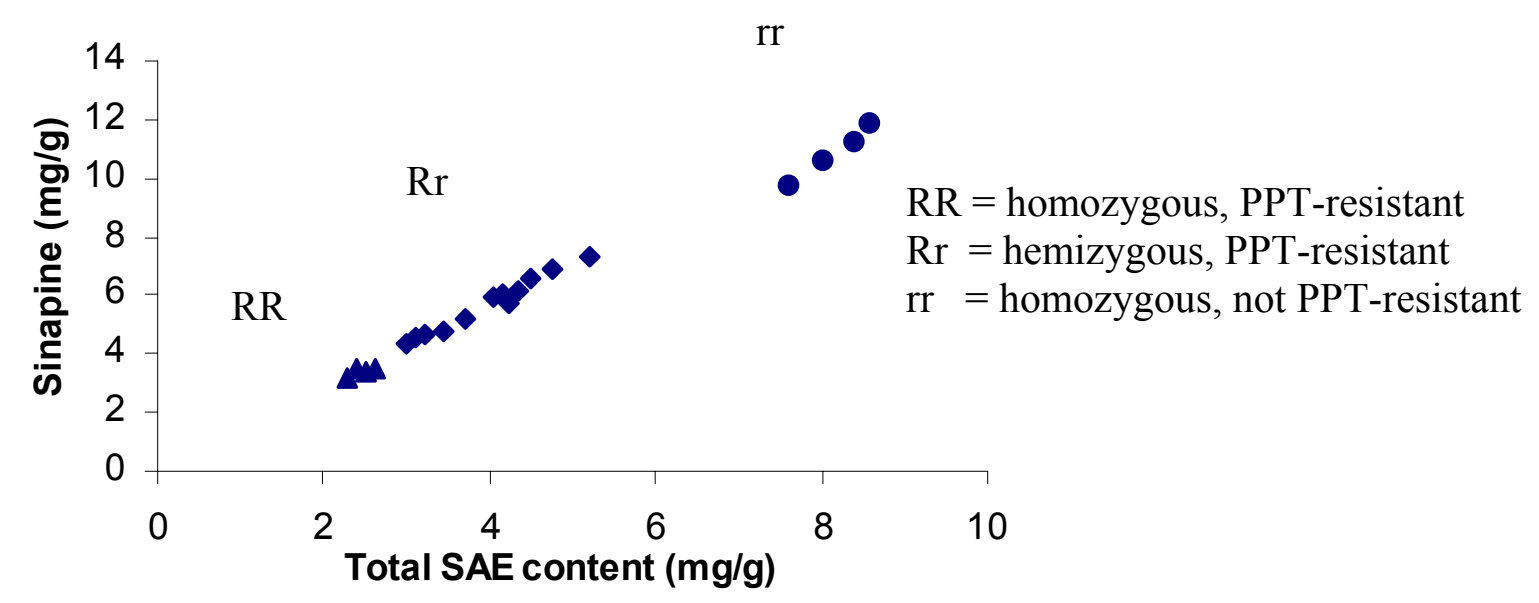

Fig.7: Sinapine $(\mathrm{mg} / \mathrm{g})$ and total SAE $(\mathrm{mg} / \mathrm{g})$ content of T3-seeds obtained from T2-plants (line 1501.6, $\mathrm{n}=20$ ) 


\section{Discussion}

\section{Reduction of the Sinapic Acid Ester (SAE) content in transgenic plants}

A homozygous transgenic T2-plant with a single copy integrated, containing the SGT gene cloned from Brassica napus as an inverted repeat, showed in the seeds a significant reduction of sinapic acid ester to $76 \%(1.82 \mathrm{mg} / \mathrm{g})$ in contrast to the lowest out of 22 control plants $(7.48$ $\mathrm{mg} / \mathrm{g}$ ). The contents of sinapoylglucose and of the sum of not characterised sinapic acid esters was reduced by $100 \%$. The sinapine suppression reached $72 \%(2.66 \mathrm{mg} / \mathrm{g})$. These results show that using the SGT gene as an inverted repeat under control of the seed specific napin promoter for Agrobacterium mediated transformation is an effective way to achieve a significant sinapic acid ester reduction in Brassica napus.

It could be shown in the present study, that homozygous T2-plants with a single copy integrated had the lowest sinapine and total SAE content, the hemizygous ones had a medium and the homozygous not-transgene ones had the highest sinapine and total SAE content. Studies in Arabidopsis have shown that hemizygous transgenic plants already express a highly effective suppression, but generally did not equal the degree of silencing achieved in homozygotes (SINGH et al., 2000; STOUTJESDIJK et al., 2002). Furthermore LIU et al. (2002) reported that a single copy of the silencing transgene (i.e. inverted-repeat construct containing the FAD2 gene used for cotton transformation) can be sufficient to achieve maximum suppression of the target gene.

Through post-transscriptional gene silencing (PTGS) a maximum suppression of $100 \%$ can be achieved. SINGH et al. (2000) showed that the inverted-repeat construct containing the FAD2 gene used for Arabidopsis transformation can induce PTGS with $100 \%$ efficiency. The antisense construct using the full-length $F A D 2$ gene gave only a $15 \%$ suppression. Since no $100 \%$ reduction of SAE was found in the present study, this leaves open some questions on how sinapic acid ester is regulated in Brassica napus. MILKOWSKI et al. (2004) reported, that the SGT transcript level increases throughout early stages of rapeseed development until the early cotyledonary stage, and stays constant in later stages. VOGT et al. (1993) found that SAE accumulation starts at about midpoint in seed development. MILKOWSKI et al. (2004) showed, that sinapoylglucose and sinapine accumulation in seeds starts ad midpoint of seed development and reached the highest value in late developmental state. The results suggests that the accumulation of SAE occurs in transgenic plants in later stages of the seed 
development, when the emplo-yed napin promotor is not active. The employed napin promoter activates gene expression during early and mid maturation, but not during late maturation (EZCURRA, 1998). Furthermore it may be possible that more SGT related genes are involved in the SAE pathway (LIM et al., 2001; MILKOWSKI et al., 2004). MILKOWSKI et al. (2004) sug-gested that the Brassica genome contain several SGT related genes. They found in Southern blot analysis two major SGT bands, derived from Brassica napus progenitors, and several minor bands. This would explain in the present study the lower correlation between sinapine and sinapoylglucose $\left(\mathrm{r}_{\mathrm{s}}=0.76^{* *}\right)$, in contrast to the correlation between sinapoylglucose and the sum of not characterised sinapic acid esters $\left(\mathrm{r}_{\mathrm{s}}=0.92 * *\right)$, which were reduced by $100 \%$. The sinapoyl choline transferase (SCT) could also be a rate limi-ting enzyme in the sinapine synthesis. Then a reduction in sinapine can only be expected if a more drastical suppression of the sinapoylglucose synthesis is achieved further downstream in the seed development or with suppression of more SGT related genes. Another hypothesis is, that the SAE pathway in the seeds is also regulated during the vegetative phases of B. napus. NAIR et al (2000) showed that using antisense constructs of the BNF5H gene, that catalyse the hydroxylation of ferulate to 5-OH-ferulate, under control of the constitutive CaMV-35S promoter led to a $40 \%$ reduction in the sinapine content. Using the seed specific napin promoter the reduction was only a $25 \%$. The possibility that SAE or their precursors are synthesised in maternal tissue and then transported to the seeds can not be excluded.

\section{Implications for rapeseed quality improvement}

Rapeseed meal is a significant source of protein supplement in human and animal nutrition. In the present work it was shown, that it is possible to achieve a $76 \%$ reduction in the sinapic acid ester content by suppressing the SGT. In the present work was no indication that other important agronomic traits, like oil, protein, fatty acid and glucosinolate content of the seeds are effected by lowering the sinapic acid ester content. ZUM FELDE (2004) studied the correlation of SAE content with other seed quality traits in segregating doubled haploid winter rapeseed populations. They found no significant correlation between SAE and oil, protein, fatty acid and glucosinolate content, respectively. Therefore, a drastical suppression of SAE in B. napus should not have any negative impacts on other important seed quality traits. 
Approaches for further lowering SAE content in rapeseed

Only one other gene involved in sinapic acid pathway has been cloned from Brassica napus, i.e. the $\mathrm{F} 5 \mathrm{H}$ gene, ferulate-5-hydroxilase, that catalyse the hydroxylation of ferulate to 5-OHferulate (NAIR, 2000). Antisense constructs of the BnF5H gene under control of a CaMV$35 \mathrm{~S}$ promoter led in one transgenic plant to a reduction of the sinapine content from 9.0 (mean of the controls) to $5.3 \mathrm{mg} / \mathrm{g}$. Using the napin promoter the reduction was only to 6.9 $\mathrm{mg} / \mathrm{g}$. A crossing between SGT-ds-RNAi (napin promotor) and F5H antisense under control of a 35S-promoter or a transformation of Brassica napus with the SGT-ds-RNAi construct under control of a 35S-promoter may offer greater benefits.

An important aspect while using genetic engineering is the evaluation of classical breeding material. In the study of VELASCO and MÖLLERS (1998) the SAE content of B. napus breeding lines ranged from 5.0 to $17.7 \mathrm{mg} / \mathrm{g}$ and ZUM FELDE et al. (2003) found a variation between 3.5 to $13.0 \mathrm{mg} / \mathrm{g}$ in 549 selected seed samples of genotypically divergent winter rapeseed material. A crossing between low classical and low trans-genic material (SGT-dsRNAi, F5H antisence) may also result in a further reduction of the SAE content. 


\section{References}

Bell, J.M., 1993: Factors affecting the nutritional value of Canola Meal: A review. Can. J. Anim. Sci. $\underline{73}, 679-697$.

Bouchereau, A., Hamelin, J.,Lamour, I., Renard, M. und Larher, F., 1991: Distribution of sinapine and related compounds in seeds of Brassica and allied Genera. Phytochemistry $\underline{30}$, 1873-1881.

Bouchereau, A., Hamelin, J., Renard, M. and Larher, F, 1992: Structural changes in sinapic acid conjugates during seedling development of rape. Plant Physiol. Biochem. $\underline{30}$, 467-475.

Chapple, C., Vogt, T., Ellis, B.E. and Somerville, C.S., 1992: An Arabidopsis mutant defective in the general phenylproanoid pathway. The Plant Cell $\underline{4}, 1413-1424$.

De Block, M., De Brouwer, D. and Tenning, P., 1989: Transformation of Brassica napus and Brassica oleracea using Agrobacterium tumefaciens and the Expression of the bar and neo Genes in the Transgenic Plants. Plant Phyiol. 91, 694-701.

Downey, R.K. and Bell, J.M., 1990: New Development in canola research, pp. 37-46. In: F. Shahidi (Ed.), Canola and Rapeseed. Production, Chemistry, Nutrition and Processing Technology, pp. 211-220. Van Nostrand Reinhold, New York.

Ezcurra, I., 1998: Studies on the regulation of the Napin napA Promoter by Abscisic Acid and the Transciptional Activator AB13. Doctoral thesis, Swedish University of Agricultural Sciences, Agraria $\underline{102}$.

Haussmann, L. und Töpfer, R., 1999: Entwicklung von Plasmid-Vektoren. In: BioEngineering für Rapssorten nach Maß. Vorträge für Pflanzenzüchtung, 45, 155-173.

Hellens, R.P., Mullineaux, P. and Klee, H., 2000: A guide to Agrobacterium binary Ti vectors. Trends in Plant Sci. $\underline{5}$ (10), 446-451.

Ismail, F., Vaisey-Genser, M. and Fyfe, B., 1981 : Bitterness and astringency of sinapine and its components. Journal of Food Science $\underline{46}$, 1241-1244. 
Kerber, E. und Buchloh, G., 1980: Der Sinapingehalt in Cruciferensamen. Angewandte Botanik 54, 47-54.

Kozlowska, H. and Zadernowski, R., 1983: Production of proteins preparates from rapeseed. In: Proceedings $6^{\text {th }}$ International Rapeseed Congress. Paris.

Kozlowska, H., Naczk, M., Shahidi and Zadernowski, R., 1990: Phenolic acids and tannins in rapeseed and canola, pp. 193-210. In: Shahidi, F. (Ed.), Canola and Rapeseed. Production, Chemistry, Nutrition and Processing Technology. Van Nostrand Reinhold, New York.

Krähling, K., Röbbelen, G. and Thies, W., 1990: Genetic variation of the content of sinapoyl esters in seeds of rape, B. napus. Plant Breeding $\underline{106}$, 254-257.

Lim, E.K., Parr, A., Jackson, D., Ashford, D.A., and Bowles, D.J., 2001: Identification of glucosyltransferase genes involved in sinpate metabolism and lignin synthesis in Arabidopsis. J. Biol.Chem. 276, 4344-4349.

Liu, Q., Singh, P.S., and Green, A.G., 2002: High-Stearic and high-Oleic cottonseed oils produced by Hairpin RNA-mediated post-transcriptional gene-silencing. Plant Physiol. 129, 1732-1743.

Lorenzen, M., Racicot, V., Strack, D. and Chapple, C., 1996: Sinapic acid ester metabolism in wild type and a sinapoylglucose-accumulating mutant of Arabidopsis. Plant Physiol. 112, 1625-1630.

Matthäus, B., 1997: Antinutitive compounds in different oilseeds. Fett / Lipid 99, 170-174.

Milkowski, C., Baumert, A., and Strack, D., 2000: Cloning and heterologous expression of a rape cDNA encoding UDP-glucose: sinapate glucosyltransferase. Planta 211, 883-886.

Milkowski, C., Baumert, A., Schmidt, D., Nehlin, L. and Strack, D., 2004: Molecular regulation of sinapate ester metabolism in Brassica napus: expression of genes, properties of the encoded proteins and correlation of enzyme activities with metabolite accumulation. The Plant Journal $\underline{38}, 80-92$. 
Murashige, T. and Skoog, F., 1962: A revised medium for rapid growth and bioassays with tobacco tissue cultures. Physiol. Plant $\underline{15}$, 473-497.

Naczk, M., Aramowicz, A., Sullivan, A., and Shahidi, F., 1998: Current research developments on polyphenolics of rapesees/canola: a review. Food Chemistry $\underline{62}, 489-502$.

Nair, R.B., Joy, R.W., Schnaider, J., Shi, X. Datla, R.S.S., Keller, W.A. and Selvaraj, G., 1999: Metabolic Engineering of the Sinapine content of Brassica napus seeds. In: Rapeseed Congress (CD-Rom). Candorra. Australia.

Nair, R.B., Joy, R.W., Schnaider, J., Kurylo, E., Shi, X. Datla, R.S.S., Keller, W.A. and Selvaraj, G., 2000: Identification of a CYP84 family of cytochrome P450- dependent monooxygenase genes in Brassica napus and perturbation of their expression for engineering sinspine reduction in the seeds. Plant Physiol. 123, 1623-1634.

Ohlson, R., 1978: Functional properties of rapeseed oil and protein product. In: Proceedings $5^{\text {th }}$ International Rapeseed Congress, pp. 152-167. Malmö, Sweden.

Röbbelen, G. und Thies, W., 1986: Auslese von Rapsformen mit verminderten Gehalten an Phytinsäure und Sinapoyl-Estern: Forschungsbericht an die GVP, unveroffentlicht. Institut für Pflanzenbau und Pflanzenzüchtung. Universität Göttingen.

Singh, S., Green, A., Stoutjesdijk, P. and Liu, Q., 2000: Inverted-repeat DNA: a new genesilencing tool for seed lipid modification. $14^{\text {th }}$ International Symposium on Plant Lipids held at Cardiff University.

Shahidi, F. and Naczk, M., 1992: An overview of the phenolics of canola and rapeseed: Chemical, sensory and nutritional significance. J. Am. Oil Chem. Soc. 69, 917-924.

Sozulski, F., 1979: Organoleptic and nutritional effects of phenolic compounds on oilseed protein products: a review. JAOCS $\underline{56}, 711-715$.

Statistical Graphics Corp. 1997: Statgraphics Plus 3.0, Statistical graphic System by Statistical Grapic Corporation, Rockville. 
Stoutjesdijk, P., Surinder, P.S., Liu, Q., Hurlstone, C.J., Waterhouse, P.A., and Green, A.G., 2002: hpRNA-mediated targeting of the Arabidopsis FAD2 gene gives highly efficient and stable silencing. Plant Physiol. 129, 1-9.

Strack, D., Knogge, W. and Dahlbender, B., 1983: Enzymatic synthesis of sinapine from 1-0sinapoylglucose and choline by a cell-free system from developing seeds of red radish (Raphanus sativus L.). Zeitschrift für Naturforschung 38c, 21-27.

Thies, W., 1994: Produktqualität bei Öl- und Proteinpflanzen. In: Forschung für die GFP, Heft $\underline{30}, 93-96$.

Velasco, L. and Möllers, C., 1998: Nondestructive assement of sinapic acid esters in Brassica species: II. Evaluation of germplasm and identification of phenotypes with reduced levels. Crop Sci. 38, 1650-1654.

Vogt, T., Aebershold, R., and Ellis, B., 1993: Purification and characterization of sinapine synthase from seed of Brassica napus. Arch. Biochem. Biophys. $\underline{300}$ (2), 622-628.

Wang, S., Oomah, B.D., McGregor, D.I. and Downey, R.K., 1998: Genetic and seasonal variation in the sinapine content of seed from Brassica and Sinapis species. Can. J. Plant Sci. $\underline{78}, 395-400$.

Zukalova, H. and Vasak, J., 1999: Natural antioxidants in winter rape ( Brassica napus L.). In: Rapeseed Congress (CD-Rom). Candorra. Australia.

Zum Felde, T., Baumert, A., Becker H.C. and Möllers C., 2003: Genetic variation, inheritance and development of NIRS-calibrations for sinapic acid esters in oilseed rape (Brassica napus L.). In: Proceedings $11^{\text {th }}$ International Rapeseed Congress, Copenhagen.

Zum Felde, T., 2004: Genetische Variation und Vererbung von Sinpingehalt im Raps (Brassica napus L.) und Erstellung von definiertem Ausgangsmaterial. Dissertation, Universität Göttingen, in Vorbereitung. 
II 


\title{
Resveratrol production in seeds of transgenic oilseed rape
}

(Brassica napus L.)

\begin{abstract}
Resveratrol is a phytoalexin produced in several plants like grapevine, peanut and pine in response to fungal infection or UV irradiation. Moreover, resveratrol and its glucoside are considered to have beneficial effects on human health. These compounds are known to reduce heart disease, arteriosclerosis and cancer mortality. Therefore, the introduction of the gene encoding stilbene synthase for resveratrol production in rapeseed is a tempting approach to improve the quality of rapeseed products. The stilbene synthase gene isolated from grapevine (Vitis vinifera L.) under control of the seed specific napin promotor was introduced into rapeseed (Brassica napus L.) by Agrobacterium mediated co-trans-formation together with a ds-RNA-interference construct deduced from the sequence of the key enzyme sinapic acid glucosyltransferase, assuming that the suppression of the sinapic acid ester biosynthesis may increase the resveratrol production in seeds through the increa-sed availability of the precursor p-cumaric acid. Resveratrol glucoside was produced at levels up to $361 \mu \mathrm{g} / \mathrm{g}$ in the seeds of the primary transformants. There was no significant difference in other important agronomic traits, like oil, protein, fatty acid and glucosinolate content in comparison to the control plants. In the next seed generation, up to $424 \mu \mathrm{g} / \mathrm{g}$ resveratrol glucoside was found in seeds of a homozygous T2-plant with a single transgene copy integrated. The sinapic acid ester content in this homozygous T2-plant was reduced from $7.48 \mathrm{mg} / \mathrm{g}$ in the lowest out of 22 control plants to $1.30 \mathrm{mg} / \mathrm{g}$.
\end{abstract}

\section{Introduction}

Resveratrol (trans-3,5,4-trihydroxystilbene) is a phytoalexin, derived from the phenylpropanoid pathway. Several plant species like grape (LANGCAKE and PRYSE, 1976), peanut (SCHOEPPNER and KINDL, 1984) and pine (KINDL, 1985) syntheses the phytoalexin resveratrol. A correlation between fungal disease resistence and resveratrol production of grapevine cultivars has been reported (LANGCAKE and McCARTHY, 1979; STEIN and BLAICH, 1985). Resveratrol can also be induced by other stress factors like UV light (SCHÖPPNER and KINDL, 1978), wounding (LANGCAKE, 1981) and elicitor treatment (MELCHIOR and KINDL, 1990). The production of resveratrol is regulated by the 
key enzyme stilbene synthase, which converts one molecule of p-coumaroyl-CoA and three molecules of malonyl-CoA into resveratrol (3,5,4-trihydroxystilbene). As a part of the phenylpropanoid pathway these percursor molecules are present in all plant species as a substrate for chalcone synthase, the key enzyme of the flavonoid pathway (RUPPRICH and KINDL, 1978).

The gene encoding stilbene synthase (VST1) in grapevine (Vitis vinifera) has been isolated and transferred into tobacco (HAIN et al., 1993), rice (STARK-LORENZEN et al., 1997), barley and wheat (LECKBAND and LÖRZ, 1998; FETTIG and HESS, 1998; LIANG et al., 2000), kiwi (KOBAYASHI et al., 2000), alfalfa (HIPSKIND and PAIVA, 2000), grapevine (COUTOS-THEVENOT et al., 2001) and apple (SZANKOWSKI et al., 2003). This studies were initiated to increase fungal disease resistance in crop species. A relationship between resveratrol production and enhanced fungal resistance has been shown in transgenic tobacco (HAIN et al., 1993), wheat and barley (LECKBAND and LÖRZ, 1998; LIANG et al., 2000), as well as in alfalfa (HIPSKIND and PAIVA, 2000). Contrasting results were obtained in kiwi, where the production of resveratrol did not lead to an increased disease resistance (KOBAYASHI et al.; 2000). However there are alternative reasons for producing resveratrol in plants, such as using this compound as nutraceutical or beneficial food component. Resveratrol and its glucoside are also known for their positive effects on human health. It has been shown that they reduce coronary heart-disease mortality and arteriosclerosis (BERTELLI et al., 1995; SUBBARAMAIAH et al., 1998; MANNA et al., 2000), inhibit low-density lipoprotein oxidation (FRANKEL et al., 1993; Manna et al., 2000) and eicosanoid synthesis (KIMURA et al., 1985; PACE-ASCIAK et al., 1995). An anti-cancer effect of resveratrol has also been reported (JANG et al., 1997).

Resveratrol is sharing part of its biosynthetic pathway with sinapic acid esters. P-cumaric acid is a precursor for both compounds. In Brassica napus sinapic acid esters (SAE) constitute 1$2 \%$ of the seed dry matter (BELL, 1993; ZUKALOVA, 1999). Brassica napus accumulates two major sinapic acid esters, sinapoylglucose and sinapoylcholine (sinapine), and smaller amounts of not yet characterized sinapic acid containing compounds in seeds (STRACK, 1983; BOUCHERAU et al., 1992; LORENZEN et al., 1996). SAE is lowering the quality of the rapeseed meal, because it contributes to the bitter taste, adstringency and dark colour of rapeseed products (KOZLOWSKA et al., 1990; NACZK et al., 1998; SHAHIDI und NACZK, 1992). In addition, SAE may form complexes with proteins, thus lowering the 
nutritional value of the protein products (KOZLOWSKA et al., 1990; SHA-HIDI und NACZK, 1992). In a companion paper (see manuscript I) we reported that the gene encoding sinapoylglucose transferase (SGT) is the first obvious transgenic target in the sinapic acid ester pathway for a reduction of the SAE content in the seeds (Fig. 1).

Both compounds, resveratrol and SAE are derived from the phenylpropanoid pathway and depend on the precursor p-cumaric acid (Fig. 1). Hence, it was assumed that the reveratrol production in rapeseed following transformation with the VST1 gene could be enhanced by simultaneously suppressing the SAE pathway. This hypothesis was supported by the fact, that transgenic rapeseed expressing a SGT-ds-RNAi-construct showed reduced levels of all sinapic acid containing compounds (see manuscript I). Genes encoding VST1 and SGT-dsRNAi were used for Agrobacterium mediated co-transformation The present work aimed at regenerating transgenic Brassica napus plants expressing the VST1 and SGT-ds-RNAi gene, and to identify transgenic lines with high levels of resveratrol and reduced levels of SAE.

\section{Phenylalanine

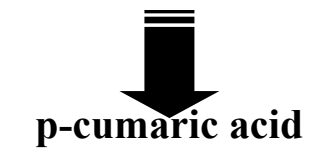

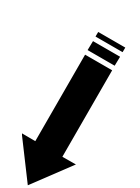

\section{Sinapic acid}
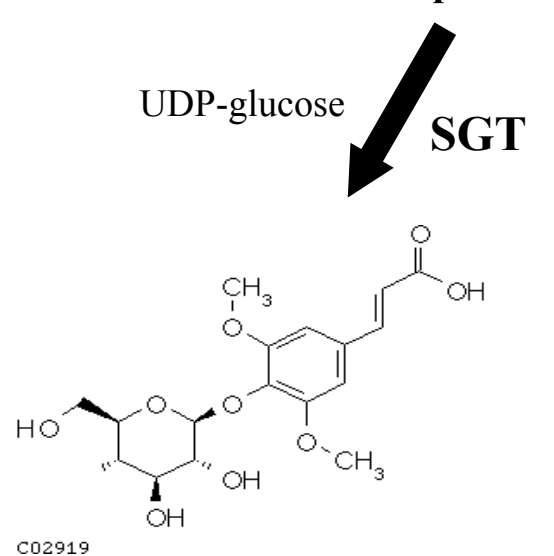

Sinapoylglucose
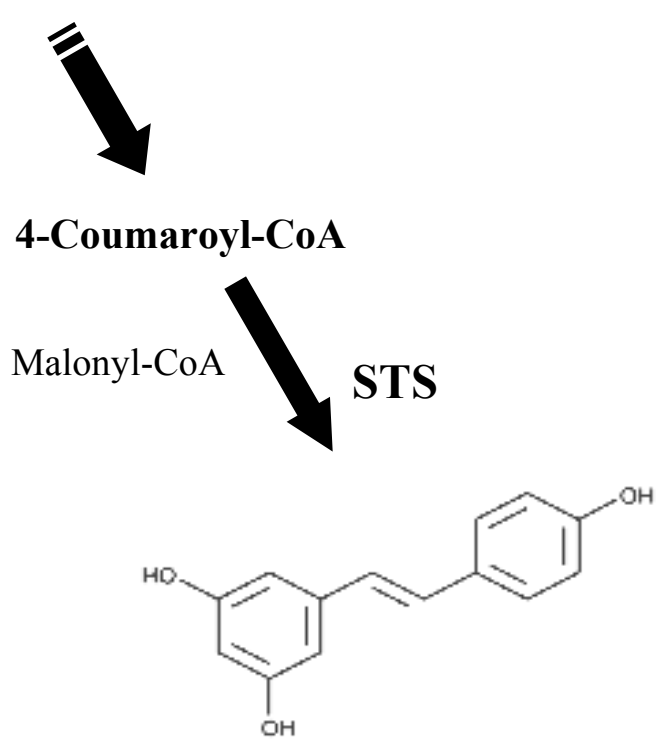

Resveratrol

Fig.1: Resveratrol and sinapic acid ester biosynthetic pathway (adapted from STRACK et al., 1983 and MELCHIOR and KINDL, 1991) 


\section{Material and methods}

\section{Plasmid and bacterial strains}

The vector pPSty5 carries the stilbene synthase gene (VST1) from Vitis vinifera L. (MELCHIOR and KINDL, 1990) under the control of the napin promoter and the NPTII-gene under control of the CaMV35S-promoter. The full-length cDNA of the SGT gene from Brassica napus has been isolated (MILKOWSKI et al., 2000) and a 200 bp-sequence was cloned as an inverted repeat with a GUS-spacer $(1 \mathrm{~kb})$ under control of a napin-promoter and a nos terminator. The plasmid pLH-SGT-GUS was constructed (C. MILKOWSKI, IPB Halle, unpublished) by cloning the SGT-ds-RNA-Interference fragment in the binary vector pLH7000 (HAUSMANN and TÖPFER, 1999) including the PAT-gene under control of the CaMV35S-promoter. Agrobacterium tumefaciens strain ATHV C58-C1 (HELLENS et al., 2000) containing the binary vector pPSty5 (P. JORASCH, Universität Hamburg, unpublished) and Agrobacterium tumefaciens strain AGL1 (HELLENS et al., 2000) carrying the binary plasmid pLH-SGT-Gus were used in the co-transformation experiments for the production of transgenic Brassica napus plants.

LB

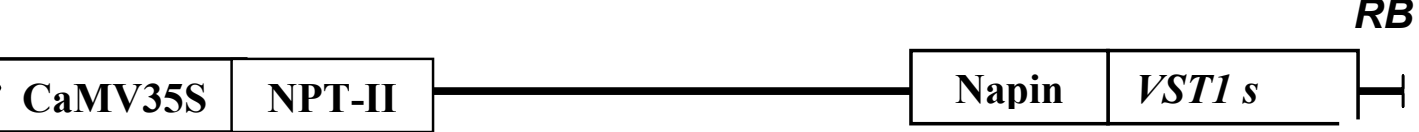

LB

$R B$

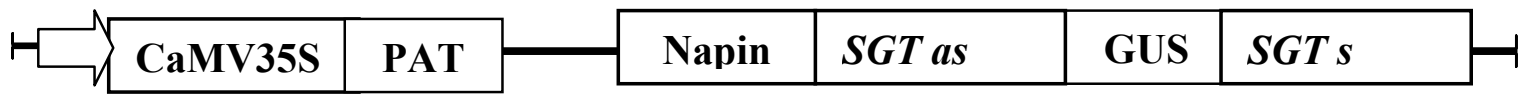

Fig.2: Schematic drawing of the T-DNA region of the binary plasmid pPSty 5 and pLH-SGTGUS used for A. tumefaciens co-transformation of Brassica napus.

\section{Plant material}

Spring rapeseed (cv. Drakkar) with „00“-quality was used. Seeds were sterilized for $30 \mathrm{~min}$ in a $5 \%$ sodium hypochlorite solution and rinsed three times in sterile distilled water. They were germinated on $1 / 2$ MS-medium (MURASHIGE and SKOOG, 1962) in a growth chamber at $20^{\circ} \mathrm{C}$ with a daylength of $16 \mathrm{~h}$.

\section{Co-transformation, selection and regeneration}

Agrobacterium-mediated transformation and plant regeneration were modified according to DE BLOCK et al. (1989). Hypocotyl segments were co-inoculated with ATHV C58C1 carrying the binary plasmid pPSty5 and AGL1 carrying the binary plasmid pLH-SGT-GUS. Transformed hypocotyl segments were regenerated in two steps on selective medium with 25 
mg/l Kanamycin (pPSty5) plus 5 mg/l PPT (pLH-SGT-GUS) and 50 mg/l Kanamycin plus 10 mg/l PPT. Three to six weeks after selection, calli with small shoots were regenerated. Shoots were separated and transferred to MS-medium (MURASHIGE and SKOOG, 1962) for further regeneration and rooting. Surface sterilized seeds of cv. Drakkar were germinated in vitro and plants obtained were propagated. These plants were transferred to the greenhouse together with the transformants and used as controls.

\section{Plant cultivation in the greenhouse and analysis of morphological traits}

Putative transgenic plants (T1-plants) propagated in vitro were transferred to the greenhouse and cultivated at $16 \mathrm{~h}$ light with a photon flux density of $200-900 \mu \mathrm{mol} \mathrm{m} \mathrm{m}^{-2}$ and $8 \mathrm{~h}$ dark conditions. The main shoot of each plant was selfed for seed production (T2-seeds). Selected T2-plants were selfed to obtain T3-seeds. Beginning of flowering, end of flowering and height of the plants at beginning and end of flowering were scored in each generation. The transgenic T1- and T2-plants were compared to non-transformed control plants in a randomized experiment.

\section{NPT-II-ELISA-test}

Leaf tissue $(50 \mathrm{mg})$ of putative transgenic plants were used. The NPT-II-ELISA-test was performed as described by the manufacturer (Agdia, USA). The absorbance of the reaction mixture was measured at room temperature at $450 \mathrm{~nm}$. The standard curve was made following the manufacturer's instructions.

\section{PAT-ELISA-test}

Leaf tissue (100mg) of putative transgenic plants were used. The PAT-ELISA-test was performed as described by the manufacturer (Steffens, Ebringen). The absorbance of the reaction mixture was measured at room temperature at $625 \mathrm{~nm}$. The standard curve was made following the manufacturer's instructions.

\section{DNA extraction, PCR and Southern blot analysis}

To detect the introduced transgenes with PCR in the putative regenerated transgenic plants, DNA samples were extracted from leaf tissue using the DNAeasy-Mini-kit (Qiagen, Hilden) following the manufacturer`s instructions. A primer pair (PAT-fw 5'-ATG GGC CCA GAA CGA CGC CC-3`; PAT-rev 5`GCG TGA TCT CAG ATC TCG GT-3` and NPTII-fw 5`ATC GGG AGC GGC GAT ACC GTA-3`; NPTII-rev 5`-GAG GCT ATT CGG CTA TGA 
CTG-3') for amplification of the 498 bp PAT-fragment (pLH-7000-SGT-GUS resistance marker) and of the $700 \mathrm{bp}$ NPTII-fragment (pPSty5 resistance marker) were designed and used for PCR. Southern blot analysis were performed to verify the integration of the transgenes and to determine the respective copy number. For Southern blot analysis, DNA samples were extracted from leaf tissue of primary transgenic plants (T1) according to the DNAeasy-Maxi-kit (Qiagen, Hilden). $5 \mu \mathrm{g}$ genomic DNA was digested with EcoR1 and separated by $0.8 \%$ agarose gel electrophoresis. Separated DNA fragments were transferred onto a positively charged nylon membrane (Amersham pharmacia, Freiburg). Probes (PATand NPT-II-resistance marker) were labeled by PCR (primer sequences see above) with digoxigenin using a DIG-HyPrime-kit (Roche, Mannheim), and a DIG Nucleic Acid Detection Kit (Roche, Mannheim) was used for filter hybridization and detection according to the manufacturer's instructions.

\section{Kanamycin and phosphinothricin resistance of T2-seedlings}

Primary transformants (T1-plants) were selfed to obtain T2 seeds. Seeds were sterilized for 30 min in a 5\% sodium hypochlorite solution. Finally, the seeds were rinsed three times in sterile distilled water. 55 seeds per T1-plant were germinated on $1 / 2$ MS-medium including 70 $\mathrm{mg} / \mathrm{l} \mathrm{Kanamycin} \mathrm{in} \mathrm{a} \mathrm{growth} \mathrm{chamber} \mathrm{at} 20^{\circ} \mathrm{C}$ with a daylength of $16 \mathrm{~h}$. The development of antibiotic damage symptoms was scored seven days post treatment. NPT-II susceptible and NPT-II tolerant seedlings could be easily distinguished. Susceptible ones didn't germinate. After that all T2-seedlings were transferred on $1 / 2$ MS-medium including $10 \mathrm{mg} / \mathrm{l} \mathrm{PPT}$. The development of herbicide damage symptoms was scored seven days post treatment. PPTsusceptible and PPT-tolerant seedlings could be easily distinguished. Susceptible ones died.

\section{Resveratrol glucoside and sinapic acid ester analysis}

The resveratrol glucoside and sinapic acid ester analysis was performed by Dr. A. Baumert (Institut für Pflanzenbiochemie, Halle/Saale). Grinded seed material (20 mg) was extracted with $1 \mathrm{ml} \mathrm{Methanol} / \mathrm{H}_{2} \mathrm{O}$ (4:1) in $2 \mathrm{ml}$-safe-lock tubes in the presence of zirconia beads (1 mm) using a bead beater (Bio Spec Products, Inc., Bartlesville, OK, USA). Reversed phase HPLC (Waters Separator 2795, Waters 2996 photodiode array detector and Waters 474 fluorescence detector) was carried out using a Nucleosil 5- $\mu \mathrm{m}_{18}$ column $(250 \times 4 \mathrm{~mm}$ i.d.; Machery\&Nagel). After centrifugation of the extracts $10 \mu 1$ samples were injected. Separation was achieved using a 20-min linear gradient at a flow rate of $1 \mathrm{ml} \mathrm{min}^{-1}$ from 10 to $50 \%$ solvent B (acetonitrile) in solvent A (1.5\% o-phosphoric acid in water). 
For detection of resveratrol glucoside a Waters 474 fluorescence detector was used at $330 \mathrm{~nm}$ for excitation and $374 \mathrm{~nm}$ for emission and quantified by external standardization with resveratrol (Sigma). Resveratrol glucoside (trans-resveratrol-3-O- $\beta$-glucoside) from Polygonum cuspidatum was used as reference compound.

Sinapic acid esters were analysed using the same method. They were detected at $330 \mathrm{~nm}$ and quantified by external standardization with 1-O-sinapoylglucose, sinapine and sinapic acid, respectively. Sinapoylglucose (SINglc) was calculated as sinapoylglucose, sinapine as sinapine and the total sinapic acid ester content (total SAE) was calculated as sinapic acid. Other not yet identified sinapic acid esters (SINrest) were also calculated as sinapic acid.

\section{Statistical analysis}

All statistical parameters (mean, $\mathrm{SD}, \chi^{2}$ ) were calculated using the StatGraphics Plus for Windows 3.0 (STATISTICAL GRAPHICS CORP. 1997). For correlation analysis Spearman rank correlation coefficients were used. 


\section{Results}

\section{Regeneration and transformation efficiency}

Altogether 48 NPT II- (70 mg/l) and PPT-resistant (10 mg/1, Tab.1) Drakkar plants were obtained from 1650 explants. PCR analysis and ELISA-tests confirmed the presence of the NPT II- and PAT-marker genes and proteins in 28 of these plants. They showed a NPT II- and PAT-ELISA signal (results not shown) and a NPT II- and PAT-specific PCR-band of the expected size (Fig. 3). The mean transformation efficiency was $1.8 \%$ with a range from 1.2 to $2.3 \%$ for the experiments (Tab.1).

Tab.1: Regeneration and transformation efficiency of Brassica napus T1-plants cotransformed with the pPSty5+pLH-SGT-GUS plasmids

\begin{tabular}{lccccc}
\hline $\begin{array}{l}\text { Experi- } \\
\text { ment }\end{array}$ & explants & $\begin{array}{c}25 \mathrm{mg} \mathrm{Kan}+ \\
5 \mathrm{mg} / \mathrm{l} \mathrm{PPT}\end{array}$ & $\begin{array}{c}70 \mathrm{mg} \mathrm{Kan}+ \\
10 \mathrm{mg} / \mathrm{l} \mathrm{PPT}\end{array}$ & $\begin{array}{c}\text { ELISA }^{1} \text { and } \\
\text { PCR }^{1} \text { positive }\end{array}$ & $\begin{array}{c}\text { Transformation } \\
\text { efficiency (\%) }\end{array}$ \\
\hline 1 & 300 & 51 & 10 & 5 & 1.7 \\
2 & 300 & 38 & 7 & 7 & 2.3 \\
3 & 350 & 41 & 9 & 5 & 1.4 \\
4 & 350 & 36 & 9 & 4 & 1.2 \\
5 & 350 & 42 & 13 & 7 & 2.0 \\
Sum/mean & 1650 & 208 & 48 & 28 & 1.8 \\
\hline
\end{tabular}

${ }^{1}$ NPTII- and PAT-ELISA-Test and NPTII- and PAT-PCR

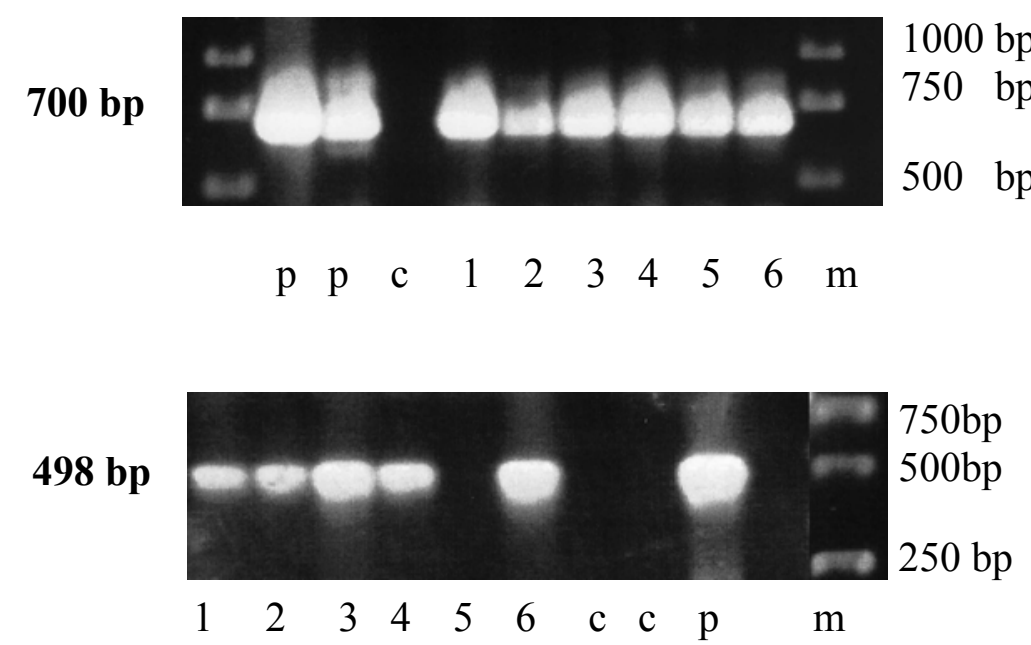

Fig. 3: PCR analysis of Brassica napus T1-plants co-transformed with pPSty5+pLH-SGTGUS plasmids. (a) Gel electrophoresis of NPTII-gene with the expected length of $700 \mathrm{bp}$. (b) Gel electrophoresis of PAT-gene with the expected length of 498 bp. Lanes: 1-6: T1-plants; c: untransformed control; p: plasmid m: marker 


\section{Resveratrol and sinapic acid ester content of T1-plants}

Twentyeight NPT II- and PAT-ELISA-test positive and NPT II- and PAT-PCR-positive T1plants were transferred to the greenhouse. The transgenic lines were fully fertile and normal in growth and morphology in comparison with the control plants. There was no significant difference in other important agronomic traits, like oil, protein, fatty acid and glucosinolate content of the seeds (s. III/3; Tab.3, Tab.4). T2-seeds obtained from 28 T1-plants were analysed by HPLC for the accumulation of resveratrol and sinapic acid esters (SAE). The resveratrol HPLC profiles from T2-seed extracts revealed a shorter retention time than that of resveratrol. This result suggest that the resveratrol has been modified by a endogenous glucosyltransferase into resveratrol glucoside. This was confirmed by HPLC-MS data, the unknown peak was identified as resveratrol glucoside (A. Baumert, IPB Halle, personal communication). The resveratrol glucoside content (Tab. 2) ranged from 0.00 to $361 \mathrm{mg} / \mathrm{g}$ seeds. Resveratrol glucoside was not detectable in seeds of control plants $(n=30)$. For the total SAE content T1-plants showed varying levels (Tab. 3). The average concentration of total SAE content in the control plants was $8.79 \pm 0.70 \mathrm{mg} / \mathrm{g}$. The lowest control plant contained $7.28 \mathrm{mg} / \mathrm{g}$ total SAE. The average concentration in the T1-plants was $6.14 \pm 2.70 \mathrm{mg} / \mathrm{g}$. The lowest T1-plant contained $2.54 \mathrm{mg} / \mathrm{g}$ total SAE.

Tab.2: Variation of the resveratrol glucoside content $(\mu \mathrm{g} / \mathrm{g})$ in $\mathrm{T} 1$ plants co-transformed pPSty5 + pLH-SGT-GUS plasmids and of control plants

\begin{tabular}{lccccc}
\hline Plasmid & $\mathrm{n}$ & Mean & SD & Minimum & Maximum \\
\hline $\begin{array}{l}\text { pPSty5 + pLH- } \\
\text { SGT-GUS }\end{array}$ & 28 & 107.73 & 116.15 & 0.00 & 361.00 \\
Control plants & 30 & 0.00 & 0.00 & 0.00 & 0.00 \\
\hline
\end{tabular}

Tab.3: Variation of the total sinapic acid ester content ${ }^{1}(\mathrm{mg} / \mathrm{g})$ in $\mathrm{T} 1$ plants co-transformed pPSty5 + pLH-SGT-GUS plasmids and of control plants

\begin{tabular}{lccccc}
\hline Plasmid & $\mathrm{n}$ & Mean & SD & Minimum & Maximum \\
\hline $\begin{array}{l}\text { pPSty5 + pLH- } \\
\text { SGT-GUS }\end{array}$ & 28 & 6.14 & 2.70 & 2.54 & 10.46 \\
Control plants & 30 & 8.79 & 0.70 & 7.28 & 10.33 \\
\hline
\end{tabular}

${ }^{1}$ calculated as Sinapic acid $(\mathrm{mg} / \mathrm{g})$

Among the transgenic T1-plants was a negative, not significant correlation between resveratrol glucoside and sinapic acid esters (Tab. 4), which ranged from -0.34 to -0.36 , and a high and significant correlation between sinapoylglucose and all other sinapic acid esters, 
which ranged from $0.76^{* *}$ to $0.96^{* *}$. Furthermore, sinapine, the sum of not characterized SAE and the total SAE content were highly correlated to each other.

Tab.4: Spearman rank correlations $\left(\mathrm{r}_{\mathrm{s}}\right)$ between sinapic acid esters and resveratrol glucoside in T1 plants transformed with pPSty5+pLH-SGT-GUS plasmid $(\mathrm{n}=28)$

\begin{tabular}{|c|c|c|c|c|}
\hline & $\begin{array}{l}\text { Sinapoyl- } \\
\text { glucose }\end{array}$ & Sinapine & $\begin{array}{c}\text { Sum of not fully } \\
\text { characterized SAE }\end{array}$ & $\begin{array}{c}\text { Total SAE } \\
\text { content }^{1} \\
\end{array}$ \\
\hline Sinapine & $0.93 * *$ & & & \\
\hline $\begin{array}{l}\text { Sum of not fully } \\
\text { characterized } \text { SAE }^{1}\end{array}$ & $0.92 * *$ & $0.88 * *$ & & \\
\hline Total SAE content ${ }^{1}$ & $0.97 * *$ & $0.99 * *$ & $0.94 * *$ & \\
\hline Resveratrol glucoside & -0.34 & -0.35 & -0.34 & -0.36 \\
\hline
\end{tabular}

${ }^{1}$ calculated as sinapic acid

Tab. 5 shows the resveratrol glucoside content and sinapic acid ester composition of the three T1-plants with the highest resveratrol glucoside content. One of the T1-plants (1502.17) containing $361 \mu \mathrm{g} / \mathrm{g}$ resveratrol glucoside showed a sinapoylglucose content reduction to 0.48 $\mathrm{mg} / \mathrm{g}$, whereas the minimum of the controls contained $1.21 \mathrm{mg} / \mathrm{g}$. The sinapine content in seeds of this line showed a reduction to $5.00 \mathrm{mg} / \mathrm{g}$, the total SAE cont-ent was reduced to $4.00 \mathrm{mg} / \mathrm{g}$.

Tab.5: Total amount of resveratrol glucoside $(\mu \mathrm{g} / \mathrm{g})$ and sinapic acid esters $(\mathrm{mg} / \mathrm{g})$ in the T2seeds of B. napus T1-plants co-transformed with pPSty $5+$ pLH-SGT-GUS plasmids and of a control plant

\begin{tabular}{lccccc}
\hline Line & $\begin{array}{c}\text { Resveratrol } \\
\text { glucoside }\end{array}$ & $\begin{array}{c}\text { Sinapoyl- } \\
\text { glucose }\end{array}$ & Sinapine & $\begin{array}{c}\text { Sum of not fully } \\
\text { characterized SAE }\end{array}$ & $\begin{array}{c}\text { Total SAE } \\
\text { content }^{1}\end{array}$ \\
\hline Control $^{2}$ & 0.00 & 1.21 & 7.44 & 0.72 & 7.28 \\
1502.15 & 351 & 0.48 & 4.46 & 0.19 & 3.68 \\
1502.16 & 335 & 0.30 & 4.38 & 0.11 & 3.44 \\
1502.17 & 361 & 0.48 & 5.00 & 0.12 & 4.00 \\
\hline
\end{tabular}

${ }^{1}$ calculated as Sinapic acid $(\mathrm{mg} / \mathrm{g})$

${ }^{2}$ control plant with the lowest total SAE content (from $n=30$ )

Transgene copy number as determined by Kanamycin/PPT-resistance and Southern blot analysis

The three transgenic T1-plants with the highest resveratrol glucoside content as determined in the T2-seeds were characterised for their Kanamycin- and PPT-resistance segregation in T2- 
seeds and analysed by Southern blot hybridisation for the integration of the transgenes in T1plants. The resistance to Kanamycin and PPT of T2 -seeds ( $\mathrm{n}=55)$ was tested in this experiment. It was found, that 9 to 12 from 55 seedlings of each line were not resistant to kanamycin (Tab. 6), indicating a 3:1 inheritance pattern, suggesting that each of the three transformants contain only one T-DNA locus. This seedlings $(n=55)$ were tested to PPT resistance and they showed similar results (Tab. 6). These results correspond to a integra-ted single copy for each resistance marker gene (NPT II, PPT) as determined by Southern blot (Tab. 6; Fig. 4).

Tab.6: Kanamycin and phosphinothricin (PPT) resistance of T2-seedlings and copy number as determined by Southern blot

\begin{tabular}{|c|c|c|c|c|c|c|c|c|}
\hline \multirow[t]{2}{*}{ Line } & \multicolumn{2}{|c|}{$\begin{array}{l}\text { T2-seedlings } \\
\quad(\mathrm{n}=55)\end{array}$} & \multirow{2}{*}{$\begin{array}{c}\text { Segregation } \\
\left(\chi^{2}\right)^{2}\end{array}$} & \multicolumn{2}{|c|}{$\begin{array}{l}\text { T2-seedlings } \\
\quad(\mathrm{n}=55)\end{array}$} & \multirow{2}{*}{$\begin{array}{l}\text { Segregation } \\
\qquad\left(\chi^{2}\right)^{2}\end{array}$} & \multicolumn{2}{|c|}{$\begin{array}{c}\text { Copy } \\
\text { Number }^{4}\end{array}$} \\
\hline & $\mathrm{r}^{1}$ & n.r. ${ }^{1}$ & & $\mathrm{r}^{3}$ & n.r. ${ }^{3}$ & & NPT II & PAT \\
\hline 1502.15 & 44 & 11 & $3: 1(0.7)$ & 47 & 8 & $3: 1(3.2)$ & 1 & 1 \\
\hline 1502.16 & 46 & 9 & $3: 1(2.2)$ & 47 & 8 & $3: 1(3.2)$ & 1 & 1 \\
\hline 1502.17 & 43 & 12 & $3: 1(0.3)$ & 45 & 10 & $3: 1(1.3)$ & 1 & 1 \\
\hline
\end{tabular}

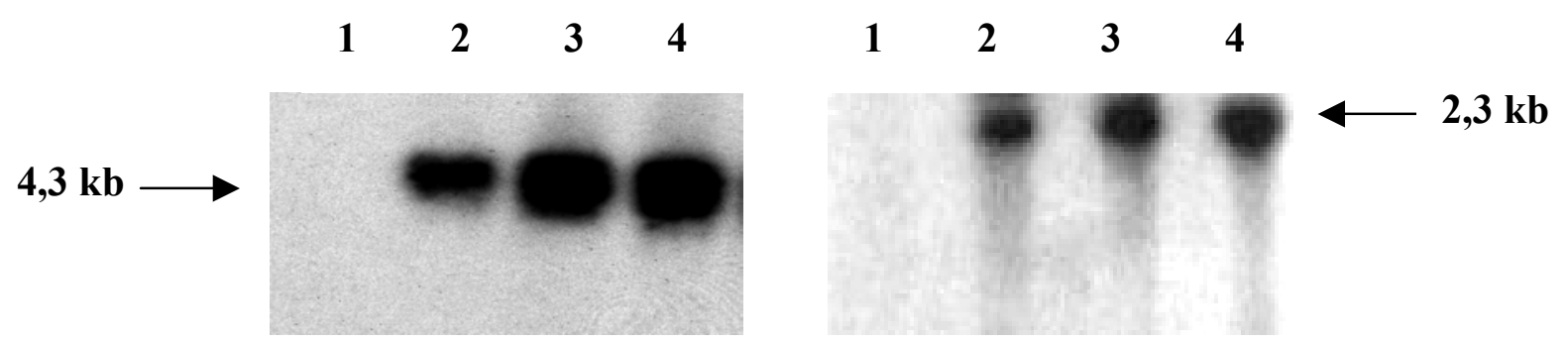

Fig. 4: Southern blot analysis of T1-plants co-transformed with pPSty5+pLH-SGT-GUS plasmids. (a) Hybridisation with NPT-II-probe. (b) Hybridisation with PAT-probe. Lane 1: untransformed control; Lane 2: 1502.15; Lane 3: 1502.16; Lane 4: 1502.17

\section{Resveratrol glucoside and sinapic acid ester content of selected T2-plants}

From each of the three transgenic lines with the highest resveratrol glucoside content and single copy integration for the pPSty5 and pLH-SGT-GUS plasmid 20 T2-seeds were sown together with cv. Drakkar control plants $(n=22)$ in the greenhouse. All T2-plants were normal during the vegetative and reproductive phase of their growth in the greenhouse. There was no difference in other important agronomic traits, like oil, protein, fatty acid and glucosinolate content of harvested T3-seeds in comparison with the control plants (III/4; Tab.7, Tab.8). The average resveratrol glucoside concentration in the T2-plants (T3-seeds) was $310 \pm 52 \mu \mathrm{g} / \mathrm{g}$ for 
line $1502.15,203 \pm 63 \mu \mathrm{g} / \mathrm{g}$ for line 1502.16 and $182 \pm 88 \mu \mathrm{g} / \mathrm{g}$ for line 1502.17 . The highest resveratrol glucoside content $(424 \mu \mathrm{g} / \mathrm{g}$ ) was detec-ted in one T2-plant of line 1502.15 (Tab. 7). The average concentration of total SAE cont-ent in the control plants was $8.40 \pm 0.57$ $\mathrm{mg} / \mathrm{g}$. The average concentration in the T2-plants was $2.80 \pm 1.20 \mathrm{mg} / \mathrm{g}$ for line $1502.15,3.60$ $\pm 1.77 \mathrm{mg} / \mathrm{g}$ for line 1502.16 and $4.30 \pm 2.37 \mathrm{mg} / \mathrm{g}$ for line 1502.17 . In one T2-plant of line 1502.15 with the highest resveratrol glucoside content the total SAE content was reduced to $1.30 \mathrm{mg} / \mathrm{g}$ (Tab. 7). In comparison to the lowest control plant $(7.48 \mathrm{mg} / \mathrm{g})$ the reduction was $83 \%$. The sinapine content in this T2-plant of line 1502.15 was $1.90 \mathrm{mg} / \mathrm{g}$. This means a relative reduction of $75 \%$ in comparison to the lowest control plant with $9.46 \mathrm{mg} / \mathrm{g}$.

Tab.7: Resveratrol glucoside $(\mu \mathrm{g} / \mathrm{g})$, sinapine and total SAE content $(\mathrm{mg} / \mathrm{g})$ in $\mathrm{T} 3-$ seeds of selected T2-plants with the highest resveratrol glucoside content co-transformed with the pPSty5+pLH-SGT-GUS plasmid and of a control plant

\begin{tabular}{lccc}
\hline Line & $\begin{array}{c}\text { Resveratrol } \\
\text { glucoside }\end{array}$ & Sinapine & Total SAE $^{1}$ content \\
\hline Control $^{2}$ & 0.00 & 9.46 & 7.48 \\
1502.15 & 424 & 1.90 & 1.30 \\
1502.16 & 308 & 2.21 & 1.51 \\
1502.17 & 326 & 2.10 & 1.44 \\
\hline
\end{tabular}

${ }^{1}$ calculated as sinapic acid $(\mathrm{mg} / \mathrm{g})$

${ }^{2}$ control plant with the lowest total SAE content (from $n=22$ )

The increase of the resveratrol glucoside in T2-plants is associated with a total SAE reduction with $r_{\mathrm{s}}=-0.69 * *$ (Fig. 5)

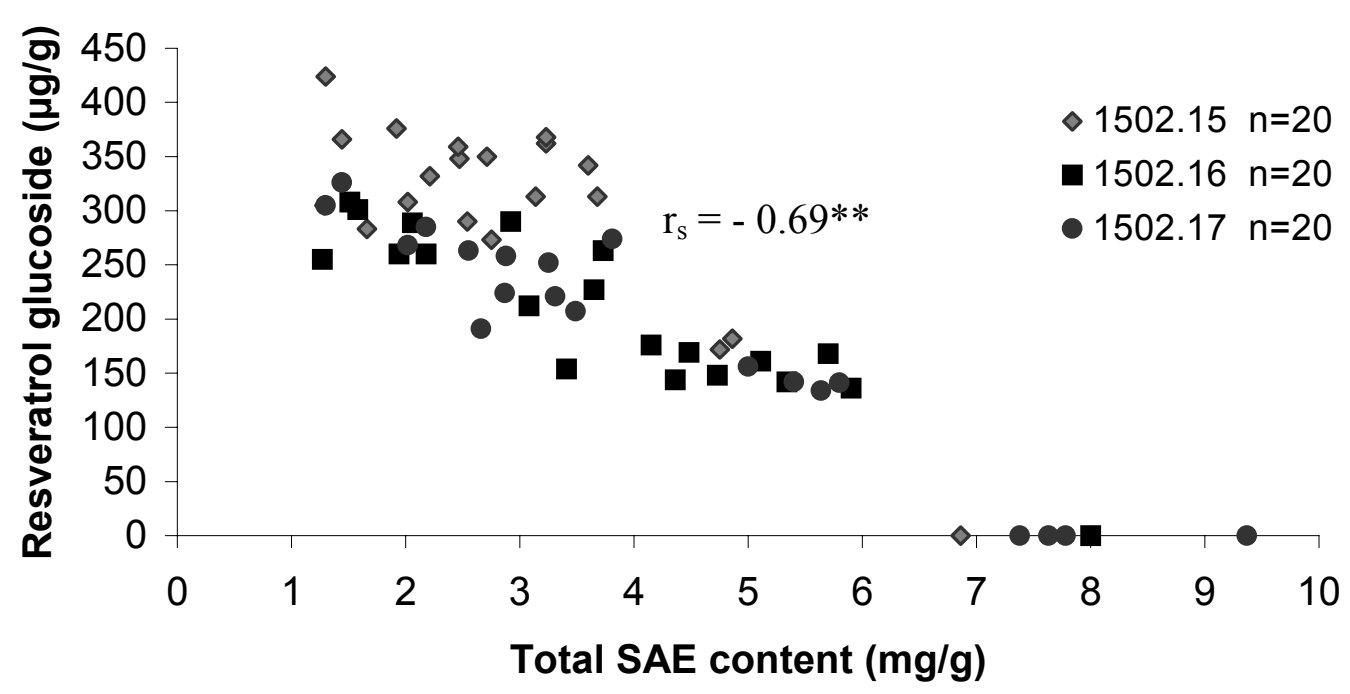

Fig.5: Correlation between resveratrol glucoside and total SAE content in T2-plants $(n=60)$ derived from three T1-plants with the highest resveratrol glucoside content. 
Twenty T2-plants derived from T1-plant 1502.17 were grouped according to their resveratrol glucoside and total SAE content (T3-seeds). By analysing the kanamycin and PPTsegregation of the T3-seedlings of these T2-plants it could be shown that the T2-plants that were homozygous and hemizygous for both integrated genes (VST1+ SGT-dsRNAi) had the highest resveratrol glucoside and the lowest total SAE content (Fig. 6). The T2-plants that were homozygous or hemizygous for the VST1 gene, but were lacking the SGT-dsRNAi gene had an intermediate resveratrol glucoside and total SAE content. The T2-plants carrying only the SGT-dsRNAi gene had a lower total SAE content than the segregating one which did not have either one of the two transgenes. These groups are showing the expected 9:3:3:1 segregation, respectively.

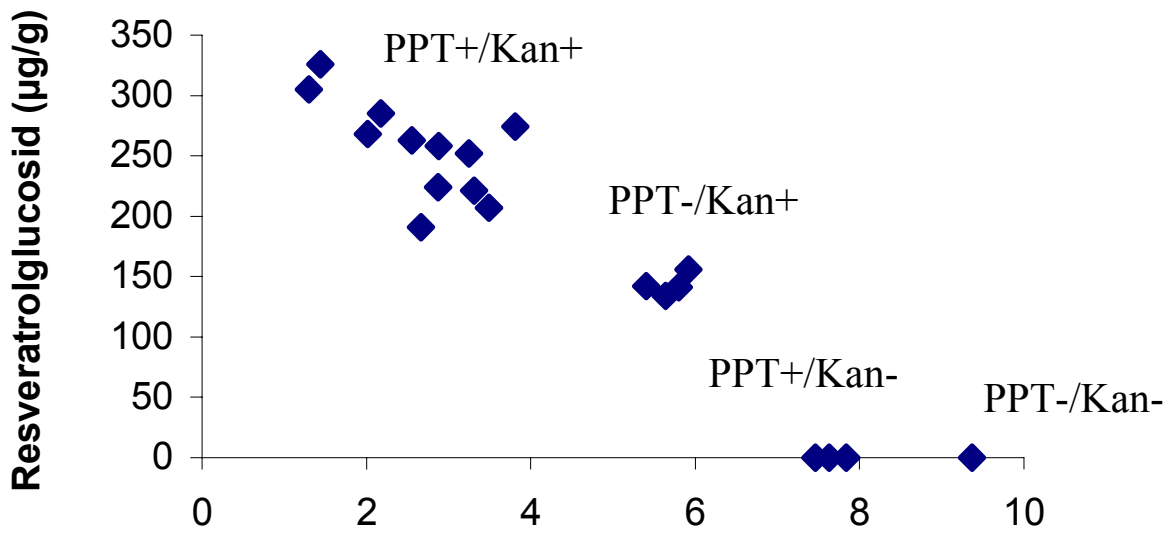

Total SAE content $(\mathrm{mg} / \mathrm{g})$

Fig.6: Resveratrol glucoside $(\mu \mathrm{g} / \mathrm{g})$ and total SAE $(\mathrm{mg} / \mathrm{g})$ content of T3-seeds obtained from T2-plants (line 1502.17, n=20). PPT +/-: Phosphinothricin resistant/not-resistant; Kan +/-: Kanamycin resistant/not-resistant. 


\section{Discussion}

\section{Production of resveratrol glucosid in transgenic plants}

Homozygous transgenic plants containing the VST1 gene from Vitis vinifera and the SGT-dsRNAi gene from Brassica napus produced high levels of resveratrol which was accu-mulated in a glycosidic form. Following the formation of resveratrol, conjugation to sugar or other derivations may occur (SOTHEESWARAN and PASUPATHY, 1993). JEAN-DET et al. (1997) showed that resveratrol glucoside has a shorter retention time than res-veratrol. Resveratrol glucoside accumulation has been described for Vitis (WATER-HOUSE and LAMUELA, 1994), transgenic wheat (FETTIG and HESS, 1998), transgenic kiwi (KOBAYASHI et al; 2000), transgenic alfalfa (HIPSKIND and PAIVA, 2000) and as well as for transgenic rapeseed (ORSINI et al., 2003). Among the transformants obtained, the highest resveratrol glucosid content was $424 \mu \mathrm{g} / \mathrm{g}$ seeds in one T2-plant. Stilbene synthase genes have been introduced in several plant species. In transgenic rice (STARK-LORENZEN et al., 1997), barley and wheat (LECKBAND and LÖRZ, 1998) the resveratrol or resveratrol glucoside content was not examined. The resveratrol $(\mathrm{R})$ levels or resveratrol glucoside (RGlc) levels reported in the literature for wine (50-100 $\mu \mathrm{g} \mathrm{R} / \mathrm{g}$ fresh weight grape skin, LANGCAKE and PRYCE, 1976), transgenic wheat (2 $\mu \mathrm{g}$ RGlc/g fresh weight leaves, FETTIG and HESS, 1998), transgenic kiwi (182 $\mu \mathrm{g} \mathrm{RGlc} / \mathrm{g}$ fresh weight leaves, KOBAYASHI et al, 2000), transgenic alfalfa (20 $\mu \mathrm{g}$ RGlc/g fresh weight leaves, HIPSKIND and PAIVA, 2000) and transgenic rapeseed (159 $\mu \mathrm{g}$ RGlc/g seeds, ORSINI et al., 2003) are considerally lower than the $424 \mu \mathrm{g}$ RGlc/g seeds found in the present study.

KOMARI et al. (1996) reported that tobacco and rice plants co-transformed with two separate T-DNAs by a single bacterial strain (containing two separate T-DNAs) and double bacterial (each strain contain one T-DNA) method contained one locus for each single copy DNA. Linked loci were not favoured in either the double method or the single strain method by using an octopine-type strain for co-transformation. DE BLOCK and DEBROUWER (1991) evaluated linkage of transgenes in Brassica napus transformants produced by a double method. They observed that linked loci were favoured. They used a derivate of a nopalinetype strain C58, and suggested that the use of nopaline-type strains in the double method might favor linked co-transformation. Therefore, the use of C58C1 (nopaline-type) and AGL1 (succinamopine-type) in this experiment may be an importand factor contributing to unlinked loci, i.e. progeny with a single copy integration for both T-DNAs segregating independently for both transgenes. The co-transformation efficiency in the present study amounted $1.8 \%$, it 
is only half of that compared to that found in manuskript I. KOMARI et al. (1996) reported that the frequency of co-transformation was relatively low using the double method compared to the single strain method.

There are conflicting reports about the relationship between transgene copy number and expression level (HOBBS et al., 1993; MCCABE et al., 1999). They have been shown to be negatively correlated (CERVERA et al., 2000; HOBBS et al., 1993; MANNERLÖF et al., 1997), not correlated (BAUER et al., 1998; HOBBS et al., 1993; MCCABE et al., 1999), or positively correlated (GENDLOFF et al., 1990; HOBBS et al., 1993; MCCABE et al., 1999; VOELKER et al. 1996). In many reports, the results were mainly based on analyses of primary transformants (CERVERA et al., 2000; GENDLOFF et al., 1990; HOBBS et al., 1990; MANNERLÖF et al., 1997). HIPSKIND and PAIVA (2000) reported that many of the higher resveratrol glucosid accumulating transgenic alfalfa T1-plants contained only one copy of the VST1 gene, as determined by Southern blot, while the lower accumulating lines contained mostly two or three copies. This confirm the results in the present study, the three selected T1-plants with the highest resveratrol glucoside content contained a single copy for the VST1 gene. Reduced expression levels at higher copy numbers may be due to posttranscriptional-gene-silencing (PICKFORD and COGONI, 2003) or transcriptional-genesilencing (JAKOWITSCH et al., 1998).

While rapeseed does not accumulate resveratrol or its glucosid, it does contain the necessary precursor p-cumaric acid for their biosynthesis. P-cumaric acid is present in rapeseed as a precursor of lignin, flavonoids, isoflavonoids, stilbene and sinapic acid esters. ORSINI et al. (2003) reported that the pPSty5 plasmid (also used in our experiment) was introduced into rapeseed cv. Drakkar. Among the transformants obtained, the highest resveratrol glucosid content in the seeds was $159 \mu \mathrm{g} / \mathrm{g}$. The hypothesis that the suppression of sinapic acid esters may increase the resveratrol production in seeds through additional p-cumaric acid is confirmed. i.e. additional p-cumaric acid present through the suppression of SAE biosynthesis was used for resveratrol glucoside production up to $424 \mu \mathrm{g} / \mathrm{g}$ seeds.

\section{Implications for rapeseed quality improvement}

It was shown, that it is possible to achieve a high amount of resveratrol glucosid $(424 \mu \mathrm{g} / \mathrm{g})$ and a drastical reduction of sinapic acid esters $(1.30 \mathrm{mg} / \mathrm{g})$ in seeds. There was no indication that other important agronomic traits, like oil, protein, fatty acid and glucosinolate content of 
the seeds are affected by expressing the stilbene synthase gene and lowering the sinapic acid ester content. In tobacco and petunia, overexpression of stilbene synthase genes under control of a CaMV $35 \mathrm{~S}$ promoter led to a substrate competition bet-ween stilbene and chalcon synthases causing male sterility (FISCHER et al., 1997). In our experiment, there was no evidence for male sterility due to an overexpression of the stilbene synthase gene, which can be explained by the use of a seed specific napin promoter. ZUM FELDE (2004) studied the correlation of SAE content with other seed quality traits in segregating doubled haploid winter rapeseed populations. They found no significant correlation between SAE and oil, protein, fatty acid and glucosinolate content, respectively. Therefore, a high expression of resveratrol glucosid and a drastical suppression of SAE in B. napus should not have any negative impacts on other important seed quality traits. 


\section{References}

Bauer, M., Libantova, J., Moravcikova, J. and Bekesiova, I., 1998: Transgenic tobaccco plants constitutively expressing acidic chitinase from cucumber. Biologia $\underline{52}$, 749-758.

Bell, J.M., 1993: Factors affecting the nutritional value of Canola Meal: A review. Can. J. Anim. Sci. $\underline{73}$, 679-697.

Bertelli, A., Giovannini, L., Giannessi, D., Migliori, M., Bernini, W. and Fregoni, M., 1995: Antiplatelet activity of synthetic and natural resveratrol in red wine. Int. J. Tissue React $\underline{17}, 1$ 3.

Bouchereau, A., Hamelin, J., Lamour, I., Renard, M. und Larher, F., 1991: Distribution of sinapine and related compounds in seeds of Brassica and allied Genera. Phytochemistry $\underline{30}$, $1873-1881$.

Cevera, M., Pina, J.A., Juarez, J., Navarro, L. and Pena, L., 2000: A broad exploration of a transgenic population of citrus: stability of gene expression and phenotype. Theor. Appl. Genet. 100, 670-677.

Coutos-Thevenot, P., Poinssot, B., Bonomelli, A., Yean, H., Breda, C., Buffard, D., Esnault, R., Hain, R. and Boulay, M., 2000: In vitro tolerance to Botrytis cinera of grapevine 41B rootstock in transgenic plants expressing the stilbene synthase Vst1 gene under the control of a pathogen-inducible PR 10 promoter. J. Exp. Bot. 52, 901-910.

De Block, M., De Brouwer, D. and Tenning, P., 1989: Transformation of Brassica napus and Brassica oleracea using Agrobacterium tumefaciens and the Expression of the bar and neo Genes in the Transgenic Plants. Plant Phyiol. 91, 694-701.

De Block, M. and De Brouwer, D., 1991: Two T- DNA`s cotransformed into Brassica napus by a double Agrobacterium tumefaciens infection are mainly integrated at the same locus.

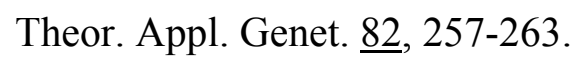


Fettig, S. and Hess, D., 1999: Expression of a chimeric stilbene synthase gene in transgenic wheat lines. Transgenic Research $\underline{8}, 179-189$.

Fischer, R., Budde, I. and Hain, R., 1997: Stilbene synthase gene expression causes changes in flower colour and male sterility in tobacco. Plant J. 11, 489-498.

Frankel, E.N., Waterhouse, A.L. and Kinsella J.E., 1993: Inhibition of human LDL oxidation by resveratrol. Lancet $\underline{24}, 1103-1104$.

Gendloff, E.H., Bowen, B. and Buchholz, W.G., 1990: Quantitation of chloramphenicol acetyl transferase in transgenic tobacco plants by ELISA and correlation with gene copy number. Plant Mol. Biol. 14, 575-583.

Hain, R., Reif, H.J., Krause E., Langebartels, R., Kindl, H., Vornam, B., Wiese, W., Schmelzer, E., Schreier, P.H., Stöcker, R.H. and Stenzel, K., 1993: Disease resistance results from foreign phytoalexin expression in a novel plant. Nature $\underline{361}, 153-156$.

Haussmann, L. und Töpfer, R., 1999: Entwicklung von Plasmid-Vektoren. In: BioEngineering für Rapssorten nach Maß. Vorträge für Pflanzenzüchtung, 4ㅌ, 155-173.

Hellens, R.P., Mullineaux, P. and Klee, H., 2000: A guide to Agrobacterium binary Ti vectors. Trends in Plant Sci. $\underline{5}$ (10), 446-451.

Hipskind, J.D. and Paiva, N.L., 2000: Constitutive accumulation of a resveratrol-glucoside in transgenic alfalfa increases resistance to Phoma medicaginis. Mol. Plant Microbe Interact $\underline{13}$, $551-562$.

Hobbs, S. L.A., Kpodar, P. and DeLong, C.M.O., 1990: The effect of T-DNA copy number, position and methylation on reporter gene expression in tobacco transformants. Plant Mol. Biol. 15, 851-864.

Hobbs, S. L.A., Warkentin, T.D. and DeLong, C.M.O., 1993: Transgene copy number can be positively or negatively associated with transgene expression. Plant Mol. Biol. 21, 17-26. 
Jang, M., Cai, L., Udeani, G.O., Slowing, K.V., Thomas, C.F., Beecher, C.W.W., Fong, H.H.S., Farnswoth, N.R., Kinghorn, A.D., Metha, R.G., Moon, R.C. and Pezzuto, J.M., 1997: Cancer chemopreventive activity of resveratrol, a natural product derived from grapes. Science 275, 218-220.

Jeandet, P., Breuil, A.C., Adrian, M., Weston, L.A., Debord, S., Meunier, P., Maume, G. and Bessis, R., 1997: HPLC analysis of grapevine phytoalexins coupling photodiode array detection and fluorometry. Anal. Chem. $\underline{69}, 5172-5177$.

Jakowitsch, J., Papp, I., Moscone E.A., van der Winden, J., Matzke, M. and Matzke, A.J., 1999: Molecular and cytogenetic characterization of a transgene locus that induces silencing and methylation of homologous promoters in trans. Plant J. 17 (2) $)$ 131-140.

Kimura, Y., Pkuda, H. and Arichi, S., 1985: Effects of stilbenes on arachidonate metabolism in leukocytes. Biochem. Biophys. Acta $\underline{834}, 275-278$.

Kindl, H., 1985: Biosythesis of stilbenes. In: Biosynthesis and biodegradation of wood components (T. Higuchi, Ed.), Academic Press, New York, 349-377.

Kobayashi, S., Ding, C.K., Nakamura, Y., Nakajima, I. and Matsumoto, R., 2000: Kiwifruit (Actinida deliciosa) transformed with a Vitis stilbene synthase gene produce piceid (resveratrol-glucoside). Plant Cell Rep. 19, 904-910.

Komari, T., Hiei, Y., Saito, Y., Murai, N. and Kumashiro, T., 1996: Vectors carrying two TDNA for cotransformation of higher plants mediated by Agrobacterium tumefaciens and segregation of transformants free from selection markers. The Plant Journal 10(1), 165-174.

Kozlowska, H., Naczk, M., Shahidi and Zadernowski, R., 1990: Phenolic acids and tannins in rapeseed and canola, pp. 193-210. In: Shahidi, F. (Ed.), Canola and Rapeseed. Production, Chemistry, Nutrition and Processing Technology. Van Nostrand Reinhold, New York.

Langcake, P., 1981: Disease resistance of Vitis spp. and the production of stress metabolites resveratrol, $\varepsilon$-viniferin, $\alpha$-viniferin and pterostilben. Physiol. Plant Pathol. $\underline{18}$, 213-226. 
Langcake, P. and McCarthy, W.V., 1979: The relationship of resveratrol production to infection of grapevine leaves by Botrytis cinera. Vitis $\underline{18}, 244-253$.

Langcake, P. and Pryce, R.J., 1976: The production of resveratrol by Vitis vinifera and other members of the Vitaceae as a response to infection or injury. Physol. Plant Pathol. $\underline{9}$, 77-86.

Leckband, G. and Lörz, H., 1998: Transformation and expression of a stilbene synthase gene of Vitis vinifera L. in barley and wheat for increased fungal resistance. Theor. Appl. Genet. $\underline{96}$ , 1001-1012 .

Liang, H., Zheng, J., Duan, X., Sheng, B., Jia, S., Wang, D., Ouyang, J., Li, J., Li, L., Tian, W. and Jia, X., 2000: A transgenic wheat with a stilbene synthase gene resistant to powdery mildew obtained by biolistic method. Chinese Science Bulletin, Vol. 45, No. $\underline{7}$, 634-638.

Lorenzen, M., Racicot, V., Strack, D. and Chapple, C., 1996: Sinapic acid ester metabolism in wild type and a sinapoylglucose-accumulating mutant of Arabidopsis. Plant Physiol. 112, 1625-1630.

Manna, S.K., Mukhopadhyay, A. and Aggarwal, B.B., 2000: Resveratrol suppresses TNFinduced activation of nuclear transcription factors NF- $k \mathrm{~B}$, activator protein-1, and apoptosis: potential role of reactive oxygen intermediates and lipid peroxidation. J. Immunol. $164,6509-$ 6519.

Mannerlöf, M., Tuvesson, S., Stehen, P. and Tenning, P., 1997: Transgenic sugar beet tolerant to glyphosate. Euphytica $\underline{94}, 83-91$.

McCabe, M.S., Mohapatra, U.B., Debnath, S.C., Power, J.B and Davey, M.R., 1999: Integration, expression and inheritance of two linked T-DNA marker genes in transgenic lettuce. Mol. Breed. $\underline{5}$, 329-344.

Melchior, F. and Kindl, H., 1990: Grapevine stilbene synthase cDNA only slightly differing from chalcone synthase cDNA is expressed in Escherichia coli into catalytically active enzyme. FEBS Lett 268, 17-20. 
Melchior, F. and Kindl, H., 1991: Coordinate- and elicitor-dependent expression of stilbene synthase and phenylalanine ammonialyase genes in Vitis cv. Optima. Arch. Biochem. Biophys. 288, 552-557.

Milkowski, C., Baumert, A., and Strack, D., 2000: Cloning and heterologous expression of a rape cDNA encoding UDP-glucose: sinapate glucosyltransferase. Planta 211, 883-886.

Murashige, T. and Skoog, F., 1962: A revised medium for rapid growth and bioassays with tobacco tissue cultures. Physiol. Plant $\underline{15}$, 473-497.

Naczk, M., Aramowicz, A., Sullivan, A., and Shahidi, F., 1998: Current research developments on polyphenolics of rapeseed/canola: a review. Food Chemistry $\underline{62}, 489-502$.

Orsini, J., Baumert, A., Milkowski, C., Weyen, J. and Leckband, G., 2003: Agrobacteriummediated production of Brassica napus transgenic plants with a stilbene synthase gene. In: Proceedings $11^{\text {th }}$ International Rapeseed Congress, Copenhagen.

Pace-Asciak, C.R., Hahn, S., Diamanidis, E.P., Soleas, G. and Goldberg, D.M., 1995: The red wine phenolics trans-resveratrol and quercetin block human platelet aggregation and eicosanoid synthesis: implications for protection against coronary heart disease. Clin. Chim. Acta $235,207-219$.

Pickford, A.S. and Cogoni, C., 2003: RNA-mediated gene silencing. Cell. Mol. Life Sci. $\underline{60}$ (5), 871-82.

Rupprich, N. and Kindl, H., 1978: Stilbene synthase and stilbene carboxylate synthases. I. Enzymatic synthesis of 3,5,4,- trihydroxystilbene from p-coumaryl-CoA and malonyl-CoA. Hoppe Seyler's Z. .Physiol. Chem. 359, 165-175.

Schoeppner, A. and Kindl, H., 1979: Stilbene synthase (Pinosylvine synthase) and its function induction by ultraviolet light. FEBS Lett. 108, 125-133.

Schoeppner, A. and Kindl, H., 1984: Purification and properties of a stilbene synthase from induced cell suspension cultures of peanut. J. Biol. Chem. 259, 6806-6811. 
Shahidi, F. and Naczk, M., 1992: An overview of the phenolics of canola and rapeseed: Chemical, sensory and nutritional significance. J. Am. Oil Chem. Soc. $\underline{69}$, 917-924.

Sotheeswaran, S. and Pasuphaty, P., 1993: Distribution of resveratrol oligomers in plants. Phytochemistry $\underline{32}, 1083-1093$.

Stark-Lorenzen, P., Nelke, P., Hänßler, G., Mühlbach, H.P. and Thomzik, J.E., 1997: Tranfer of a grapevine stilbene synthase gene to rice (Oryza sativa L.). Plant Cell Rep. 16, 668-673.

Statistical Graphics Corp. 1997: Statgraphics Plus 3.0, Statistical graphic System by Statistical Grapic Corporation, Rockville.

Stein, U. and Blaich, R., 1985: Untersuchungen über Stilbenproduktion und Botrytisanfälligkeit bei Vitis-Arten. Vitis $\underline{24}, 75-87$.

Strack, D., Knogge, W. and Dahlbender, B., 1983: Enzymatic synthesis of sinapine from 1-0sinapoylglucose and choline by a cell-free system from developing seeds of red radish (Raphanus sativus L.). Zeitschrift für Naturforschung 38c, 21-27.

Subbaramaiah, K., Chung, W.J., Michaluart, P., Telang, N., Tanabe, T., Inoue, H., Jang, M., Pezzuto, J.M. and Dannenberg, A., 1998: Resveratrol inhibits cyclooxygenase-2 transcription and activity in phorbol ester-treated human mammary epithelial cells. J. Biol. Chem. 273, 21875-21882.

Szankowski, I., Briviba, K., Fleschhut, J., Schönherr, J., Jacobsen, H.J. and Kiesecker, H., 2003: Transformation of apple (Malus domestica Borkh.) with the stilbene synthase gene from grapevine (Vitis vinifera L.) and a PGIP gene from kiwi (Actinida deliciosa). Plant Cell Rep. 22, 141-149.

Voelker, T.A., Hayes, T.R., Cranmer, A..M., Turner, J.C. and Davies, H.M., 1996: Genetic engineering of a quantitative trait: metabolic and genetic parameters influencing the accumulation of laurate in rapeseed. Plant J. $\underline{9}, 229-241$. 
Waterhouse, A.L. and Lamuela-Raventos, R.M., 1994: The occurrence of piceid, as a stilbene glucoside, in grape berries. Phytochemistry $37,571-573$.

Zukalova, H. and Vasak, J., 1999: Natural antioxidants in winter rape (Brassica napus L.). In: Rapeseed Congress (CD-Rom). Candorra. Australia.

Zum Felde, T., 2004: Genetische Variation und Vererbung von Sinpingehalt im Raps (Brassica napus L.) und Erstellung von definiertem Ausgangsmaterial. Dissertation, Universität Göttingen, in Vorbereitung. 
III 


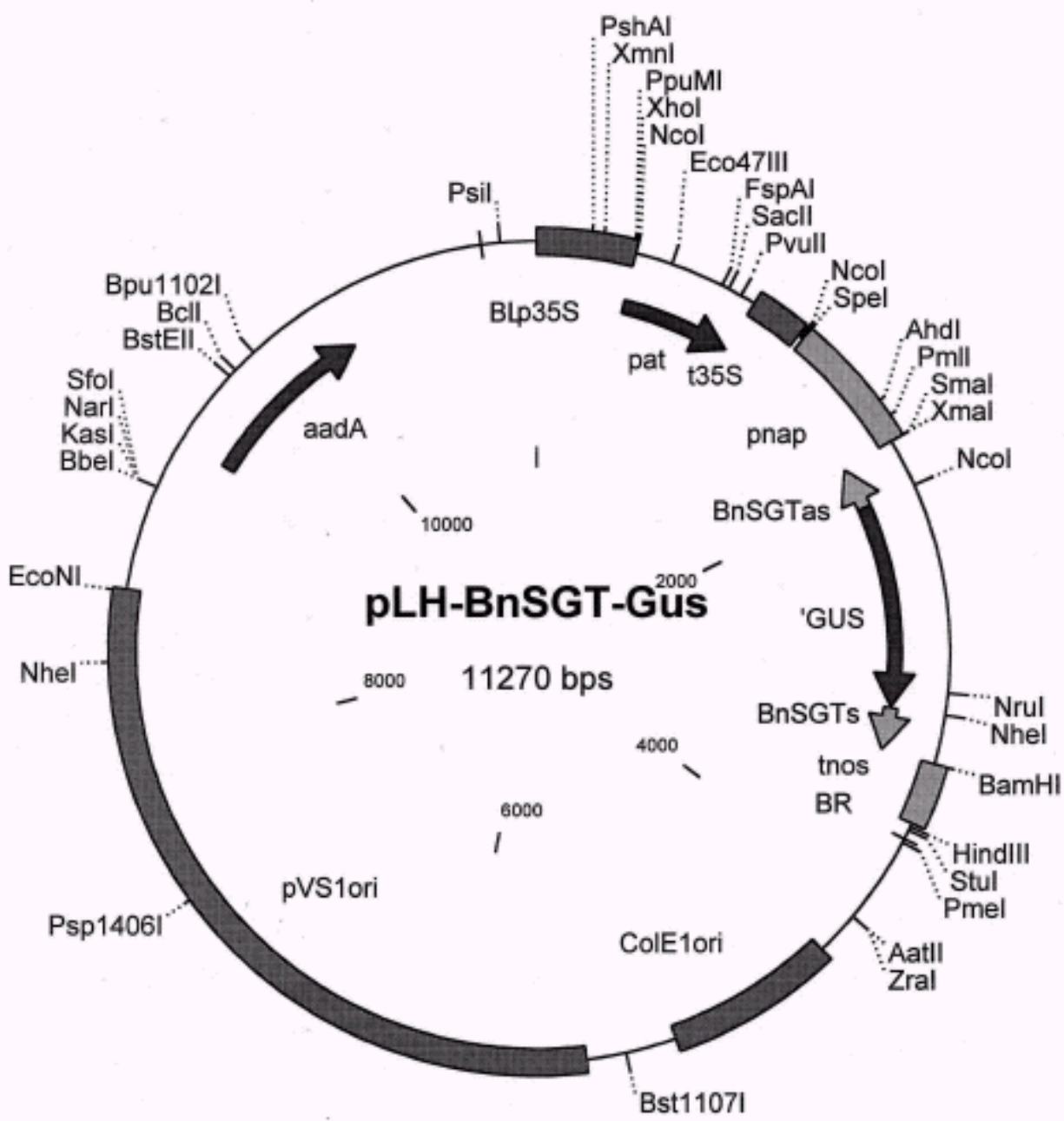

Abb.1: Plasmid pLH-BnSGT-GUS 


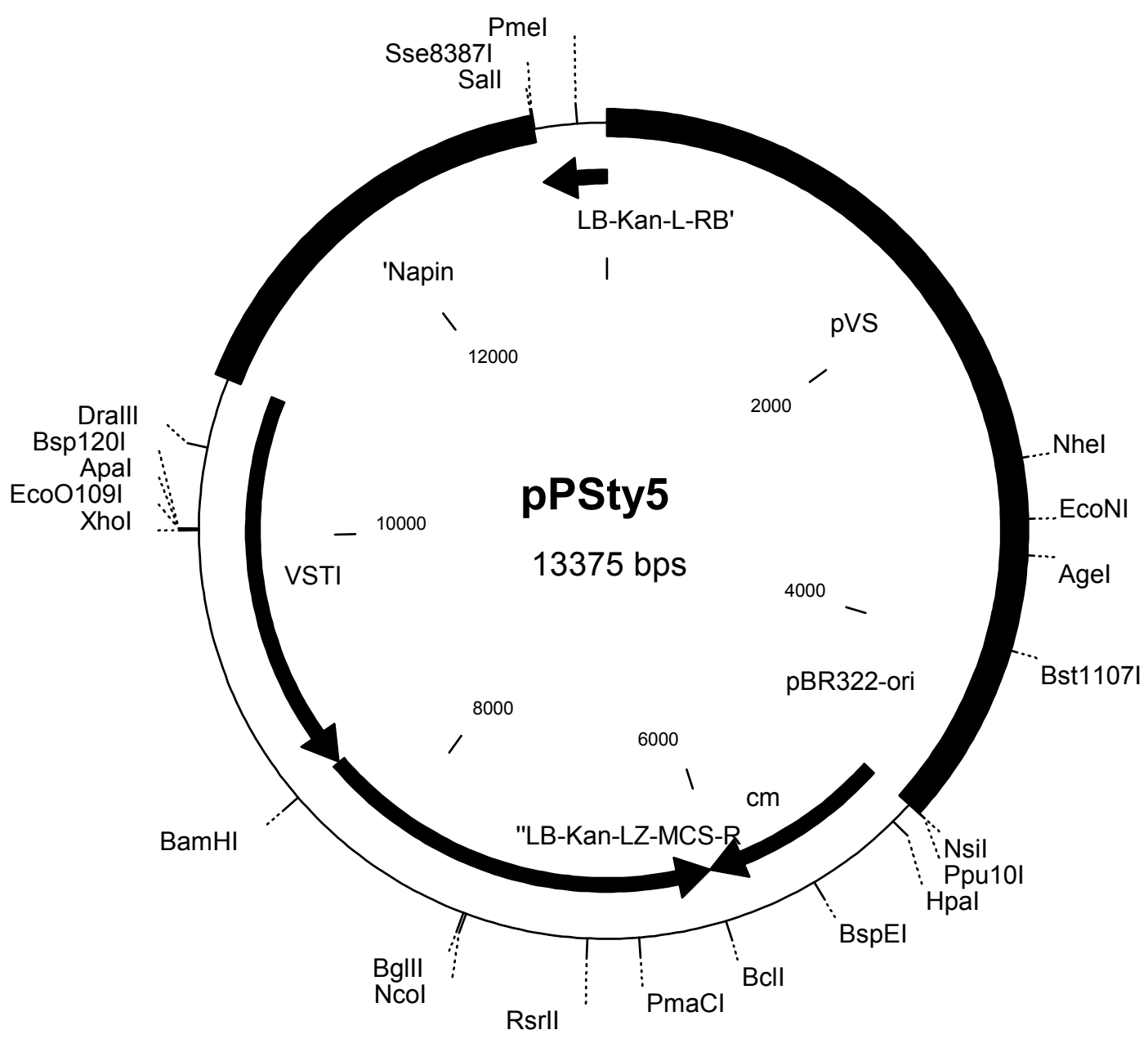

Abb.2: Plasmid pPSty5 
Tab.1: Vergleich (MW \pm SD) zwischen T1-Pflanzen des Genkonstruktes pLH-BnSGT-GUS und Kontrollen bezüglich im Gewächshaus erhobener Merkmale

\begin{tabular}{lll}
\hline & $\begin{array}{l}\text { Kontrolle } \\
\mathbf{n = 3 0}\end{array}$ & $\begin{array}{l}\mathbf{1 5 0 1 . S} \\
\mathbf{n = 3 0}\end{array}$ \\
\hline Blühbeginn (d) & $64,8 \pm 1,7$ & $65,7 \pm 2,6$ \\
Pfl.höhe (cm) & $46,2 \pm 9,1$ & $56,7 \pm 15,8$ \\
Blühende (d) & $89,9 \pm 4,8$ & $88,6 \pm 15,7$ \\
Pfl.höhe (cm) & $117,6 \pm 5,5$ & $119,2 \pm 6,3$ \\
Blühdauer (d) & $25,2 \pm 3,4$ & $22,8 \pm 4,38^{* *}$ \\
TKG (g) & $3,7 \pm 0,3$ & $3,60 \pm 0,42$ \\
g Samen/Pfl. & $7,5 \pm 1,0$ & $7,89 \pm 1,62$ \\
\hline
\end{tabular}

Tab.2: Vergleich (MW \pm SD) zwischen T1-Pflanzen des Genkonstruktes pLH-BnSGT-GUS und Kontrollen bezüglich agronomisch wichtiger Merkmale

\begin{tabular}{|c|c|c|c|c|c|}
\hline & $\begin{array}{l}\text { Kontrolle } \\
\mathbf{n}=\mathbf{3 0}\end{array}$ & $\begin{array}{l}1501 . S \\
n=30\end{array}$ & & $\begin{array}{l}\text { Kontrolle } \\
\mathbf{n}=\mathbf{3 0}\end{array}$ & $\begin{array}{l}1501 . S \\
n=30\end{array}$ \\
\hline Oel (\%) & $44,9 \pm 2,4$ & $44,7 \pm 2,7$ & C18:1 (\%) & $68,5 \pm 2,3$ & $68,2 \pm 2,8$ \\
\hline Protein (\%) & $24,7 \pm 1,9$ & $24,3 \pm 2,4$ & C18:3 (\%) & $6,7 \pm 0,8$ & $6,5 \pm 0,7$ \\
\hline GSL $(\mu \mathrm{mol} / \mathrm{g})$ & $22,4 \pm 2,1$ & $21,2 \pm 3,5$ & C22:1 (\%) & $0,0 \pm 0,0$ & $0,0 \pm 0,0$ \\
\hline
\end{tabular}

Tab.3 : Vergleich (MW \pm SD) zwischen T1-Pflanzen der Genkonstrukte pLH-BnSGT-GUS + pPSty5 und Kontrollen bezüglich im Gewächshaus erhobener Merkmale

\begin{tabular}{lll}
\hline & $\begin{array}{l}\text { Kontrolle } \\
\mathbf{n = 3 0}\end{array}$ & $\begin{array}{l}\mathbf{1 5 0 2 . S} \\
\mathbf{n = 2 8}\end{array}$ \\
\hline Blühbeginn (d) & $64,8 \pm 1,7$ & $65,8 \pm 3,3$ \\
Pfl.höhe (cm) & $46,2 \pm 9,1$ & $62,7 \pm 12,9 * *$ \\
Blühende (d) & $89,9 \pm 4,8$ & $88,6 \pm 7,2$ \\
Pfl.höhe (cm) & $117,6 \pm 5,5$ & $118,6 \pm 8,4$ \\
Blühdauer (d) & $25,2 \pm 3,4$ & $22,8 \pm 4,5 * *$ \\
TKG (g) & $3,7 \pm 0,3$ & $3,6 \pm 0,4$ \\
g Samen/Pfl. & $7,5 \pm 1,0$ & $7,7 \pm 1,5$ \\
\hline
\end{tabular}

Tab.4 : Vergleich (MW \pm SD) zwischen T1-Pflanzen der Genkonstrukte pLH-BnSGT-GUS + pPSty5 und Kontrollen bezüglich agronomisch wichtiger Merkmale

\begin{tabular}{|c|c|c|c|c|c|}
\hline & $\begin{array}{l}\text { Kontrolle } \\
\mathbf{n}=\mathbf{3 0}\end{array}$ & $\begin{array}{l}1502 . S \\
n=28\end{array}$ & & $\begin{array}{l}\text { Kontrolle } \\
\mathbf{n}=\mathbf{3 0}\end{array}$ & $\begin{array}{l}1502 . S \\
n=28\end{array}$ \\
\hline Oel (\%) & $44,9 \pm 2,4$ & $43,6 \pm 2,9$ & C18:1 (\%) & $68,5 \pm 2,3$ & $67,6 \pm 2,9$ \\
\hline Protein (\%) & $24,7 \pm 1,9$ & $25,7 \pm 1,9$ & C18:3 (\%) & $6,7 \pm 0,8$ & $6,9 \pm 1,2$ \\
\hline GSL $(\mu \mathrm{mol} / \mathrm{g})$ & $22,4 \pm 2,1$ & $22,7 \pm 3,2$ & C22:1 (\%) & $0,0 \pm 0,0$ & $0,0 \pm 0,0$ \\
\hline
\end{tabular}


Tab.5: Vergleich (MW \pm SD) zwischen T2-Pflanzen des Genkonstruktes pLH-BnSGT-GUS und Kontrollen bezüglich im Gewächshaus erhobener Merkmale

\begin{tabular}{lcc}
\hline & $\begin{array}{c}\text { Kontrolle } \\
\mathbf{n}=\mathbf{2 2}\end{array}$ & $\begin{array}{c}\mathbf{1 5 0 1 . S} \\
\mathbf{n = 6 0}\end{array}$ \\
\hline Blühbeginn (d) & $59,3 \pm 1,7$ & $60,5 \pm 2,5$ \\
Pfl.höhe (cm) & $57,2 \pm 10,6$ & $59,6 \pm 7,5$ \\
Blühende (d) & $82,3 \pm 3,7$ & $81,5 \pm 6,4$ \\
Pfl.höhe (cm) & $122,8 \pm 7,5$ & $123,4 \pm 4,3$ \\
Blühdauer (d) & $22,5 \pm 1,23$ & $22,6 \pm 2,8$ \\
TKG (g) & $3,2 \pm 0,6$ & $3,3 \pm 0,6$ \\
g Samen/Pfl. & $2,9 \pm 1,64$ & $3,0 \pm 1,3$ \\
\hline
\end{tabular}

Tab.6: Vergleich (MW $\pm \mathrm{SD})$ zwischen T2-Pflanzen des Genkonstruktes pLH-BnSGT-GUS und Kontrollen bezüglich agronomisch wichtiger Merkmale

\begin{tabular}{lccccc}
\hline & $\begin{array}{c}\text { Kontrolle } \\
\mathbf{n = 2 2}\end{array}$ & $\begin{array}{c}\mathbf{1 5 0 1 . S} \\
\mathbf{n = 6 0}\end{array}$ & & $\begin{array}{c}\text { Kontrolle } \\
\mathbf{n = 2 2}\end{array}$ & $\begin{array}{c}\mathbf{1 5 0 1 . S} \\
\mathbf{n = 6 0}\end{array}$ \\
\hline Oel (\%) & $37,7 \pm 1,3$ & $38,2 \pm 1,5$ & $\mathbf{C 1 8 : 1}(\boldsymbol{\%})$ & $71,4 \pm 2,5$ & $71,0 \pm 2,1$ \\
Protein (\%) & $20,4 \pm 0,6$ & $20,0 \pm 0,8$ & $\mathbf{C 1 8 : 3 ( \% )}$ & $6,2 \pm 0,7$ & $6,0 \pm 0,6$ \\
GSL $(\boldsymbol{\mu m o l} / \mathbf{g})$ & $22,0 \pm 5,3$ & $20,2 \pm 3,8$ & $\mathbf{C 2 2 : 1 ( \% )}$ & $0,0 \pm 0,0$ & $0,0 \pm 0,0$ \\
\hline
\end{tabular}

Tab.7 : Vergleich (MW \pm SD) zwischen T2-Pflanzen der Genkonstrukte pLH-BnSGT-GUS + pPSty5 und Kontrollen bezüglich im Gewächshaus erhobener Merkmale

\begin{tabular}{lll}
\hline & $\begin{array}{l}\text { Kontrolle } \\
\mathbf{n = 2 2}\end{array}$ & $\begin{array}{l}\mathbf{1 5 0 2 . S} \\
\mathbf{n = 6 0}\end{array}$ \\
\hline Blühbeginn (d) & $59,3 \pm 1,7$ & $59,7 \pm 3,2$ \\
Pfl.höhe (cm) & $57,2 \pm 10,6$ & $60,6 \pm 7,8$ \\
Blühende (d) & $82,3 \pm 3,7$ & $80,4 \pm 5,5$ \\
Pfl.höhe (cm) & $122,8 \pm 7,5$ & $123,2 \pm 4,3$ \\
Blühdauer (d) & $22,5 \pm 1,23$ & $21,5 \pm 2,8$ \\
TKG (g) & $3,2 \pm 0,6$ & $3,5 \pm 0,4$ \\
g Samen/Pfl. & $2,9 \pm 1,64$ & $3,6 \pm 1,3^{* *}$ \\
\hline
\end{tabular}

Tab.8 : Vergleich (MW \pm SD) zwischen T2-Pflanzen der Genkonstrukte pLH-BnSGT-GUS + pPSty5 und Kontrollen bezüglich agronomisch wichtiger Merkmale

\begin{tabular}{|c|c|c|c|c|c|}
\hline & $\begin{array}{c}\text { Kontrolle } \\
\mathbf{n}=\mathbf{2 2}\end{array}$ & $\begin{array}{l}1502 . S \\
n=60\end{array}$ & & $\begin{array}{c}\text { Kontrolle } \\
\mathbf{n}=\mathbf{2 2} \\
\end{array}$ & $\begin{array}{l}1502 . S \\
\mathrm{n}=60\end{array}$ \\
\hline Oel (\%) & $37,7 \pm 1,3$ & $38,3 \pm 1,3$ & C18:1 (\%) & $71,4 \pm 2,5$ & $71,5 \pm 2,1$ \\
\hline Protein (\%) & $20,4 \pm 0,6$ & $20,2 \pm 0,6$ & C18:3 (\%) & $6,2 \pm 0,7$ & $6,2 \pm 0,6$ \\
\hline GSL $(\mu \mathrm{mol} / \mathrm{g})$ & $22,0 \pm 5,3$ & $20,7 \pm 3,2$ & C22:1 (\%) & $0,0 \pm 0,0$ & $0,0 \pm 0,0$ \\
\hline
\end{tabular}




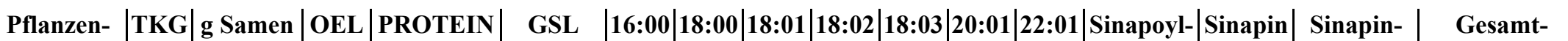

\begin{tabular}{|c|c|c|c|c|c|c|c|c|c|c|c|c|c|c|c|c|}
\hline Nr. & (g) & /Pfl. & $(\%)$ & (\%) & $(\mu \mathrm{mol} / \mathrm{g})$ & $(\%)$ & (\%) & $(\%)$ & $(\%)$ & $(\%)$ & (\%) & $(\%)$ & $\begin{array}{c}\text { glucose } \\
(\mathrm{mg} / \mathrm{g})\end{array}$ & $(\mathrm{mg} / \mathrm{g})$ & $\begin{array}{l}\text { säurerest } \\
\text { (mg/g) }\end{array}$ & $\begin{array}{c}\text { Sinapinsäure- } \\
\text { ester (mg/g) }\end{array}$ \\
\hline 1501.1 & 3,03 & 7,18 & 47,46 & 20,94 & 12,55 & 4,65 & 4,48 & 66,92 & 13,31 & 6,57 & 1,19 & 0,37 & 2,45 & 7,80 & 1,33 & 8,37 \\
\hline 1501.2 & 3,53 & 6,48 & 44,69 & 23,13 & 23,97 & 5,67 & 3,64 & 64,95 & 14,88 & 6,50 & 1,52 & 0,24 & 0,39 & 5,64 & 0,26 & 4,55 \\
\hline 1501.3 & 3,45 & 7,92 & 43,02 & 25,40 & 21,12 & 4,72 & 2,77 & 69,68 & 12,80 & 6,49 & 1,44 & 0,21 & 2,05 & 8,04 & 1,21 & 8,19 \\
\hline 1501.4 & 3,23 & 3,43 & 45,33 & 24,91 & 25,49 & 4,75 & 3,35 & 68,59 & $|14,06|$ & 5,85 & 1,54 & 0,00 & 0,48 & 8,39 & 0,51 & 6,83 \\
\hline 1501.5 & 3,38 & 6,85 & 49,20 & 22,67 & 13,00 & 4,55 & 3,69 & 66,24 & 15,16 & 7,01 & 1,28 & 0,00 & 0,66 & 4,84 & 0,19 & 4,06 \\
\hline 1501.6 & 3,05 & 6,08 & 43,75 & 22,76 & 20,40 & 4,51 & 4,16 & 60,28 & 20,00 & 6,92 & 1,23 & 0,12 & 0,12 & 5,30 & 0,00 & 3,83 \\
\hline 1501.7 & 3,18 & 8,60 & 46,57 & 23,24 & 18,13 & 4,26 & 2,69 & 68,90 & 14,61 & 6,67 & 1,36 & 0,00 & 2,85 & 8,50 & 1,36 & 9,13 \\
\hline 1501.8 & 3,10 & 8,67 & 41,54 & 28,59 & 23,77 & 4,18 & 4,33 & 68,99 & 13,43 & 6,13 & 1,17 & 0,00 & 3,05 & 8,34 & 1,35 & 9,12 \\
\hline 1501.9 & 3,20 & 8,69 & 45,82 & 24,70 & 21,56 & 4,27 & 4,78 & 65,80 & 15,64 & 6,37 & 1,09 & 0,00 & 0,81 & 5,23 & 0,32 & 4,56 \\
\hline 1501.10 & 3,35 & 6,89 & 40,05 & 28,77 & 26,36 & 4,43 & 3,60 & 64,25 & 17,76 & 6,85 & 1,17 & 0,00 & 0,47 & 4,49 & 0,19 & 3,70 \\
\hline 1501.11 & 3,55 & 9,10 & 45,07 & 23,83 & 20,82 & 3,93 & 5,51 & 69,07 & 11,99 & 6,21 & 1,14 & 0,00 & 2,28 & 8,19 & 1,26 & 8,48 \\
\hline 1501.12 & 3,78 & 10,33 & 38,89 & 30,16 & 29,40 & 3,85 & 8,26 & 65,00 & 13,21 & 6,43 & 1,03 & 0,00 & 0,41 & 5,10 & 0,43 & 4,34 \\
\hline 1501.13 & 3,75 & 9,72 & 46,58 & 23,11 & 21,08 & 3,71 & 5,98 & 66,94 & 13,26 & 7,16 & 1,10 & 0,00 & 3,75 & 9,06 & 1,91 & 10,61 \\
\hline 1501.14 & 3,68 & 9,02 & 44,72 & 25,21 & 20,53 & 4,07 & 3,48 & 71,21 & 11,93 & 6,22 & 1,19 & 0,00 & 3,90 & 8,72 & 1,59 & 10,13 \\
\hline 1501.15 & 4,48 & 9,13 & 46,14 & 22,02 & 19,17 & 4,75 & 2,83 & 67,40 & 14,23 & 7,90 & 1,15 & 0,00 & 2,66 & 8,86 & 1,26 & 9,18 \\
\hline 1501.16 & 3,35 & 8,27 & 43,65 & 24,71 & 22,11 & 4,78 & 2,80 & 69,90 & 12,86 & 6,72 & 1,20 & 0,00 & 2,30 & 8,49 & 1,28 & 8,73 \\
\hline 1501.17 & 3,53 & 8,12 & 44,22 & 25,14 & 20,43 & 4,21 & 2,68 & 70,17 & 12,98 & 6,61 & 1,20 & 0,00 & 3,17 & 8,35 & 1,50 & 9,35 \\
\hline 1501.18 & 3,98 & 9,29 & 47,41 & 22,47 & 17,79 & 3,58 & 2,66 & 70,96 & 13,06 & 6,09 & 1,11 & 0,00 & 3,00 & 8,30 & 1,69 & 9,41 \\
\hline 1501.19 & 3,63 & 9,06 & 49,48 & 21,33 & 22,36 & 4,58 & 2,55 & 67,53 & 13,87 & 7,56 & 1,51 & 0,00 & 2,75 & 8,72 & 1,53 & 9,40 \\
\hline 1501.20 & 3,95 & 5,95 & 47,49 & 23,14 & 19,86 & 5,06 & 3,14 & 67,59 & 14,83 & 6,43 & 1,18 & 0,00 & 0,58 & 9,52 & 0,52 & 7,71 \\
\hline 1501.21 & 4,40 & 5,48 & 47,34 & 22,47 & 18,09 & 4,95 & 3,11 & 64,42 & 16,11 & 8,35 & 1,01 & 0,00 & 1,24 & 10,88 & 0,56 & 9,11 \\
\hline 1501.22 & 4,13 & 7,85 & 44,22 & 27,21 & 21,92 & 4,44 & 2,62 & 68,19 & 14,44 & 6,83 & 1,12 & 0,00 & 3,08 & 9,78 & 1,73 & 10,56 \\
\hline 1501.23 & 4,13 & 9,27 & 46,86 & 23,07 & 18,52 & 5,28 & 2,63 & 66,24 & 15,31 & 7,56 & 1,24 & 0,00 & 3,20 & 9,68 & 1,41 & 10,24 \\
\hline 1501.25 & 3,30 & 7,13 & 42,84 & 25,91 & 23,36 & 4,03 & 2,53 & 72,65 & 12,21 & 5,91 & 1,37 & 0,00 & 1,06 & 7,18 & 1,22 & 7,00 \\
\hline 1501.26 & 4,70 & 8,68 & 44,29 & 25,80 & 26,86 & 4,18 & 2,58 & 72,35 & 12,76 & 5,28 & 1,37 & 0,00 & 0,20 & 3,71 & 0,07 & 2,86 \\
\hline 1501.24 & 3,15 & 6,71 & 39,26 & 30,39 & 23,89 & 4,73 & 2,68 & 71,16 & 12,94 & 5,54 & 1,36 & 0,00 & 0,00 & 4,02 & 0,00 & 2,84 \\
\hline 1501.27 & 3,15 & 9,81 & 42,97 & 26,44 & 22,38 & 4,41 & 2,47 & 70,61 & 14,27 & 5,83 & 1,27 & 0,00 & 1,42 & 6,08 & 1,01 & 6,21 \\
\hline 1501.28 & 4,13 & 8,99 & 47,31 & 23,62 & 20,63 & 4,27 & 3,14 & 69,72 & 14,28 & 5,84 & 1,26 & 0,00 & 1,47 & 6,31 & 1,41 & 6,81 \\
\hline 1501.29 & 3,65 & 8,83 & 41,23 & 29,51 & 21,52 & 4,50 & 2,68 & 70,42 & 13,79 & 5,73 & 1,37 & 0,00 & 0,72 & 6,50 & 1,14 & 6,24 \\
\hline 1501.30 & 3,08 & 7,63 & 44,67 & 25,36 & 19,70 & 4,28 & 2,61 & 71,54 & 13,32 & 5,42 & 1,40 & 0,00 & 2,03 & 7,62 & 1,06 & 7,72 \\
\hline $1501.1 \mathrm{~K}$ & 3,39 & 5,79 & 50,79 & 19,92 & 21,57 & 4,36 & 3,00 & 65,48 & 16,86 & 7,30 & 1,12 & 0,00 & 1,62 & 9,75 & 0,98 & 8,94 \\
\hline $1501.2 \mathrm{~K}$ & 4,17 & 9,19 & 45,01 & 24,94 & 24,00 & 4,12 & 2,77 & 68,10 & 14,56 & 7,23 & 1,01 & 0,00 & 2,16 & 8,46 & 1,47 & 8,81 \\
\hline $1501.3 \mathrm{~K}$ & 3,42 & 7,47 & 43,61 & 27,22 & 21,13 & 3,92 & 2,68 & 71,81 & 12,35 & 5,42 & 1,19 & 0,00 & 2,34 & 8,06 & 1,24 & 8,40 \\
\hline $1501.4 \mathrm{~K}$ & 3,96 & 8,96 & 44,86 & 25,17 & 18,80 & 3,83 & 2,84 & 72,80 & $|11,25|$ & 5,64 & 1,13 & 0,00 & 2,55 & 7,61 & 1,18 & 8,14 \\
\hline
\end{tabular}




\begin{tabular}{|c|c|c|c|c|c|c|c|c|c|c|c|c|c|c|c|c|}
\hline $\begin{array}{c}\text { Pflanzen- } \\
\text { Nr. }\end{array}$ & $\begin{array}{c}\text { TKG } \\
(\mathrm{g})\end{array}$ & $\begin{array}{c}\text { g Samen } \\
\text { /Pfl. }\end{array}$ & $\left|\begin{array}{c}\text { OEL } \\
(\%)\end{array}\right|$ & $\begin{array}{c}\text { PROTEIN } \\
(\%)\end{array}$ & $\begin{array}{c}\text { GSL } \\
(\mu \mathrm{mol} / \mathrm{g})\end{array}$ & $\begin{array}{c}16: 00 \\
(\%)\end{array}$ & $\begin{array}{c}18: 00 \\
(\%)\end{array}$ & $\left|\begin{array}{c}18: 01 \\
(\%)\end{array}\right|$ & $\begin{array}{c}18: 02 \\
(\%)\end{array}$ & $\begin{array}{c}18: 03 \\
(\%)\end{array}$ & $\begin{array}{c}20: 01 \\
(\%)\end{array}$ & $\begin{array}{c}22: 01 \\
(\%)\end{array}$ & $\begin{array}{c}\text { Sinapoyl- } \\
\text { glucose } \\
\text { (mg/g) } \\
\end{array}$ & $\left|\begin{array}{c}\text { Sinapin } \\
(\mathrm{mg} / \mathrm{g})\end{array}\right|$ & $\begin{array}{c}\text { Sinapin- } \\
\text { säurerest } \\
(\mathrm{mg} / \mathrm{g}) \\
\end{array}$ & $\begin{array}{c}\text { Gesamt- } \\
\text { Sinapinsäure- } \\
\text { ester (mg/g) }\end{array}$ \\
\hline $1501.5 \mathrm{~K}$ & 3,54 & 7,91 & 48,53 & 23,04 & 23,88 & 3,89 & 2,68 & 69,92 & 13,57 & 7,25 & 0,94 & 0,00 & 2,92 & 8,26 & 1,46 & 9,10 \\
\hline $1501.6 \mathrm{~K}$ & 3,39 & 7,40 & 41,34 & 26,19 & 29,73 & 3,89 & 4,12 & 67,28 & 14,76 & 6,73 & 1,08 & 0,00 & 2,15 & 8,65 & 1,79 & 9,26 \\
\hline $1501.7 \mathrm{~K}$ & 3,24 & 7,09 & 42,22 & 27,05 & 22,95 & 4,09 & 2,89 & 66,98 & 16,11 & 6,92 & 1,13 & 0,00 & 2,04 & 8,55 & 1,07 & 8,41 \\
\hline $1501.8 K$ & 3,57 & 7,33 & 45,62 & 24,55 & 19,80 & 3,96 & 5,81 & 65,47 & 14,25 & 7,11 & 1,06 & 0,00 & 2,32 & 8,67 & 1,72 & 9,31 \\
\hline $1501.9 K$ & 3,18 & 6,08 & 46,77 & 23,03 & 20,26 & 4,08 & 3,93 & 68,20 & 14,23 & 6,28 & 1,10 & 0,00 & 2,18 & 9,56 & 1,46 & 9,61 \\
\hline $1501.10 \mathrm{~K}$ & 3,81 & 7,31 & 45,13 & 23,00 & 19,30 & 3,89 & 2,96 & 72,64 & 11,79 & 5,50 & 1,16 & 0,00 & 2,62 & 8,12 & 1,25 & 8,62 \\
\hline $1501.11 \mathrm{~K}$ & 3,90 & 7,79 & 43,62 & 24,29 & 23,35 & 4,09 & 2,78 & 68,54 & 14,91 & 6,28 & 1,41 & 0,00 & 2,03 & 9,00 & 1,01 & 8,67 \\
\hline $1501.12 K$ & 3,90 & 8,48 & 42,08 & 26,58 & 23,52 & 4,31 & 2,51 & 68,78 & 14,97 & 6,50 & 1,31 & 0,00 & 2,18 & 8,44 & 1,32 & 8,66 \\
\hline 1501.13K & 3,81 & 8,09 & 42,58 & 25,35 & 25,73 & 3,99 & 2,58 & 70,79 & 13,06 & 6,34 & 1,13 & 0,00 & 2,55 & 8,68 & 0,86 & 8,59 \\
\hline $1501.14 K$ & 4,08 & 8,04 & 43,48 & 26,32 & 22,24 & 3,65 & 3,78 & 71,01 & 13,06 & 6,27 & 1,11 & 0,00 & 3,14 & 8,24 & 1,50 & 9,25 \\
\hline $1501.15 K$ & 3,66 & 8,09 & 44,97 & 23,99 & 22,25 & 3,93 & 2,76 & 69,70 & 13,23 & 7,56 & 1,08 & 0,00 & 2,74 & 8,54 & 1,13 & 8,87 \\
\hline $1501.16 \mathrm{~K}$ & 3,60 & 7,63 & 42,34 & 28,53 & 22,19 & 3,94 & 3,22 & 68,27 & 14,42 & 7,58 & 1,04 & 0,00 & 2,27 & 8,40 & 1,14 & 8,50 \\
\hline $1501.17 \mathrm{~K}$ & 3,90 & 8,22 & 42,33 & 27,16 & 22,98 & 4,05 & 2,66 & 67,43 & 16,32 & 6,30 & 1,17 & 0,00 & 2,79 & 7,87 & 1,11 & 8,39 \\
\hline 1501.18K & 3,90 & 9,11 & 44,87 & 24,89 & 20,67 & 3,96 & 2,27 & 69,09 & 14,54 & 7,48 & 1,04 & 0,00 & 3,23 & 9,03 & 1,73 & 10,10 \\
\hline $1501.19 K$ & 3,69 & 6,77 & 47,30 & 21,86 & 22,75 & 3,91 & 3,60 & 67,97 & 14,40 & 7,52 & 1,03 & 0,00 & 1,94 & 9,14 & 0,92 & 8,63 \\
\hline $1501.20 \mathrm{~K}$ & 3,90 & 8,60 & 48,20 & 22,53 & 21,88 & 4,21 & 2,54 & 67,73 & 16,08 & 6,51 & 1,22 & 0,00 & 2,13 & 8,42 & 1,57 & 8,87 \\
\hline $1501.21 \mathrm{~K}$ & 3,51 & 6,23 & 44,83 & 24,58 & 21,57 & 4,04 & 2,67 & 64,36 & 17,60 & 7,49 & 1,15 & 0,00 & 1,34 & 8,24 & 1,08 & 7,79 \\
\hline $1501.22 \mathrm{~K}$ & 3,99 & 6,93 & 45,57 & 24,80 & 18,78 & 4,00 & 2,68 & 66,25 & 16,47 & 7,19 & 1,07 & 0,00 & 2,55 & 9,33 & 1,86 & 10,06 \\
\hline $1501.23 \mathrm{~K}$ & 3,93 & 8,97 & 47,34 & 22,76 & 22,09 & 3,87 & 2,64 & 68,11 & 14,88 & 7,65 & 1,06 & 0,00 & 3,10 & 8,98 & 2,07 & 10,33 \\
\hline $1501.24 K$ & 3,81 & 7,08 & 44,46 & 24,51 & 23,61 & 3,78 & 2,97 & 73,71 & 11,21 & 5,22 & 1,12 & 0,00 & 2,93 & 8,05 & 1,45 & 8,95 \\
\hline $1501.25 \mathrm{~K}$ & 3,42 & 7,60 & 47,15 & 23,47 & 22,05 & 4,29 & 2,67 & 68,57 & 15,35 & 6,25 & 1,14 & 0,00 & 1,88 & 8,06 & 1,46 & 8,35 \\
\hline $1501.26 \mathrm{~K}$ & 3,36 & 7,14 & 39,60 & 28,41 & 23,18 & 4,02 & 3,10 & 70,31 & 14,12 & 5,07 & 1,27 & 0,00 & 1,38 & 7,44 & 1,18 & 7,34 \\
\hline $1501.27 \mathrm{~K}$ & 3,96 & 7,83 & 46,16 & 24,02 & 22,21 & 4,18 & 2,89 & 67,75 & 15,50 & 6,83 & 1,10 & 0,00 & 2,62 & 7,69 & 1,78 & 8,84 \\
\hline $1501.28 \mathrm{~K}$ & 3,78 & 7,27 & 46,14 & 22,58 & 23,34 & 3,98 & 4,79 & 65,49 & 15,23 & 7,76 & 1,06 & 0,00 & 2,21 & 8,57 & 1,65 & 9,10 \\
\hline $1501.29 \mathrm{~K}$ & 3,60 & 7,92 & 45,81 & 23,80 & 21,25 & 4,40 & 2,69 & 67,50 & 15,51 & 7,31 & 1,11 & 0,00 & 1,78 & 7,89 & 1,68 & 8,39 \\
\hline $1501.30 \mathrm{~K}$ & 3,21 & 4,94 & 45,24 & 25,25 & 21,97 & 4,36 & 3,01 & 66,09 & 16,77 & 6,53 & 1,21 & 0,00 & 1,21 & 8,13 & 0,72 & 7,28 \\
\hline 1501.6.1 & 2,90 & 1,90 & 8,08 & 19,60 & 19,37 & 3,86 & 1,66 & 68,69 & 17,70 & 5,52 & 1,04 & 0,00 & 0 & 6,58 & 0,00 & 4,50 \\
\hline 1501.6.2 & 3,00 & 1,74 & 37,77 & 19,74 & 18,29 & 2,40 & 1,71 & 68,48 & 18,93 & 6,40 & 0,95 & 0,00 & 0,00 & 6,04 & 0,00 & 4,14 \\
\hline 1501.6 .3 & 2,05 & 2,02 & 37,22 & 20,36 & 18,73 & 3,91 & 1,56 & 68,37 & 17,73 & 6,24 & 0,89 & 0,00 & 0,00 & 6,94 & 0,00 & 4,75 \\
\hline 1501.6.4 & 3,00 & 1,65 & 38,69 & 19,53 & 18,71 & 1,06 & 1,67 & 73,02 & 15,74 & 6,14 & 1,40 & 0,00 & 0,00 & 10,62 & 0,35 & 8,00 \\
\hline 1501.6.5 & 2,70 & 3,18 & 38,59 & 19,81 & 16,75 & 4,44 & 1,69 & 70,32 & 15,81 & 5,75 & 1,38 & 0,00 & 0,00 & 5,72 & 0,13 & 4,25 \\
\hline 1501.6.6 & 3,25 & 1,93 & 38,49 & 19,63 & 19,21 & 3,01 & 1,59 & 71,45 & 16,55 & 5,98 & 1,02 & 0,00 & 0,00 & 6,15 & 0,00 & 4,33 \\
\hline 1501.6.7 & 3,45 & 2,48 & 37,68 & 20,34 & 22,29 & 1,51 & 1,79 & 72,91 & 15,60 & 6,49 & 1,12 & 0,00 & 0,00 & 4,52 & 0,00 & 3,10 \\
\hline 1501.6 .8 & 3,20 & 2,78 & $38,30 \mid$ & 19,58 & 16,35 & 4,26 & 1,55 & $|71,78|$ & 15,08 & 5,51 & 1,07 & 0,00 & 0,00 & 5,93 & 0,00 & 4,06 \\
\hline
\end{tabular}


Pflanzen- $\mid$ TKG $\mid$ g Samen $\mid$ OEL $\mid$ PROTEIN| GSL $\mid$ 16:00| 18:00|18:01|18:02 |18:03|20:01|22:01|Sinapoyl- $\mid$ Sinapin $\mid$ Sinapin- $\mid$ Gesamt-

\begin{tabular}{|c|c|c|c|c|c|c|c|c|c|c|c|c|c|c|c|c|}
\hline Nr. & (g) & /Pfl. & $(\%)$ & $(\%)$ & $(\mu \mathrm{mol} / \mathrm{g})$ & $\begin{array}{l}1 \% 00 \\
(\%)\end{array}$ & $(\%)$ & $\begin{array}{l}10.01 \\
(\%)\end{array}$ & $\begin{array}{c}10.02 \\
(\%)\end{array}$ & $\begin{array}{c}10.03 \\
(\%)\end{array}$ & $\begin{array}{l}20.01 \\
(\%)\end{array}$ & $(\%)$ & $\begin{array}{l}\text { glucose } \\
(\mathrm{mg} / \mathrm{g})\end{array}$ & (mg/g) & $\begin{array}{c}\text { säurerest } \\
(\mathrm{mg} / \mathrm{g})\end{array}$ & $\begin{array}{l}\text { Sinapinsäure- } \\
\text { ester (mg/g) }\end{array}$ \\
\hline 1501.6 .9 & 3,10 & 2,31 & 38,50 & 19,53 & 15,42 & 3,07 & 1,69 & 74,01 & 14,95 & 5,50 & 0,78 & 0,00 & 0,00 & 3,67 & 0,00 & 2,52 \\
\hline 1501.6.10 & 2,30 & 1,49 & 37,32 & 20,36 & 20,46 & 3,83 & 1,51 & 69,06 & 17,47 & 6,25 & 1,17 & 0,00 & 0,00 & 4,80 & 0,00 & 3,45 \\
\hline 1501.6.11 & 3,00 & 2,01 & 37,75 & 19,96 & 21,58 & 4,27 & 1,71 & 67,50 & 18,08 & 6,19 & 0,98 & 0,00 & 0,00 & 7,36 & 0,00 & 5,20 \\
\hline 1501.6.12 & 2,75 & 2,42 & 37,55 & 19,56 & 17,87 & 3,43 & 1,64 & 71,72 & 15,68 & 5,44 & 0,94 & 0,00 & 0,00 & 11,28 & 0,27 & 8,39 \\
\hline 1501.6.13 & 2,65 & 3,32 & 38,14 & 19,63 & 18,37 & 4,08 & 1,60 & 69,82 & 16,33 & 6,18 & 0,91 & 0,00 & 0,00 & 9,78 & 0,58 & 7,62 \\
\hline 1501.6.14 & 3,05 & 2,24 & 37,47 & 20,22 & 21,10 & 4,61 & 1,75 & 68,53 & 15,76 & 5,94 & 2,24 & 0,00 & 0,00 & 3,86 & 0,00 & 2,64 \\
\hline 1501.6.15 & 2,60 & 0,41 & 32,11 & 20,32 & 27,61 & 4,00 & 3,86 & 72,89 & 11,21 & 4,04 & 1,73 & 0,43 & 0,00 & 3,48 & 0,00 & 2,40 \\
\hline 1501.6.16 & 2,30 & 1,20 & 37,14 & 20,51 & 20,96 & 3,78 & 1,57 & 71,27 & 16,36 & 5,54 & 0,92 & 0,00 & 0,00 & 11,83 & 0,05 & 8,57 \\
\hline 1501.6.17 & 2,75 & 1,92 & 38,12 & 20,10 & 15,81 & 4,30 & 1,56 & 70,29 & 15,97 & 6,09 & 0,99 & 0,00 & 0,00 & 4,39 & 0,00 & 3,00 \\
\hline 1501.6.18 & 2,90 & 0,81 & 37,55 & 20,23 & 21,70 & 4,08 & 1,51 & 68,52 & 17,66 & 6,22 & 1,08 & 0,00 & 0,00 & 4,68 & 0,00 & 3,21 \\
\hline 1501.6.19 & 2,65 & 2,95 & 38,04 & 19,60 & 18,66 & 3,64 & 1,68 & 69,95 & 17,11 & 6,00 & 0,96 & 0,00 & 0,00 & 5,22 & 0,00 & 3,70 \\
\hline 1501.6.20 & 2,10 & 1,24 & 36,35 & 20,91 & 22,36 & 3,83 & 1,57 & 70,38 & 16,53 & 5,99 & 1,09 & 0,00 & 0,00 & 3,33 & 0,00 & 2,28 \\
\hline 1501.24.1 & 3,75 & 2,06 & 37,78 & 20,61 & 26,02 & 3,84 & 1,38 & 70,14 & 16,64 & 6,38 & 0,94 & 0,00 & 0,00 & 3,26 & 0,00 & 2,23 \\
\hline 1501.24.2 & 3,85 & 2,17 & 37,50 & 20,96 & 27,08 & 3,98 & 1,42 & 69,75 & 16,91 & 6,24 & 0,95 & 0,00 & 0,00 & 12,54 & 0,00 & 9,00 \\
\hline 1501.24 .3 & 2,00 & 0,35 & 35,92 & 22,01 & 32,03 & 4,06 & 1,82 & 71,74 & 14,63 & 5,72 & 1,12 & 0,00 & 0,08 & 11,72 & 0,14 & 8,58 \\
\hline 1501.24.4 & 3,85 & 2,36 & 38,70 & 20,48 & 21,36 & 3,79 & 1,60 & 69,18 & 17,55 & 6,25 & 0,93 & 0,00 & 0,00 & 4,33 & 0,00 & 2,97 \\
\hline 1501.24.5 & 2,90 & 6,57 & 40,31 & 18,82 & 17,24 & 4,03 & 1,44 & 70,68 & 15,88 & 6,06 & 1,00 & 0,00 & 0,00 & 5,56 & 0,00 & 3,96 \\
\hline 1501.24 .6 & 3,70 & 2,78 & 37,87 & 20,13 & 23,66 & 3,93 & 1,62 & 69,66 & 16,96 & 5,93 & 1,03 & 0,00 & 0,00 & 4,33 & 0,04 & 3,16 \\
\hline 1501.24 .7 & 3,80 & 3,23 & 38,43 & 20,03 & 22,45 & 3,55 & 1,62 & 70,43 & 16,08 & 5,93 & 1,27 & 0,00 & 0,00 & 3,97 & 0,00 & 2,72 \\
\hline 1501.24 .8 & 3,70 & 1,51 & 37,54 & 20,06 & 19,98 & 3,79 & 1,72 & 72,50 & 14,56 & 6,03 & 0,70 & 0,00 & 0,00 & 11,97 & 0,00 & 8,36 \\
\hline 1501.24 .9 & 2,80 & 5,60 & 41,47 & 17,97 & 14,58 & 3,25 & 1,46 & 68,52 & 18,48 & 6,14 & 1,14 & 0,13 & 0,17 & 10,87 & 0,75 & 8,58 \\
\hline 1501.24.10 & 3,25 & 3,39 & 37,87 & 20,63 & 23,40 & 3,85 & 1,48 & 68,16 & 17,57 & 6,55 & 1,52 & 0,16 & 0,00 & 10,00 & 0,00 & 7,10 \\
\hline 1501.24.11 & 3,25 & 5,04 & 39,19 & 19,74 & 18,30 & 3,71 & 1,37 & 69,87 & 16,53 & 6,34 & 1,16 & 0,00 & 0,00 & 8,08 & 0,00 & 5,53 \\
\hline 1501.24.12 & 3,30 & 2,32 & 36,66 & 21,63 & 24,62 & 4,03 & 1,35 & 66,84 & 18,84 & 7,54 & 0,94 & 0,00 & 0,00 & 7,03 & 0,00 & 4,81 \\
\hline 1501.24.13 & 3,10 & 5,16 & 39,78 & 19,32 & 17,50 & 3,66 & 1,32 & 70,01 & 16,59 & 7,42 & 0,70 & 0,00 & 0,00 & 10,31 & 0,27 & 7,69 \\
\hline 1501.24.14 & 3,70 & 2,63 & 37,09 & 21,30 & 26,40 & 3,98 & 1,28 & 66,22 & 19,19 & 7,80 & 0,80 & 0,20 & 0,00 & 12,20 & 0,00 & 8,71 \\
\hline 1501.24.15 & 3,30 & 4,45 & 38,80 & 19,96 & 15,03 & 3,89 & 1,53 & 72,45 & 14,76 & 5,78 & 0,98 & 0,00 & 0,00 & 6,02 & 0,04 & 4,37 \\
\hline 1501.24.16 & 3,30 & 1,98 & 37,90 & 20,63 & 23,53 & 3,76 & 1,65 & 71,98 & 15,08 & 6,10 & 0,97 & 0,00 & 0,00 & 4,50 & 0,00 & 3,08 \\
\hline 1501.24.17 & 2,70 & 5,89 & 41,48 & 17,76 & 15,68 & 4,00 & 1,64 & 72,08 & 15,43 & 5,29 & 0,95 & 0,00 & 0,00 & 6,60 & 0,00 & 4,72 \\
\hline 1501.24.18 & 2,40 & 6,21 & 41,08 & 18,04 & 14,66 & 3,90 & 1,45 & 69,16 & 17,49 & 6,73 & 0,78 & 0,00 & 0,00 & 2,66 & 0,00 & 1,82 \\
\hline 1501.24.19 & 3,40 & 4,36 & 39,01 & 19,81 & 19,10 & 3,37 & 1,42 & 71,23 & 16,26 & 6,01 & 1,09 & 0,20 & 0,00 & 3,93 & 0,00 & 2,69 \\
\hline 1501.24 .20 & 1,85 & 0,61 & 34,99 & 22,22 & 29,96 & 4,38 & 1,60 & 66,29 & 19,19 & 7,06 & 0,85 & 0,13 & 0,00 & 11,75 & 0,00 & 8,38 \\
\hline 1501.26.1 & 2,66 & 6,61 & 40,93 & 18,78 & 15,40 & 3,91 & 1,30 & 71,93 & 15,21 & 6,52 & 0,80 & 0,00 & 0,00 & 4,84 & 0,00 & 3,31 \\
\hline 1501.26 .2 & 2,70 & 4,79 & 38,84 & 20,24 & 16,09 & 3,91 & 1,39 & 72,23 & 14,50 & 5,87 & 1,08 & 0,38 & 0,00 & 4,95 & 0,00 & 3,45 \\
\hline 1501.26 .3 & 3,63 & 3,77 & 38,43 & 20,17 & 17,03 & 3,95 & 1,54 & 71,76 & 15,27 & 5,77 & 1,01 & 0,00 & 0,00 & 8,15 & 1,93 & 7,80 \\
\hline
\end{tabular}




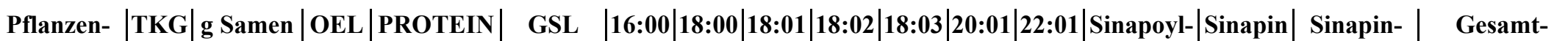

\begin{tabular}{|c|c|c|c|c|c|c|c|c|c|c|c|c|c|c|c|c|}
\hline Nr. & (g) & /Pfl. & $\begin{array}{l}\text { OEL } \\
(\%)\end{array}$ & $(\%)$ & $(\mu \mathrm{mol} / \mathrm{g})$ & $\begin{array}{c}10.00 \\
(\%)\end{array}$ & $(\%)$ & $(\%)$ & $\begin{array}{c}10.02 \\
(\%)\end{array}$ & $(\%)$ & $\begin{array}{c}20.01 \\
(\%)\end{array}$ & (\%) & $\begin{array}{l}\text { glucose } \\
\text { (mg/g) }\end{array}$ & (mg/g) & $\begin{array}{c}\text { säurerest } \\
(\mathrm{mg} / \mathrm{g})\end{array}$ & $\begin{array}{c}\text { Sinapinsäure- } \\
\text { ester (mg/g) }\end{array}$ \\
\hline 1501.26 .4 & 3,76 & 3,58 & 38,41 & 20,36 & 20,05 & 3,90 & 1,64 & 72,32 & 14,79 & 5,47 & 0,97 & 0,00 & 0,00 & 9,97 & 0,22 & 7,40 \\
\hline 1501.26 .5 & 2,86 & 5,13 & 40,10 & 19,08 & 16,14 & 3,83 & 1,45 & 72,83 & 14,68 & 5,66 & 0,95 & 0,11 & 0,00 & 3,70 & 0,00 & 2,54 \\
\hline 1501.26 .6 & 2,86 & 5,43 & 39,74 & 19,44 & 15,11 & 3,91 & 1,45 & 72,82 & 14,78 & 5,63 & 0,90 & 0,00 & 0,00 & 6,30 & 0,00 & 4,31 \\
\hline 1501.26.7 & 3,46 & 5,05 & 38,45 & 19,94 & 17,00 & 3,88 & 1,53 & 72,36 & 14,69 & 5,91 & 0,97 & 0,10 & 0,00 & 10,16 & 0,10 & 7,42 \\
\hline 1501.26 .8 & 4,00 & 2,05 & 38,24 & 20,21 & 20,12 & 3,84 & 1,62 & 72,87 & 14,45 & 5,72 & 1,01 & 0,00 & 0,00 & 8,94 & 1,31 & 7,75 \\
\hline 1501.26.9 & 3,20 & 4,11 & 38,55 & 20,21 & 21,58 & 3,22 & 1,63 & 72,78 & 15,14 & 5,65 & 0,89 & 0,00 & 0,00 & 8,86 & 0,75 & 7,13 \\
\hline 1501.26.10 & 3,20 & 4,88 & 39,51 & 18,91 & 16,95 & 3,73 & 1,37 & 70,89 & 15,79 & 6,48 & 0,90 & 0,00 & 0,00 & 5,46 & 0,00 & 3,74 \\
\hline 1501.26.11 & 3,13 & 3,75 & 38,40 & 19,69 & 20,48 & 3,55 & 1,69 & 73,54 & 13,46 & 5,34 & 1,00 & 0,00 & 0,00 & 5,92 & 0,00 & 4,06 \\
\hline 1501.26.12 & 3,56 & 3,43 & 37,60 & 20,93 & 19,68 & 3,82 & 1,54 & 73,06 & 14,20 & 5,45 & 1,01 & 0,00 & 0,00 & 3,27 & 0,00 & 2,24 \\
\hline 1501.26 .13 & 3,66 & 3,54 & 38,55 & 19,75 & 18,12 & 3,43 & 1,59 & 73,37 & 13,79 & 5,47 & 1,11 & 0,00 & 0,00 & 5,62 & 0,00 & 3,85 \\
\hline 1501.26.14 & 3,50 & 3,56 & 38,56 & 19,88 & 20,14 & 3,88 & 1,69 & 73,43 & 13,78 & 5,16 & 1,01 & 0,00 & 0,00 & 8,69 & 1,16 & 7,42 \\
\hline 1501.26.15 & 3,40 & 1,53 & 36,82 & 20,95 & 26,04 & 3,95 & 1,75 & 72,68 & 14,91 & 5,34 & 0,79 & 0,17 & 0,00 & 6,81 & 0,00 & 4,67 \\
\hline 1501.26.16 & 3,73 & 2,92 & 38,79 & 20,10 & 19,00 & 3,86 & 1,55 & 73,66 & 14,07 & 5,27 & 0,88 & 0,00 & 0,00 & 4,57 & 0,00 & 3,14 \\
\hline 1501.26.17 & 3,33 & 3,12 & 37,70 & 20,76 & 21,07 & 3,98 & 1,75 & 71,03 & 15,84 & 5,52 & 0,99 & 0,00 & 0,26 & 9,93 & 1,60 & 8,90 \\
\hline 1501.26 .18 & 3,83 & 3,23 & 38,72 & 20,13 & 21,23 & 3,61 & 1,56 & 76,45 & 11,63 & 5,11 & 0,92 & 0,00 & 0,00 & 5,93 & 0,00 & 4,06 \\
\hline 1501.26.19 & 3,46 & 3,25 & 38,33 & 20,23 & 20,29 & 3,94 & 1,62 & 72,50 & 14,60 & 5,44 & 0,93 & 0,00 & 0,00 & 5,39 & 0,16 & 4,04 \\
\hline 1501.26 .20 & 3,40 & 2,07 & 36,56 & 21,25 & 23,92 & 3,90 & 1,75 & 71,90 & 15,39 & 5,44 & 0,85 & 0,00 & 0,00 & 4,62 & 0,00 & 3,16 \\
\hline $1501.1 \mathrm{~K}$ & 3,10 & 4,08 & 38,72 & 20,05 & 16,33 & 3,72 & 1,79 & 74,24 & 13,32 & 5,14 & 1,03 & 0,00 & 0,00 & 10,64 & 0,28 & 7,94 \\
\hline $1501.2 \mathrm{~K}$ & 3,26 & 3,70 & 38,58 & 20,33 & 18,24 & 3,64 & 1,60 & 73,52 & 14,02 & 5,24 & 1,20 & 0,00 & 0,28 & 10,66 & 0,32 & 8,00 \\
\hline $1501.3 K$ & 2,86 & 0,55 & 36,48 & 21,28 & 26,94 & 3,92 & 1,77 & 72,89 & 13,94 & 5,52 & 1,17 & 0,00 & 0,00 & 12,92 & 0,00 & 9,11 \\
\hline $1501.4 \mathrm{~K}$ & 3,03 & 2,55 & 36,54 & 21,07 & 24,59 & 3,48 & 1,94 & 71,10 & 15,23 & 6,24 & 1,11 & 0,00 & 0,18 & 12,20 & 0,36 & 9,14 \\
\hline $1501.5 \mathrm{~K}$ & 3,66 & 2,95 & 38,63 & 19,92 & 23,89 & 3,93 & 1,77 & 72,89 & 13,28 & 5,73 & 1,21 & 0,00 & 0,00 & 13,10 & 0,00 & 9,21 \\
\hline $1501.6 \mathrm{~K}$ & 2,23 & 1,62 & 37,21 & 21,04 & 26,47 & 3,71 & 1,73 & 72,63 & 14,21 & 6,15 & 0,92 & 0,00 & 0,00 & 11,22 & 0,00 & 7,98 \\
\hline $1501.7 \mathrm{~K}$ & 3,03 & 4,28 & 38,95 & 20,08 & 16,81 & 3,55 & 1,74 & 72,42 & 14,36 & 6,10 & 1,11 & 0,00 & 0,24 & 10,20 & 0,66 & 8,00 \\
\hline $1501.8 K$ & 2,96 & 2,94 & 37,53 & 20,82 & 15,82 & 3,68 & 1,63 & 73,26 & 13,06 & 6,12 & 1,17 & 0,00 & 0,00 & 7,53 & 2,25 & 7,67 \\
\hline $1501.9 \mathrm{~K}$ & 3,50 & 3,12 & 38,01 & 20,55 & 20,20 & 3,78 & 1,52 & 73,18 & 13,23 & 6,40 & 1,08 & 0,00 & 0,00 & 12,44 & 0,17 & 9,13 \\
\hline $1501.10 \mathrm{~K}$ & 2,76 & 4,75 & 39,87 & 19,06 & 15,47 & 3,85 & 1,61 & 73,09 & 13,19 & 6,05 & 1,15 & 0,00 & 0,22 & 10,14 & 0,51 & 7,81 \\
\hline 1501.11K & 2,76 & 3,15 & 37,79 & 20,54 & 17,40 & 3,89 & 1,72 & 73,32 & 12,92 & 5,85 & 1,09 & 0,00 & 0,20 & 10,42 & 0,63 & 8,13 \\
\hline $1501.12 K$ & 2,76 & 0,68 & 35,76 & 20,29 & 32,42 & 4,36 & 1,72 & 68,71 & 16,61 & 6,42 & 1,00 & 0,00 & 0,00 & 9,46 & 0,00 & 7,48 \\
\hline $1501.13 K$ & 3,40 & 3,44 & 38,38 & 20,37 & 20,32 & 4,40 & 1,80 & 68,85 & 16,55 & 6,70 & 0,93 & 0,00 & 0,00 & 11,16 & 0,00 & 8,03 \\
\hline $1501.14 K$ & 2,80 & 5,65 & 39,80 & 19,52 & 13,30 & 3,70 & 1,72 & 74,41 & 12,22 & 5,73 & 1,09 & 0,00 & 0,30 & 10,24 & 0,68 & 8,05 \\
\hline $1501.15 K$ & 3,00 & 4,50 & 39,75 & 19,31 & 15,90 & 3,76 & 1,67 & 74,32 & 12,10 & 5,78 & 1,22 & 0,00 & 0,33 & 10,15 & 0,84 & 8,15 \\
\hline $1501.16 \mathrm{~K}$ & 2,60 & 2,55 & 36,61 & 20,52 & 24,52 & 3,96 & 1,58 & 71,42 & 14,44 & 6,31 & 1,07 & 0,00 & 0,00 & 11,63 & 0,06 & 8,43 \\
\hline $1501.17 \mathrm{~K}$ & 2,46 & 2,80 & 37,10 & 20,05 & 29,04 & 4,26 & 1,66 & 69,18 & 16,19 & 6,44 & 1,01 & 0,00 & 0,00 & 11,68 & 0,00 & 8,10 \\
\hline
\end{tabular}




\begin{tabular}{|c|c|c|c|c|c|c|c|c|c|c|c|c|c|c|c|c|}
\hline $\begin{array}{c}\text { Pflanzen- } \\
\text { Nr. }\end{array}$ & $\begin{array}{c}\text { TKG } \\
(\mathrm{g})\end{array}$ & $\begin{array}{c}\text { g Samen } \\
\text { /Pfl. }\end{array}$ & $\begin{array}{l}\text { OEL } \\
(\%)\end{array}$ & $\begin{array}{c}\text { PROTEIN } \\
(\%)\end{array}$ & $\begin{array}{c}\text { GSL } \\
(\mu \mathrm{mol} / \mathrm{g})\end{array}$ & $\mid \begin{array}{c}16: 00 \\
(\%)\end{array}$ & $\begin{array}{c}18: 00 \\
(\%)\end{array}$ & \begin{tabular}{|c}
$18: 01$ \\
$(\%)$
\end{tabular} & $\begin{array}{c}18: 02 \\
(\%)\end{array}$ & $\begin{array}{c}18: 03 \\
(\%)\end{array}$ & $\mid \begin{array}{c}20: 01 \\
(\%)\end{array}$ & \begin{tabular}{|c}
$22: 01$ \\
$(\%)$
\end{tabular} & \begin{tabular}{|} 
Sinapoyl- \\
glucose \\
$(\mathrm{mg} / \mathrm{g})$ \\
\end{tabular} & $\begin{array}{c}\text { Sinapin } \\
(\mathrm{mg} / \mathrm{g})\end{array}$ & $\begin{array}{c}\text { Sinapin- } \\
\text { säurerest } \\
(\mathrm{mg} / \mathrm{g}) \\
\end{array}$ & $\begin{array}{c}\text { Gesamt- } \\
\text { Sinapinsäure- } \\
\text { ester (mg/g) }\end{array}$ \\
\hline & & & & & & & & & & & & & & & & 8,77 \\
\hline & 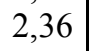 & & & & 2 & 2 & 1,60 & 8 & & & 0,86 & 0 & & & & \\
\hline 150 & 2,76 & 0,69 & 04 & 21,70 & 26,64 & 4,45 & 1,69 & 65,79 & 18,32 & 7,59 & 1,06 & 0,00 & 0,22 & & 0, & 10,55 \\
\hline $1501.21 \mathrm{~K}$ & 2,66 & 2,26 & 36,75 & 21,10 & 22,76 & 4,30 & 1,65 & 65,99 & 18,31 & 7,63 & 0,97 & 0,00 & 0,00 & 10,20 & 0,21 & 7,55 \\
\hline $1501.22 \mathrm{~K}$ & 2,53 & 3,19 & 36,66 & 21,00 & 22,54 & 3,99 & 1,56 & 71,41 & 14,80 & 6,10 & 1,05 & 0,00 & 0,00 & 12,11 & 0,34 & 9,06 \\
\hline
\end{tabular}

\begin{tabular}{|c|c|c|c|c|c|c|c|c|c|c|c|c|c|c|c|c|c|}
\hline $\begin{array}{c}\text { Pflanzen- } \\
\text { Nr. }\end{array}$ & $\begin{array}{c}\text { TKG } \\
\text { (g) }\end{array}$ & $\begin{array}{c}\text { g Samen } \\
\text { /Pfl. }\end{array}$ & $\left|\begin{array}{c}\text { OEL } \\
(\%)\end{array}\right|$ & $\begin{array}{c}\text { PROTEIN } \\
(\%)\end{array}$ & $\begin{array}{c}\text { GSL } \\
(\mu \mathrm{mol} / \mathrm{g})\end{array}$ & $\begin{array}{c}16: 00 \\
(\%)\end{array}$ & $\begin{array}{c}\text { 18:00 } \\
(\%)\end{array}$ & $\mid \begin{array}{c}18: 01 \\
(\%)\end{array}$ & $\left|\begin{array}{c}18: 02 \\
(\%)\end{array}\right|$ & $\begin{array}{c}18: 03 \\
(\%)\end{array}$ & $\begin{array}{c}20: 01 \\
(\%)\end{array}$ & $\begin{array}{c}22: 01 \\
(\%)\end{array}$ & \begin{tabular}{|c|} 
Sinapoyl- \\
glucose \\
$(\mathrm{mg} / \mathrm{g})$
\end{tabular} & $\left|\begin{array}{c}\text { Sinapin } \\
(\mathrm{mg} / \mathrm{g})\end{array}\right|$ & $\begin{array}{c}\text { Sinapin- } \\
\text { säurerest } \\
\text { (mg/g) }\end{array}$ & $\begin{array}{c}\text { Gesamt- } \\
\text { Sinapinsäure- } \\
\text { ester (mg/g) }\end{array}$ & $\begin{array}{c}\text { Resveratrol- } \\
\text { glucosid } \\
(\mathrm{mg} / \mathrm{kg})\end{array}$ \\
\hline 1502.1 & 3,13 & 7,08 & 46,55 & 24,43 & 19,63 & 3,86 & 2,79 & 67,36 & 14,31 & 7,44 & 1,65 & 0,00 & 2,83 & 8,88 & 1,93 & 9,96 & 29,40 \\
\hline 1502.2 & 4,39 & 9,63 & 46,40 & 24,21 & 21,21 & 4,25 & 3,06 & 64,47 & 15,94 & 8,15 & 1,59 & 0,00 & 0,29 & 4,89 & 0,12 & 3,81 & 189,50 \\
\hline 1502.3 & 4,42 & 3,56 & 39,59 & 28,38 & 26,72 & 5,62 & 2,94 & 63,36 & 15,00 & 9,08 & 2,03 & 0,00 & 0,00 & 3,70 & 0,00 & 2,58 & 11,50 \\
\hline 1502.4 & 3,68 & 6,32 & 40,83 & 27,87 & 33,71 & 5,58 & 3,19 & 64,12 & 14,90 & 8,76 & 1,18 & 0,00 & 2,03 & 9,10 & 1,27 & 9,00 & 230,00 \\
\hline 1502.5 & 3,45 & 8,34 & 46,20 & 23,56 & 23,45 & 4,06 & 3,35 & 65,03 & 16,52 & 7,86 & 0,97 & 0,00 & 0,57 & 5,50 & 0,13 & 4,42 & 171,00 \\
\hline 1502.6 & 3,80 & 7,63 & 45,02 & 25,39 & 23,51 & 4,03 & 2,91 & 66,44 & 15,50 & 7,11 & 1,24 & 0,00 & 2,23 & 8,14 & 1,00 & 8,15 & 0,00 \\
\hline 1502.7 & 3,36 & 8,52 & 44,38 & 25,59 & 23,48 & 3,62 & 2,90 & 68,51 & 14,19 & 6,76 & 1,35 & 0,00 & 2,79 & 8,73 & 1,70 & 9,60 & 5,66 \\
\hline 1502.8 & 3,73 & 7,10 & 42,48 & 28,00 & 21,14 & 4,95 & 2,92 & 64,83 & 16,91 & 7,53 & 1,27 & 0,00 & 0,18 & 3,82 & 0,00 & 2,73 & 149,60 \\
\hline 1502.9 & 3,36 & 6,80 & 36,98 & 29,77 & 27,02 & 4,97 & 2,90 & 64,93 & 16,28 & 7,08 & 1,09 & 0,00 & 0,18 & 3,56 & 0,00 & 2,54 & 119,60 \\
\hline 1502.10 & 3,91 & 8,83 & 44,25 & 25,12 & 19,44 & 4,31 & 2,88 & 67,21 & 14,40 & 7,68 & 1,27 & 0,00 & 1,74 & 7,81 & 0,75 & 7,38 & 72,60 \\
\hline 1502.11 & 3,36 & 10,40 & 47,06 & 22,89 & 22,23 & 4,01 & 2,48 & 67,48 & 14,88 & 8,04 & 1,17 & 0,00 & 2,42 & 8,07 & 0,88 & 8,09 & 68,20 \\
\hline 1502.12 & 3,22 & 6,97 & 43,31 & 27,36 & 23,32 & 4,16 & 2,72 & 70,46 & 13,30 & 5,04 & 1,20 & 0,00 & 1,08 & 7,68 & 0,47 & 6,63 & 0,00 \\
\hline 1502.13 & 4,21 & 6,33 & 45,63 & 25,00 & 24,29 & 5,15 & 3,10 & 68,03 & 14,25 & 5,87 & 1,15 & 0,00 & 0,75 & 7,41 & 0,30 & 6,07 & 20,10 \\
\hline 1502.14 & 3,38 & 9,43 & 45,48 & 24,17 & 21,82 & 3,97 & 2,50 & 67,71 & 13,80 & 8,21 & 1,06 & 0,00 & 3,10 & 8,48 & 1,10 & 9,00 & 0,00 \\
\hline 1502.15 & 3,04 & 7,71 & 44,59 & 25,19 & 22,06 & 4,03 & 2,98 & 67,95 & 13,58 & 7,41 & 1,28 & 0,00 & 0,48 & 4,46 & 0,19 & 3,68 & 351,00 \\
\hline 1502.16 & 3,24 & 7,76 & 45,29 & 25,00 & 21,37 & 4,22 & 2,59 & 65,51 & 14,71 & 8,14 & 0,90 & 0,00 & 0,30 & 4,38 & 0,11 & 3,44 & 335,00 \\
\hline 1502.17 & 3,68 & 8,90 & 46,51 & 24,34 & 23,97 & 4,00 & 3,17 & 66,16 & 14,04 & 7,99 & 1,12 & 0,21 & 0,48 & 5,00 & 0,12 & 4,00 & 361,00 \\
\hline 1502.18 & 3,34 & 8,53 & 42,28 & 26,61 & 20,85 & 3,87 & 2,52 & 63,58 & 15,69 & 7,44 & 1,00 & 0,00 & 1,84 & 7,20 & 0,85 & 7,10 & 183,40 \\
\hline 1502.19 & 3,89 & 7,51 & 42,35 & 26,25 & 22,31 & 3,96 & 2,59 & 64,49 & 14,21 & 6,80 & 1,06 & 0,00 & 1,89 & 7,51 & 0,95 & 7,45 & 168,00 \\
\hline 1502.20 & 3,43 & 9,76 & 43,08 & 27,90 & 18,25 & 3,87 & 2,50 & 73,39 & 12,73 & 4,40 & 1,32 & 0,00 & 1,12 & 7,00 & 0,89 & 6,58 & 186,00 \\
\hline 1502.21 & 3,43 & 9,10 & 44,90 & 25,96 & 21,46 & 4,16 & 2,59 & 72,67 & 12,63 & 5,28 & 1,38 & 0,00 & 0,20 & 3,90 & 0,00 & 2,91 & 0,00 \\
\hline 1502.22 & 3,65 & 7,61 & 42,52 & 26,79 & 18,60 & 4,55 & 2,88 & 66,89 & 15,13 & 7,71 & 1,24 & 0,00 & 1,16 & 7,79 & 1,56 & 7,84 & 0,00 \\
\hline 1502.23 & 3,18 & 4,56 & $|40,47|$ & 27,65 & 26,76 & 4,69 & 2,55 & 67,93 & $|16,19|$ & 5,64 & 1,22 & $|0,00|$ & 0,09 & 4,78 & 0,31 & 3,80 & 0,00 \\
\hline
\end{tabular}




\begin{tabular}{|c|c|c|c|c|c|c|c|c|c|c|c|c|c|c|c|c|c|}
\hline $\begin{array}{c}\text { Pflanzen- } \\
\text { Nr. }\end{array}$ & $\begin{array}{c}\text { TKG } \\
\text { (g) }\end{array}$ & $\begin{array}{c}\text { g Samen } \\
\text { /Pfl. }\end{array}$ & $\begin{array}{l}\text { OEL } \\
(\%)\end{array}$ & $\begin{array}{l}\text { PROTEIN } \\
(\%)\end{array}$ & $\mid \begin{array}{c}\text { GSL } \\
(\mu \mathrm{mol} / \mathrm{g})\end{array}$ & $\begin{array}{c}16: 00 \\
(\%)\end{array}$ & $\begin{array}{c}18: 00 \\
(\%)\end{array}$ & $\begin{array}{c}18: 01 \\
(\%)\end{array}$ & $\begin{array}{c}18: 02 \\
(\%)\end{array}$ & $\begin{array}{c}18: 03 \\
(\%)\end{array}$ & $\left|\begin{array}{c}20: 01 \\
(\%)\end{array}\right|$ & $\begin{array}{c}22: 01 \\
(\%)\end{array}$ & $\begin{array}{c}\text { Sinapoyl- } \\
\text { glucose } \\
(\mathrm{mg} / \mathrm{g})\end{array}$ & $\begin{array}{c}\text { Sinapin } \\
(\mathrm{mg} / \mathrm{g})\end{array}$ & $\begin{array}{l}\text { Sinapin- } \\
\text { säurerest } \\
\text { (mg/g) }\end{array}$ & \begin{tabular}{|c|} 
Gesamt- \\
Sinapinsäure- \\
ester (mg/g)
\end{tabular} & $\begin{array}{c}\text { Resveratrol- } \\
\text { glucosid } \\
\text { (mg/kg) }\end{array}$ \\
\hline 1502.24 & 3,85 & 10,78 & 46,21 & 23,42 & 20,79 & 4,14 & 2,54 & 72,53 & 12,41 & 5,89 & 1,28 & 0,00 & 2,76 & 8,51 & 2,21 & 9,94 & 0,00 \\
\hline 1502.25 & 5,70 & 3,89 & 35,91 & 29,83 & 22,80 & 3,92 & 2,78 & 70,14 & 14,40 & 6,08 & 1,24 & 0,00 & 0,00 & 4,15 & 0,00 & 2,84 & 212,00 \\
\hline 1502.26 & 3,15 & 5,88 & 39,57 & 27,01 & 25,17 & 4,17 & 2,79 & 70,21 & 14,37 & 5,99 & 1,23 & 0,00 & 0,28 & 4,15 & 0,08 & 3,23 & 30,00 \\
\hline 1502.27 & 3,90 & 10,56 & 46,71 & 23,12 & 21,01 & 4,22 & 2,48 & 72,09 & 13,03 & 5,92 & 1,17 & 0,00 & 2,60 & 7,57 & 1,86 & 8,82 & 0,00 \\
\hline 1502.28 & 4,10 & 10,53 & 46,33 & 23,37 & 18,79 & 4,31 & 2,34 & 70,31 & 14,36 & 6,15 & 1,16 & 0,00 & 3,00 & 8,43 & 2,65 & 10,46 & 123,00 \\
\hline $1502.1 \mathrm{~K}$ & 3,39 & 5,79 & 44,16 & 24,33 & 24,35 & 4,36 & 3,00 & 65,48 & 16,86 & 7,30 & 1,12 & 0,00 & 1,62 & 9,75 & 0,98 & 8,94 & 0,00 \\
\hline $1502.2 \mathrm{~K}$ & 4,17 & 9,19 & 50,79 & 19,92 & 21,57 & 4,12 & 2,77 & 68,10 & 14,56 & 7,23 & 1,01 & 0,00 & 2,16 & 8,46 & 1,47 & 8,81 & 0,00 \\
\hline $1502.3 \mathrm{~K}$ & 3,42 & 7,47 & 45,01 & 24,94 & 24,00 & 3,92 & 2,68 & 71,81 & 12,35 & 5,42 & 1,19 & 0,00 & 2,34 & 8,06 & 1,24 & 8,40 & 0,00 \\
\hline $1502.4 \mathrm{~K}$ & 3,96 & 8,96 & 43,61 & 27,22 & 21,13 & 3,83 & 2,84 & 72,80 & 11,25 & 5,64 & 1,13 & 0,00 & 2,55 & 7,61 & 1,18 & 8,14 & 0,00 \\
\hline $1502.5 \mathrm{~K}$ & 3,54 & 7,91 & 44,86 & 25,17 & 18,80 & 3,89 & 2,68 & 69,92 & 13,57 & 7,25 & 0,94 & 0,00 & 2,92 & 8,26 & 1,46 & 9,10 & 0,00 \\
\hline $1502.6 \mathrm{~K}$ & 3,39 & 7,40 & 48,53 & 23,04 & 23,88 & 3,89 & 3,12 & 67,28 & 14,76 & 6,73 & 1,08 & 0,00 & 2,15 & 8,65 & 1,79 & 9,26 & 0,00 \\
\hline $1502.7 \mathrm{~K}$ & 3,24 & 7,09 & 41,34 & 26,19 & 29,73 & 4,09 & 2,89 & 66,98 & 16,11 & 6,92 & 1,13 & 0,00 & 2,04 & 8,55 & 1,07 & 8,41 & 0,00 \\
\hline $1502.8 \mathrm{~K}$ & 3,57 & 7,33 & 42,22 & 27,05 & 22,95 & 3,96 & 2,81 & 65,47 & 14,25 & 7,11 & 1,06 & 0,00 & 2,32 & 8,67 & 1,72 & 9,31 & 0,00 \\
\hline $1502.9 \mathrm{~K}$ & 3,18 & 6,08 & 45,62 & 24,55 & 19,80 & 4,08 & 3,93 & 68,20 & 14,23 & 6,28 & 1,10 & 0,00 & 2,18 & 9,56 & 1,46 & 9,61 & 0,00 \\
\hline $1502.10 \mathrm{~K}$ & 3,81 & 7,31 & 46,77 & 23,03 & 20,26 & 3,89 & 2,96 & 72,64 & 11,79 & 5,50 & 1,16 & 0,00 & 2,62 & 8,12 & 1,25 & 8,62 & 0,00 \\
\hline $150211 \mathrm{~K}$ & 3,90 & 7,79 & 45,13 & 23,00 & 19,30 & 4,09 & 2,78 & 68,54 & 14,91 & 6,28 & 1,41 & 0,00 & 2,03 & 9,00 & 1,01 & 8,67 & 0,00 \\
\hline $1502.12 K$ & 3,90 & 8,48 & 43,62 & 24,29 & 23,35 & 4,31 & 2,51 & 68,78 & 14,97 & 6,50 & 1,31 & 0,00 & 2,18 & 8,44 & 1,32 & 8,66 & 0,00 \\
\hline $1502.13 \mathrm{~K}$ & 3,81 & 8,09 & 42,08 & 26,58 & 23,52 & 3,99 & 2,58 & 70,79 & 13,06 & 6,34 & 1,13 & 0,00 & 2,55 & 8,68 & 0,86 & 8,59 & 0,00 \\
\hline $1502.14 K$ & 4,08 & 8,04 & 42,58 & 25,35 & 25,73 & 3,65 & 3,78 & 71,01 & 13,06 & 6,27 & 1,11 & 0,00 & 3,14 & 8,24 & 1,50 & 9,25 & 0,00 \\
\hline $1502.15 K$ & 3,66 & 8,09 & 43,48 & 26,32 & 22,24 & 3,93 & 2,76 & 69,70 & 13,23 & 7,56 & 1,08 & 0,00 & 2,74 & 8,54 & 1,13 & 8,87 & 0,00 \\
\hline $1502.16 \mathrm{~K}$ & 3,60 & 7,63 & 44,97 & 23,99 & 22,25 & 3,94 & 3,22 & 68,27 & 14,42 & 7,58 & 1,04 & 0,00 & 2,27 & 8,40 & 1,14 & 8,50 & 0,00 \\
\hline $1502.17 \mathrm{~K}$ & 3,90 & 8,22 & 42,34 & 28,53 & 22,19 & 4,05 & 2,66 & 67,43 & 16,32 & 6,30 & 1,17 & 0,00 & 2,79 & 7,87 & 1,11 & 8,39 & 0,00 \\
\hline $1502.18 \mathrm{~K}$ & 3,90 & 9,11 & 42,33 & 27,16 & 22,98 & 3,96 & 2,27 & 69,09 & 14,54 & 7,48 & 1,04 & 0,00 & 3,23 & 9,03 & 1,73 & 10,10 & 0,00 \\
\hline $1502.19 K$ & 3,69 & 6,77 & 44,87 & 24,89 & 20,67 & 3,91 & 2,60 & 67,97 & 14,40 & 7,52 & 1,03 & 0,00 & 1,94 & 9,14 & 0,92 & 8,63 & 0,00 \\
\hline $1502.20 \mathrm{~K}$ & 3,90 & 8,60 & 47,30 & 21,86 & 22,75 & 4,21 & 2,54 & 67,73 & 16,08 & 6,51 & 1,22 & 0,00 & 2,13 & 8,42 & 1,57 & 8,87 & 0,00 \\
\hline $1502.21 \mathrm{~K}$ & 3,51 & 6,23 & 48,20 & 22,53 & 21,88 & 4,04 & 2,67 & 64,36 & 17,60 & 7,49 & 1,15 & 0,00 & 1,34 & 8,24 & 1,08 & 7,79 & 0,00 \\
\hline $1502.22 \mathrm{~K}$ & 3,99 & 6,93 & 44,83 & 24,58 & 21,57 & 4,00 & 2,68 & 66,25 & 16,47 & 7,19 & 1,07 & 0,00 & 2,55 & 9,33 & 1,86 & 10,06 & 0,00 \\
\hline $1502.23 \mathrm{~K}$ & 3,93 & 8,97 & 45,57 & 24,80 & 18,78 & 3,87 & 2,64 & 68,11 & 14,88 & 7,65 & 1,06 & 0,00 & 3,10 & 8,98 & 2,07 & 10,33 & 0,00 \\
\hline $1502.24 K$ & 3,81 & 7,08 & 47,34 & 22,76 & 22,09 & 3,78 & 2,97 & 73,71 & 11,21 & 5,22 & 1,12 & 0,00 & 2,93 & 8,05 & 1,45 & 8,95 & 0,00 \\
\hline $1502.25 \mathrm{~K}$ & 3,42 & 7,60 & 44,46 & 24,51 & 23,61 & 4,29 & 2,67 & 68,57 & 15,35 & 6,25 & 1,14 & 0,00 & 1,88 & 8,06 & 1,46 & 8,35 & 0,00 \\
\hline $1502.26 \mathrm{~K}$ & 3,36 & 7,14 & 47,15 & 23,47 & 22,05 & 4,02 & 3,10 & 70,31 & 14,12 & 5,07 & 1,27 & 0,00 & 1,38 & 7,44 & 1,18 & 7,34 & 0,00 \\
\hline $1502.27 \mathrm{~K}$ & 3,96 & 7,83 & 39,60 & 28,41 & 23,18 & 4,18 & 2,89 & 67,75 & 15,50 & 6,83 & 1,10 & 0,00 & 2,62 & 7,69 & 1,78 & 8,84 & 0,00 \\
\hline $1502.28 \mathrm{~K}$ & 3,78 & 7,27 & 46,16 & 24,02 & 22,21 & 3,98 & 2,79 & 65,49 & 15,23 & 7,76 & 1,06 & 0,00 & 2,21 & 8,57 & 1,65 & 9,10 & 0,00 \\
\hline $1502.29 \mathrm{~K}$ & 3,60 & 7,92 & 46,14 & 22,58 & 23,34 & 4,40 & 2,69 & 67,50 & 15,51 & 7,31 & 1,11 & 0,00 & 1,78 & 7,89 & 1,68 & 8,39 & 0,00 \\
\hline
\end{tabular}




\begin{tabular}{|c|c|c|c|c|c|c|c|c|c|c|c|c|c|c|c|c|c|}
\hline $\begin{array}{c}\text { Pflanzen- } \\
\text { Nr. }\end{array}$ & \begin{tabular}{|c} 
TKG \\
(g)
\end{tabular} & $\begin{array}{c}\text { g Samen } \\
\text { /Pfl. }\end{array}$ & $\begin{array}{l}\text { OEL } \\
(\%)\end{array}$ & $\begin{array}{c}\text { PROTEIN } \\
(\%)\end{array}$ & $\mid \begin{array}{c}\text { GSL } \\
(\mu \mathrm{mol} / \mathrm{g})\end{array}$ & $\begin{array}{c}16: 00 \\
(\%)\end{array}$ & $\begin{array}{c}18: 00 \\
(\%)\end{array}$ & $\left|\begin{array}{c}18: 01 \\
(\%)\end{array}\right|$ & $\left|\begin{array}{c}18: 02 \\
(\%)\end{array}\right|$ & $\begin{array}{c}18: 03 \\
(\%)\end{array}$ & $\begin{array}{c}20: 01 \\
(\%)\end{array}$ & $\begin{array}{c}22: 01 \\
(\%)\end{array}$ & $\begin{array}{c}\text { Sinapoyl- } \\
\text { glucose } \\
(\mathrm{mg} / \mathrm{g})\end{array}$ & $\mid \begin{array}{c}\text { Sinapin } \\
(\mathrm{mg} / \mathrm{g})\end{array}$ & $\begin{array}{c}\text { Sinapin- } \\
\text { säurerest } \\
(\mathrm{mg} / \mathrm{g}) \\
\end{array}$ & $\begin{array}{c}\text { Gesamt- } \\
\text { Sinapinsäure- } \\
\text { ester (mg/g) }\end{array}$ & $\begin{array}{c}\text { Resveratrol- } \\
\text { glucosid } \\
\text { (mg/kg) }\end{array}$ \\
\hline $1502.30 \mathrm{~K}$ & 3,21 & 4,94 & 45,81 & 23,80 & 21,25 & 4,36 & 3,01 & 66,09 & 16,77 & 6,53 & 1,21 & 0,00 & 1,21 & 8,13 & 0,72 & 7,28 & 0,00 \\
\hline 1502.15 .1 & 3,66 & 3,46 & 38,26 & 20,21 & 19,12 & 3,73 & 1,88 & 70,64 & 15,33 & 6,81 & 0,90 & 0,00 & 0,00 & 2,81 & 0,00 & 1,92 & 376,00 \\
\hline 1502.15 .2 & 3,26 & 2,06 & 37,54 & 20,76 & 19,56 & 3,98 & 1,96 & 72,37 & 14,05 & 5,63 & 0,99 & 0,00 & 0,00 & 3,72 & 0,00 & 2,54 & 290,00 \\
\hline 1502.15 .3 & 3,36 & 2,01 & 36,78 & 20,87 & 22,26 & 3,92 & 2,13 & 73,16 & 13,66 & 5,50 & 0,85 & 0,00 & 0,00 & 3,60 & 0,00 & 2,47 & 348,00 \\
\hline 1502.15 .4 & 3,40 & 4,06 & 39,01 & 19,93 & 14,78 & 3,76 & 1,69 & 71,76 & 14,83 & 6,51 & 0,79 & 0,11 & 0,00 & 5,38 & 0,00 & 3,68 & 313,00 \\
\hline 1502.15 .5 & 3,50 & 1,73 & 37,20 & 20,81 & 25,93 & 3,98 & 1,87 & 72,63 & 13,88 & 5,64 & 1,05 & 0,00 & 0,00 & 4,00 & 0,00 & 2,75 & 273,00 \\
\hline 1502.15 .6 & 3,73 & 3,06 & 37,65 & 20,13 & 22,14 & 3,43 & 1,99 & 71,62 & 15,17 & 6,24 & 0,92 & 0,00 & 0,00 & 4,60 & 0,00 & 3,14 & 313,00 \\
\hline 1502.15 .7 & 3,60 & 1,46 & 37,21 & 20,72 & 22,64 & 3,95 & 1,78 & 71,23 & 14,87 & 6,46 & 0,80 & 0,00 & 0,00 & 1,90 & 0,00 & 1,30 & 424,00 \\
\hline 1502.15 .8 & 3,76 & 3,32 & 37,92 & 20,70 & 20,43 & 3,94 & 1,76 & 72,20 & 14,30 & 5,86 & 1,00 & 0,00 & 0,00 & 7,10 & 0,00 & 4,86 & 182,00 \\
\hline 1502.15 .9 & 3,63 & 4,79 & 38,13 & 20,61 & 19,79 & 3,26 & 1,70 & 71,95 & 15,23 & 6,64 & 0,75 & 0,00 & 0,00 & 3,95 & 0,00 & 2,71 & 350,00 \\
\hline 1502.15.10 & 3,50 & 2,95 & 37,49 & 20,58 & 22,43 & 3,34 & 1,89 & 73,91 & 13,65 & 5,29 & 1,00 & 0,00 & 0,00 & 3,60 & 0,00 & 2,46 & 359,00 \\
\hline 1502.15.11 & 3,50 & 1,86 & 36,56 & 20,85 & 21,93 & 4,05 & 1,95 & 72,04 & 14,51 & 5,63 & 0,96 & 0,00 & 0,00 & 4,71 & 0,00 & 3,23 & 362,00 \\
\hline 1502.15.12 & 3,43 & 2,97 & 37,96 & 20,56 & 18,38 & 3,47 & 1,79 & 71,83 & 15,15 & 6,12 & 1,00 & 0,00 & 0,00 & 1,88 & 0,00 & 1,29 & 305,00 \\
\hline 1502.15 .13 & 3,63 & 3,11 & 37,94 & 20,72 & 21,89 & 4,08 & 1,73 & 72,35 & 14,16 & 5,82 & 0,98 & 0,00 & 0,00 & 5,24 & 0,00 & 3,60 & 342,00 \\
\hline 1502.15.14 & 3,40 & 5,92 & 39,14 & 19,88 & 18,34 & 3,91 & 1,96 & 72,62 & 14,16 & 5,54 & 0,96 & 0,00 & 0,00 & 4,71 & 0,00 & 3,23 & 368,00 \\
\hline 1502.15 .15 & 3,66 & 0,99 & 37,58 & 20,31 & 22,79 & 3,94 & 2,22 & 74,70 & 12,57 & 4,80 & 0,89 & 0,00 & 0,00 & 3,22 & 0,00 & 2,21 & 332,00 \\
\hline 1502.15.16 & 3,30 & 1,79 & 37,12 & 20,89 & 24,70 & 3,98 & 1,69 & 71,78 & 14,37 & 6,59 & 0,86 & 0,00 & 0,00 & 2,10 & 0,00 & 1,44 & 366,00 \\
\hline 1502.15.17 & 3,60 & 4,12 & 38,47 & 20,30 & 18,00 & 3,94 & 1,85 & 70,91 & 15,26 & 6,31 & 0,83 & 0,00 & 0,00 & 2,95 & 0,00 & 2,02 & 308,00 \\
\hline 1502.15 .18 & 3,63 & 3,32 & 38,01 & 20,69 & 21,14 & 3,82 & 1,67 & 72,20 & 14,51 & 6,26 & 0,94 & 0,00 & 0,00 & 6,94 & 0,00 & 4,75 & 172,00 \\
\hline 1502.15.19 & 2,96 & 1,85 & 36,75 & 20,34 & 18,53 & 4,31 & 1,81 & 66,65 & 18,18 & 7,25 & 0,90 & 0,00 & 0,00 & 2,43 & 0,00 & 1,66 & 283,00 \\
\hline 1502.15 .20 & 3,43 & 3,42 & 38,49 & 20,32 & 19,45 & 3,92 & 1,59 & 71,61 & 14,29 & 6,26 & 0,96 & 0,00 & 0,00 & 8,17 & 0,00 & 5,60 & 152,00 \\
\hline 1502.16.1 & 3,10 & 5,02 & 38,62 & 20,30 & 16,68 & 4,01 & 1,74 & 70,69 & 15,54 & 6,38 & 0,94 & 0,00 & 0,00 & 2,83 & 0,00 & 1,94 & 266,00 \\
\hline 1502.16 .2 & 3,10 & 5,02 & 39,02 & 20,13 & 14,99 & 3,90 & 1,68 & 72,99 & 13,81 & 5,87 & 1,04 & 0,00 & 0,00 & 7,47 & 0,00 & 5,11 & 161,00 \\
\hline 1502.16 .3 & 2,80 & 4,31 & 38,74 & 20,25 & 15,04 & 3,70 & 1,67 & 73,13 & 14,02 & 5,76 & 0,93 & 0,00 & 0,00 & 3,20 & 0,00 & 2,18 & 260,00 \\
\hline 1502.16 .4 & 3,40 & 4,02 & 38,53 & 20,37 & 17,29 & 3,20 & 1,59 & 73,61 & 13,94 & 6,40 & 0,89 & 0,00 & 0,00 & 6,90 & 0,00 & 4,73 & 148,00 \\
\hline 1502.16 .5 & 3,20 & 4,72 & 39,06 & 20,08 & 17,71 & 3,67 & 1,72 & 72,77 & 14,17 & 6,30 & 0,81 & 0,00 & 0,00 & 6,53 & 0,00 & 4,48 & 169,00 \\
\hline 1502.16.6 & 3,10 & 4,69 & 38,95 & 20,21 & 15,39 & 3,26 & 1,75 & 71,80 & 15,06 & 6,51 & 1,00 & 0,00 & 0,00 & 4,50 & 0,00 & 3,08 & 176,00 \\
\hline 1502.16 .7 & 3,50 & 3,55 & 37,90 & 20,50 & 20,18 & 3,76 & 1,69 & 75,45 & 12,35 & 5,00 & 1,09 & 0,00 & 0,00 & 10,53 & 0,00 & 8,00 & 0,00 \\
\hline 1502.16 .8 & 3,85 & 2,86 & 37,63 & 20,75 & 21,72 & 3,98 & 1,87 & 70,24 & 16,04 & 6,13 & 1,02 & 0,00 & 0,00 & 2,21 & 0,00 & 1,51 & 308,00 \\
\hline 1502.16 .9 & 3,05 & 5,06 & 39,88 & 19,42 & 14,97 & 3,67 & 1,55 & 73,24 & 13,66 & 6,28 & 1,00 & 0,00 & 0,00 & 7,45 & 0,00 & 5,90 & 136,00 \\
\hline 1502.16.10 & 3,80 & 3,01 & 38,04 & 20,39 & 21,01 & 3,76 & 1,89 & 71,40 & 15,12 & 6,08 & 0,95 & 0,00 & 0,00 & 2,31 & 0,00 & 1,58 & 301,00 \\
\hline 1502.16.11 & 3,10 & 4,37 & 38,17 & 20,46 & 15,93 & 3,87 & 1,69 & 71,18 & 15,05 & 6,31 & 1,00 & 0,00 & 0,00 & 1,85 & 0,00 & 1,27 & 255,00 \\
\hline 1502.16.12 & 3,50 & 4,18 & 38,93 & 19,88 & 16,42 & 3,82 & 1,97 & 73,59 & 13,51 & 5,45 & 0,87 & 0,00 & 0,00 & 4,50 & 0,00 & 3,08 & 212,00 \\
\hline 1502.16 .13 & 3,80 & 3,31 & 37,77 & 20,44 & 23,71 & 3,99 & 1,77 & 71,47 & 14,84 & 6,02 & 0,99 & 0,00 & 0,00 & 7,61 & 0,00 & 5,34 & 142,00 \\
\hline
\end{tabular}




\begin{tabular}{|c|c|c|c|c|c|c|c|c|c|c|c|c|c|c|c|c|c|}
\hline $\begin{array}{c}\text { Pflanzen- } \\
\text { Nr. }\end{array}$ & $\begin{array}{c}\text { TKG } \\
(\mathrm{g})\end{array}$ & $\begin{array}{c}\text { g Samen } \\
\text { /Pfl. }\end{array}$ & $\left|\begin{array}{l}\text { OEL } \\
(\%)\end{array}\right|$ & $\begin{array}{c}\text { PROTEIN } \\
(\%)\end{array}$ & $\mid \begin{array}{c}\text { GSL } \\
(\mu \mathrm{mol} / \mathrm{g})\end{array}$ & $\begin{array}{c}16: 00 \\
(\%)\end{array}$ & $\begin{array}{c}18: 00 \\
(\%)\end{array}$ & $\left|\begin{array}{c}18: 01 \\
(\%)\end{array}\right|$ & $\begin{array}{c}18: 02 \\
(\%)\end{array}$ & $\begin{array}{c}18: 03 \\
(\%)\end{array}$ & $\begin{array}{c}20: 01 \\
(\%)\end{array}$ & $\begin{array}{c}22: 01 \\
(\%)\end{array}$ & $\begin{array}{c}\text { Sinapoyl- } \\
\text { glucose } \\
\text { (mg/g) }\end{array}$ & $\left|\begin{array}{c}\text { Sinapin } \\
(\mathrm{mg} / \mathrm{g})\end{array}\right|$ & $\begin{array}{l}\text { Sinapin- } \\
\text { säurerest } \\
\text { (mg/g) }\end{array}$ & \begin{tabular}{|c|} 
Gesamt- \\
Sinapinsäure- \\
ester (mg/g)
\end{tabular} & $\begin{array}{c}\text { Resveratrol- } \\
\text { glucosid } \\
(\mathrm{mg} / \mathrm{kg})\end{array}$ \\
\hline 1502.16 .14 & 3,65 & 4,34 & 38,50 & 20,52 & 20,25 & 3,86 & 1,97 & 71,94 & 14,77 & 5,77 & 0,88 & 0,00 & 0,00 & 5,34 & 0,00 & 3,65 & 227,00 \\
\hline 1502.16.15 & 3,75 & 3,65 & 38,92 & 19,68 & 17,60 & 3,82 & 1,81 & 70,92 & 15,41 & 6,41 & 0,80 & 0,00 & 0,00 & 2,77 & 0,07 & 2,06 & 289,00 \\
\hline 1502.16.16 & 3,55 & 4,47 & 38,97 & 20,05 & 17,62 & 3,78 & 1,80 & 73,31 & 13,76 & 5,53 & 0,96 & 0,00 & 0,00 & 5,44 & 0,00 & 3,73 & 263,00 \\
\hline 1502.16.17 & 3,25 & 4,49 & 38,52 & 20,31 & 17,07 & 3,92 & 1,77 & 72,05 & 14,38 & 5,94 & 0,98 & 0,00 & 0,00 & 3,57 & 0,00 & 2,44 & 144,00 \\
\hline 1502.16.18 & 3,20 & 5,08 & 39,53 & 19,57 & 14,48 & 3,91 & 1,64 & 71,23 & 14,84 & 6,61 & 0,89 & 0,00 & 0,00 & 4,97 & 0,00 & 3,41 & 183,00 \\
\hline 1502.16.19 & 3,95 & 3,62 & 38,13 & 20,42 & 19,92 & 3,98 & 1,73 & 72,04 & 14,54 & 6,26 & 0,87 & 0,00 & 0,00 & 7,86 & 0,04 & 5,70 & 168,00 \\
\hline 1502.16 .20 & 3,60 & 3,39 & 38,22 & 20,44 & 17,03 & 3,91 & 1,74 & 70,64 & 15,30 & 6,61 & 0,89 & 0,00 & 0,00 & 4,12 & 0,00 & 2,92 & 290,00 \\
\hline 1502.17 .1 & 2,70 & 7,04 & 42,81 & 17,01 & 14,03 & 3,93 & 1,77 & 71,58 & 14,69 & 6,46 & 0,71 & 0,00 & 0,00 & 7,11 & 0,52 & 5,64 & 134,00 \\
\hline 1502.17 .2 & 3,15 & 5,32 & 40,14 & 18,93 & 15,65 & 3,81 & 1,84 & 71,34 & 14,93 & 6,31 & 0,87 & 0,00 & 0,00 & 4,19 & 0,00 & 2,87 & 224,00 \\
\hline 1502.17 .3 & 3,60 & 4,47 & 39,32 & 19,57 & 18,95 & 3,78 & 1,86 & 71,61 & 14,74 & 6,14 & 0,98 & 0,00 & 0,00 & 3,75 & 0,00 & 2,66 & 191,00 \\
\hline 1502.17 .4 & 3,05 & 5,26 & 39,37 & 19,47 & 15,69 & 3,93 & 1,68 & 70,18 & 15,76 & 6,69 & 0,96 & 0,00 & 0,00 & 3,73 & 0,00 & 2,55 & 263,00 \\
\hline 1502.17 .5 & 3,10 & 5,54 & 41,36 & 17,97 & 14,42 & 3,78 & 1,42 & 74,23 & 12,89 & 5,68 & 1,06 & 0,00 & 0,36 & 11,78 & 0,89 & 9,37 & 0,00 \\
\hline 1502.17 .6 & 3,70 & 2,46 & 38,70 & 20,13 & 21,49 & 3,78 & 1,72 & 74,11 & 12,90 & 5,58 & 1,02 & 0,00 & 0,00 & 11,81 & 0,08 & 8,58 & 0,00 \\
\hline 1502.17 .7 & 3,70 & 3,43 & 38,72 & 20,03 & 20,63 & 3,90 & 1,74 & 73,96 & 13,12 & 5,35 & 1,10 & 0,00 & 0,00 & 10,25 & 0,25 & 7,63 & 0,00 \\
\hline 1502.17 .8 & 3,65 & 4,27 & 39,42 & 19,51 & 17,30 & 3,78 & 1,76 & 71,10 & 15,44 & 6,21 & 0,91 & 0,00 & 0,00 & 5,10 & 0,00 & 3,49 & 207,00 \\
\hline 1502.17 .9 & 2,95 & 5,87 & 41,28 & 18,17 & 15,47 & 3,75 & 2,00 & 71,90 & 14,30 & 6,17 & 0,91 & 0,00 & 0,00 & 5,50 & 0,00 & 3,81 & 274,00 \\
\hline 1502.17.10 & 3,55 & 4,39 & 39,69 & 19,63 & 18,46 & 3,64 & 2,01 & 72,26 & 14,50 & 5,93 & 0,84 & 0,00 & 0,00 & 4,20 & 0,00 & 2,88 & 258,00 \\
\hline 1502.17.11 & 3,75 & 3,2 & 38,24 & 20,34 & 20,06 & 3,90 & 1,76 & 70,21 & 15,97 & 6,55 & 0,89 & 0,00 & 0,00 & 4,83 & 0,00 & 3,31 & 221,00 \\
\hline 1502.17.12 & 3,85 & 2,68 & 38,46 & 20,28 & 17,84 & 3,98 & 1,89 & 70,09 & 15,90 & 6,18 & 1,09 & 0,00 & 0,00 & 3,18 & 0,00 & 2,18 & 285,00 \\
\hline 1502.17.13 & 2,55 & 6,1 & 40,38 & 18,81 & 14,12 & 3,23 & 1,64 & 69,88 & 16,14 & 7,51 & 0,82 & 0,00 & 0,00 & 4,32 & 0,14 & 3,25 & 252,00 \\
\hline 1502.17.14 & 2,95 & 0,98 & 35,33 & 21,54 & 37,35 & 4,97 & 1,82 & 65,29 & 18,85 & 7,24 & 0,82 & 0,00 & 0,00 & 2,49 & 0,00 & 1,71 & 156,00 \\
\hline 1502.17.15 & 3,35 & 4,05 & 38,88 & 20,01 & 16,76 & 4,18 & 1,75 & 68,38 & 16,94 & 7,32 & 0,78 & 0,00 & 0,00 & 1,90 & 0,00 & 1,30 & 305,00 \\
\hline 1502.17.16 & 3,50 & 4,64 & 39,65 & 19,65 & 17,23 & 3,74 & 1,56 & 72,49 & 14,04 & 6,67 & 0,90 & 0,00 & 0,00 & 8,02 & 0,03 & 5,80 & 141,00 \\
\hline 1502.17.17 & 2,65 & 6,41 & 40,67 & 18,41 & 15,85 & 3,89 & 1,37 & 71,25 & 14,85 & 6,95 & 0,96 & 0,00 & 0,00 & 8,91 & 1,04 & 7,46 & 0,00 \\
\hline 1502.17.18 & 3,10 & 5,18 & 39,09 & 20,14 & 18,00 & 3,77 & 1,61 & 70,89 & 15,04 & 7,01 & 0,84 & 0,00 & 0,00 & 2,96 & 0,00 & 2,02 & 268,00 \\
\hline 1502.17.19 & 3,55 & 4,03 & 38,57 & 20,32 & 18,74 & 3,89 & 1,70 & 69,79 & 15,57 & 7,34 & 0,97 & 0,00 & 0,00 & 7,41 & 0,06 & 5,40 & 142,00 \\
\hline 1502.17.20 & 3,40 & 3,88 & 39,23 & 19,69 & 15,95 & 3,95 & 1,78 & 69,29 & 16,31 & 6,94 & 0,85 & 0,00 & 0,00 & 2,10 & 0,00 & 1,44 & 326,00 \\
\hline $1502.1 \mathrm{~K}$ & 3,10 & 4,08 & 38,72 & 20,05 & 16,33 & 3,72 & 1,79 & 74,24 & 13,32 & 5,14 & 1,03 & 0,00 & 0,00 & 10,64 & 0,28 & 7,94 & 0,00 \\
\hline $1502.2 \mathrm{~K}$ & 3,26 & 3,70 & 38,58 & 20,33 & 18,24 & 3,64 & 1,60 & 73,52 & 14,02 & 5,24 & 1,20 & 0,00 & 0,28 & 10,66 & 0,32 & 8,00 & 0,00 \\
\hline $1502.3 \mathrm{~K}$ & 2,86 & 0,55 & 36,48 & 21,28 & 26,94 & 3,92 & 1,77 & 72,89 & 13,94 & 5,52 & 1,17 & 0,00 & 0,00 & 12,92 & 0,00 & 9,11 & 0,00 \\
\hline $1502.4 \mathrm{~K}$ & 3,03 & 2,55 & 36,54 & 21,07 & 24,59 & 3,48 & 1,94 & 71,10 & 15,23 & 6,24 & 1,11 & 0,00 & 0,18 & 12,20 & 0,36 & 9,14 & 0,00 \\
\hline $1502.5 \mathrm{~K}$ & 3,66 & 2,95 & 38,63 & 19,92 & 23,89 & 3,93 & 1,77 & 72,89 & 13,28 & 5,73 & 1,21 & 0,00 & 0,00 & 13,10 & 0,00 & 9,21 & 0,00 \\
\hline $1502.6 \mathrm{~K}$ & 2,23 & 1,62 & 37,21 & 21,04 & 26,47 & 3,71 & 1,73 & 72,63 & 14,21 & 6,15 & 0,92 & 0,00 & 0,00 & 11,22 & 0,00 & 7,98 & 0,00 \\
\hline $1502.7 \mathrm{~K}$ & 3,03 & 4,28 & $|38,95|$ & 20,08 & 16,81 & 3,55 & 1,74 & $|72,42|$ & 14,36 & 6,10 & 1,11 & 0,00 & 0,24 & 10,20 & 0,66 & 8,00 & 0,00 \\
\hline
\end{tabular}




\begin{tabular}{|c|c|c|c|c|c|c|c|c|c|c|c|c|c|c|c|c|c|}
\hline $\begin{array}{c}\text { Pflanzen- } \\
\text { Nr. }\end{array}$ & $\begin{array}{c}\text { TKG } \\
\text { (g) }\end{array}$ & $\begin{array}{c}\text { g Samen } \\
\text { /Pfl. }\end{array}$ & $\begin{array}{c}\text { OEL } \\
(\%)\end{array}$ & $\begin{array}{c}\text { PROTEIN } \\
(\%)\end{array}$ & $\mid \begin{array}{c}\text { GSL } \\
(\mu \mathrm{mol} / \mathrm{g})\end{array}$ & $\begin{array}{c}16: 00 \\
(\%)\end{array}$ & $\begin{array}{c}18: 00 \\
(\%)\end{array}$ & $\begin{array}{c}18: 01 \\
(\%)\end{array}$ & $\begin{array}{c}18: 02 \\
(\%)\end{array}$ & $\begin{array}{c}18: 03 \\
(\%)\end{array}$ & $\left|\begin{array}{c}20: 01 \\
(\%)\end{array}\right|$ & $\begin{array}{c}22: 01 \\
(\%)\end{array}$ & $\begin{array}{c}\text { Sinapoyl- } \\
\text { glucose } \\
(\mathrm{mg} / \mathrm{g})\end{array}$ & $\begin{array}{c}\text { Sinapin } \\
(\mathrm{mg} / \mathrm{g})\end{array}$ & $\begin{array}{c}\text { Sinapin- } \\
\text { säurerest } \\
(\mathrm{mg} / \mathrm{g})\end{array}$ & $\begin{array}{c}\text { Gesamt- } \\
\text { Sinapinsäure- } \\
\text { ester (mg/g) } \\
\end{array}$ & $\begin{array}{c}\text { Resveratrol- } \\
\text { glucosid } \\
\text { (mg/kg) }\end{array}$ \\
\hline $1502.8 \mathrm{~K}$ & 2,96 & 2,94 & 37,53 & 20,82 & 15,82 & 3,68 & 1,63 & 73,26 & 13,06 & 6,12 & 1,17 & 0,00 & 0,00 & 7,53 & 2,25 & 7,67 & 0,00 \\
\hline $1502.9 \mathrm{~K}$ & 3,50 & 3,12 & 38,01 & 20,55 & 20,20 & 3,78 & 1,52 & 73,18 & 13,23 & 6,40 & 1,08 & 0,00 & 0,00 & 12,44 & 0,17 & 9,13 & 0,00 \\
\hline $1502.10 \mathrm{~K}$ & 2,76 & 4,75 & 39,87 & 19,06 & 15,47 & 3,85 & 1,61 & 73,09 & 13,19 & 6,05 & 1,15 & 0,00 & 0,22 & 10,14 & 0,51 & 7,81 & 0,00 \\
\hline $1502.11 \mathrm{~K}$ & 2,76 & 3,15 & 37,79 & 20,54 & 17,40 & 3,89 & 1,72 & 73,32 & 12,92 & 5,85 & 1,09 & 0,00 & 0,20 & 10,42 & 0,63 & 8,13 & 0,00 \\
\hline $1502.12 K$ & 2,76 & 0,68 & 35,76 & 20,29 & 32,42 & 4,36 & 1,72 & 68,71 & 16,61 & 6,42 & 1,00 & 0,00 & 0,00 & 9,46 & 0,00 & 7,48 & 0,00 \\
\hline $1502.13 K$ & 3,40 & 3,44 & 38,38 & 20,37 & 20,32 & 4,40 & 1,80 & 68,85 & 16,55 & 6,70 & 0,93 & 0,00 & 0,00 & 11,16 & 0,00 & 8,03 & 0,00 \\
\hline $1502.14 \mathrm{~K}$ & 2,80 & 5,65 & 39,80 & 19,52 & 13,30 & 3,70 & 1,72 & 74,41 & 12,22 & 5,73 & 1,09 & 0,00 & 0,30 & 10,24 & 0,68 & 8,05 & 0,00 \\
\hline $1502.15 \mathrm{~K}$ & 3,00 & 4,50 & 39,75 & 19,31 & 15,90 & 3,76 & 1,67 & 74,32 & 12,10 & 5,78 & 1,22 & 0,00 & 0,33 & 10,15 & 0,84 & 8,15 & 0,00 \\
\hline $1502.16 \mathrm{~K}$ & 2,60 & 2,55 & 36,61 & 20,52 & 24,52 & 3,96 & 1,58 & 71,42 & 14,44 & 6,31 & 1,07 & 0,00 & 0,00 & 11,63 & 0,06 & 8,43 & 0,00 \\
\hline $1502.17 \mathrm{~K}$ & 2,46 & 2,80 & 37,10 & 20,05 & 29,04 & 4,26 & 1,66 & 69,18 & 16,19 & 6,44 & 1,01 & 0,00 & 0,00 & 11,68 & 0,00 & 8,10 & 0,00 \\
\hline $1502.18 \mathrm{~K}$ & 2,50 & 2,33 & 37,94 & 20,28 & 27,14 & 4,37 & 1,61 & 69,93 & 15,36 & 6,48 & 0,97 & 0,00 & 0,00 & 11,91 & 0,19 & 8,77 & 0,00 \\
\hline $1502.19 K$ & 2,36 & 3,38 & 36,30 & 20,57 & 27,01 & 4,02 & 1,60 & 69,08 & 16,48 & 6,79 & 0,86 & 0,00 & 0,00 & 11,83 & 0,02 & 8,54 & 0,00 \\
\hline $1502.20 \mathrm{~K}$ & 2,76 & 0,69 & 35,04 & 21,70 & 26,64 & 4,45 & 1,69 & 65,79 & 18,32 & 7,59 & 1,06 & 0,00 & 0,22 & 13,82 & 0,60 & 10,55 & 0,00 \\
\hline $1502.21 \mathrm{~K}$ & 2,66 & 2,26 & 36,75 & 21,10 & 22,76 & 4,30 & 1,65 & 65,99 & 18,31 & 7,63 & 0,97 & 0,00 & 0,00 & 10,20 & 0,21 & 7,55 & 0,00 \\
\hline $1502.22 \mathrm{~K}$ & 2,53 & 3,19 & 36,66 & 21,00 & 22,54 & 3,99 & 1,56 & 71,41 & 14,80 & 6,10 & 1,05 & 0,00 & 0,00 & 12,11 & 0,34 & 9,06 & 0,00 \\
\hline
\end{tabular}




\section{Danksagung}

Drei Jahre sind schnell vergangen...., zum Erfolg dieser Arbeit haben viele Menschen beigetragen, denen ich an dieser Stelle herzlichst danke.

Namentlich erwähnen möchte ich Herrn Dr. Christian Möllers für sein langjähriges Vertrauen, die vielen Anregungen und seine tatkräftige Unterstützung bei der Anfertigung dieser interessanten Arbeit.

Herrn Prof. Dr. Heiko Becker für die Übernahme der Betreuung, ebenso Frau Prof. Dr. Elke Pawelzik, die das Korreferat übernahm.

Die Mitarbeiterinnen und Mitarbeiter des Institutes für Pflanzenbau und Pflanzenzüchtung für die nette Arbeitsatmosphäre, deren Hilfsbereitschaft und gute Zusammenarbeit. Besonders erwähnen möchte ich hier Rosi Clemens, Nicole Ritgen-Homayounfar und Uwe Ammermann für die tolle Unterstützung bei der Durchführung dieser Arbeit.

Herrn Dr. Jose Orsini (Resistenzlabor der Saatenunion) und Mitarbeiterinnen für die freundliche Aufnahme in ihrem Labor und für wertvolle Tips zur Transformation.

Herrn Dr. Carsten Milkowski (Institut für Pflanzenbiochemie, Halle (Saale)) für die Erstellung des Konstruktes und manch wertvollem Tip, Herrn Dr. Alfred Baumert (Institut für Pflanzenbiochemie, Halle (Saale)) für die vielen HPLC-Analysen. Beide haben wesentlich zum Erfolg dieser Arbeit beigetragen. 


\section{Lebenslauf}

Name: Alexandra Hüsken

Geburtsdatum: 25.02.1969

Geburtsort: Stadtlohn, Deutschland

\section{Schulische und berufliche Ausbildung:}

1975-1979: Besuch der Graf-Ludwig-Schule in Steinfurt

1979-1983: Besuch des Gymnasium Arnoldinum in Steinfurt

1983-1986: Besuch der Städt. Realschule in Steinfurt

1986-1987: Besuch der Technischen Berufsschule in Steinfurt

Berufsgrundschuljahr Agrarwirtschaft; Hauptschulabschluß

1987-1988: Ausbildung zur Gärtnerin bei der Stadt Duisburg

1988-1989: Besuch der Wirtschaftsschulen Steinfurt in Steinfurt

Berufsgrundschuljahr Wirtschaft und Verwaltung; Realschulabschluß

1989-1991: Ausbildung zur biologisch-technischen Assistentin an den Bernd-Blindow-

Schulen in Osnabrück

1991-1992: Tätigkeit als Verkäuferin bei Montanus aktuell

1992-1995: Besuch des Oldenburg-Kollegs in Oldenburg; Allgemeine Hochschulreife

\section{Universitätsstudium:}

1995-2001: Studium der Agrarwissenschaften an der Georg-August-Universität Göttingen Fachrichtung: Landwirtschaft und Umwelt; M.Sc. agrar

2001-2004: Promotionsstudium am Institut für Pflanzenbau und Pflanzenzüchtung der Georg-August-Universität Göttingen 
